\title{
UM MODELO PARA AVALIAR SISTEMAS MECANIZADOS PARA A APLICAÇÃO DE DEFENSIVOS EM CULTURAS PERENES
}

\author{
AleXANDRe TaCHIBANA \\ Engenheiro Agrônomo \\ Orientador: Prof. Dr. MARCOS MILAN
}

Dissertação apresentada à Escola Superior de Agricultura "Luiz de Queiroz", Universidade de São Paulo, para obtenção do título de Mestre em Agronomia, Área de Concentração: Máquinas Agricolas.

P I R A C I C A B A

Estado de São Paulo - Brasil

Setembro de 2000 


\title{
Dados Internacionais de Catalogação na Publicação (CIP) DIVISẢO DE BIBLIOTECA E DOCUMENTAÇÃO - Campus “LuIZ de Queiroz"/USP
}

\author{
Tachibana, Alexandre \\ Um modelo para avaliar sistemas mecanizados para a aplicação de defensivos em \\ culturas perenes / Alexandre Tachibana. - - Piracicaba, 2000. \\ $86 \mathrm{p}$. \\ Dissertação (mestrado) - - Escola Superior de Agricultura Luiz de Queiroz, 2000. \\ Bibliografia. \\ 1. Implemento agricola 2. Laranja 3. Pesticida 4. Planta cultivada perene 5. \\ Pulverização foliar 6. Simulação automatizada l. Título
}

CDD 632.94

"Permitida a cópia total ou parcial deste documento, desde que citada a fonte - $\mathrm{O}$ autor" 
Aos meus pais, dedico 


\section{AGRADECIMENTOS}

À Escola Superior de Agricultura "Luiz de Queiroz" e ao Departamento de Engenharia Rural por terem me recebido no curso de Mestrado em Máquinas Agrícolas.

À FAPESP pela concessão da bolsa de estudos.

Ao Professor Dr. Marcos Milan pela orientação deste trabalho, e também pela amizade, compreensão, e convivência por todo esse tempo.

Ao analista de sistemas do CIAGRI (Centro de Informática na Agricultura) Carlos Fernando Sanches pelo apoio na construção do modelo.

Aos Professores do Departamento de Engenharia Rural pelo convivio e conhecimentos transmitidos.

Aos Professores da banca examinadora pelo aperfeiçoamento do trabalho.

À Cambuhy Agrícola Ltda e ao gerente agrícola Agnaldo de Tarso Rigolin pelo fornecimento dos dados de fundamental importância para a validação do trabalho. Aos funcionários da empresa pelo apoio no trabalho de campo.

Aos funcionários do Departamento de Engenharia Rural pela colaboração durante este período.

Aos colegas de curso pela amizade e convivência nos trabalhos realizados em grupo.

A todos que de alguma forma contribuíram para a realização deste trabalho. 


\section{SUMÁRIO}

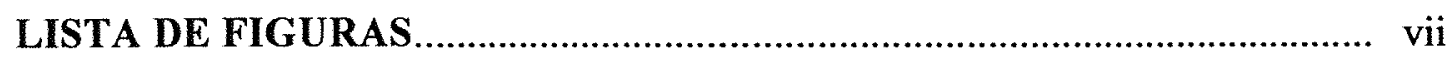

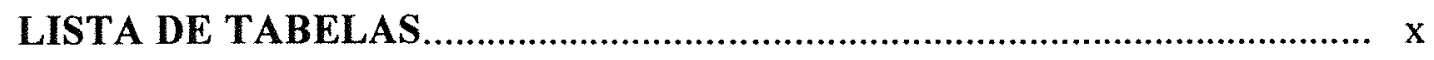

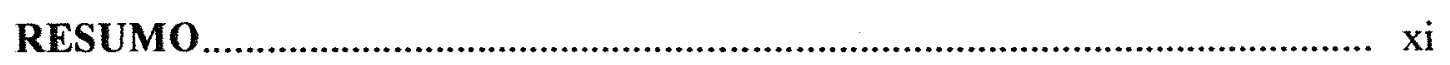

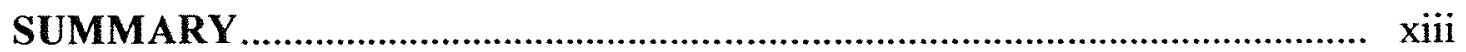

1 INTRODUÇÃO

2 REVISÃO DE LITERATURA.............................................................. 3

2.1 Cultura da laranja (Citrus sinensis, L. Osbeck)................................................ 3

2.2 Modelos computacionais aplicados à agricultura............................................ 5

2.2.1 Consumo de combustível................................................................... 13

2.3 Alguns fatores que influenciam a aplicação de produtos fitossanitários........... 15

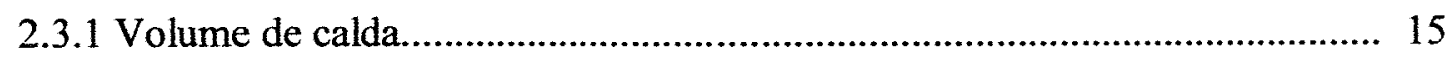

2.3.2 Dimensionamento de bicos................................................................... 16

2.3.3. Velocidade de deslocamento...................................................................... 17

2.3.4 Comparações entre modelos de pulverizadores............................................... 18

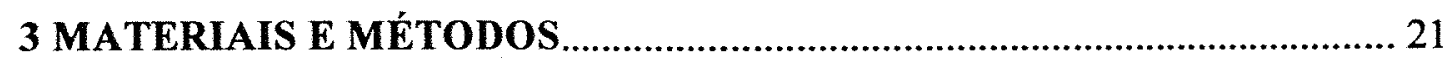

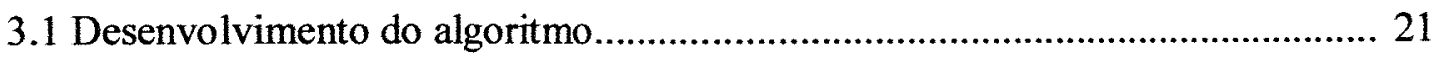

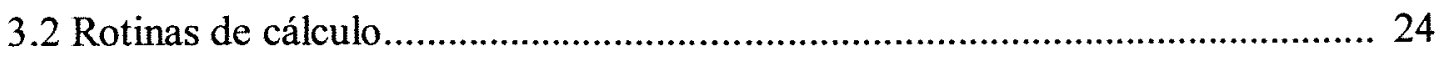

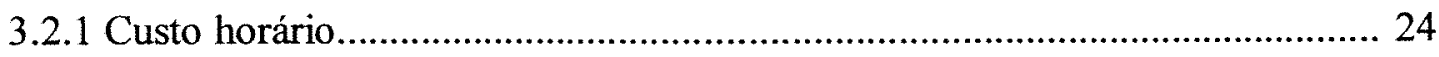

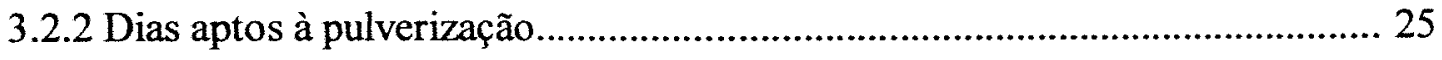

3.2.3 Parâmetros operacionais........................................................................ 25

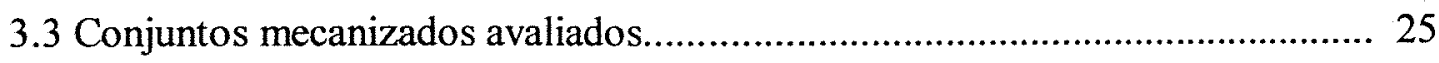

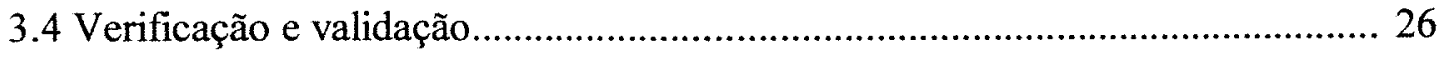

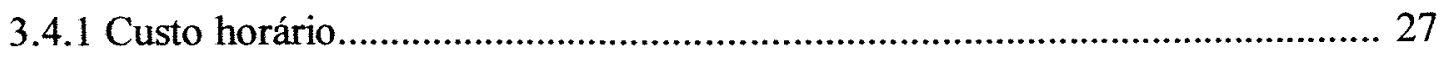




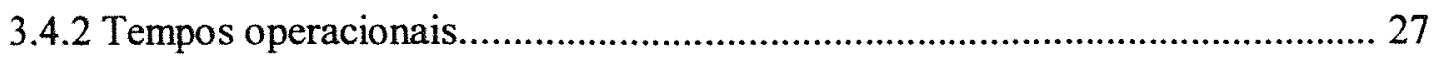

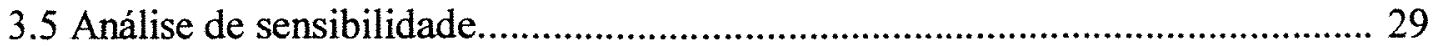

3.5.1 Parâmetros e sistemas envolvidos na análise de sensibilidade........................ 30

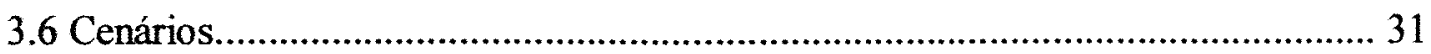

3.6.1 Necessidade de sistemas mecanizados (NSM) x fatores climáticos................ 32

3.6.2 Necessidade de sistemas mecanizados (NSM) x jornada de trabalho............ 32

3.6.3 Acréscimo do custo com máquinas $\mathrm{x}$ distância do ponto de abastecimento... 32

3.6.4 Acréscimo do custo com máquinas $x$ formato dos talhões.............................. 33

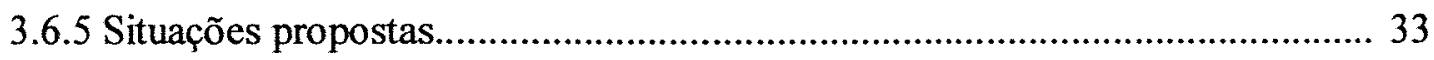

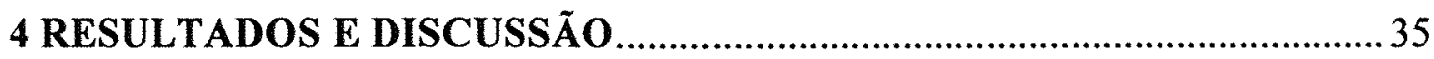

4.1 Verificação da rotina........................................................................................ 35

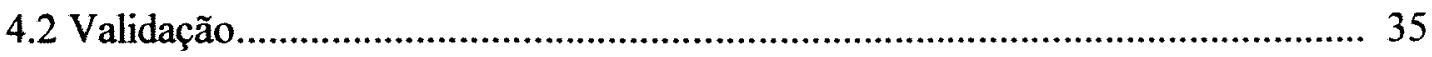

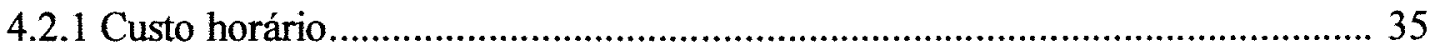

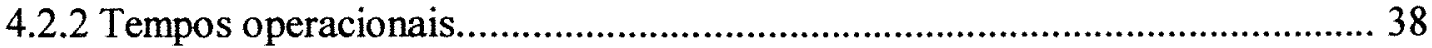

4.2.3 Considerações gerais sobre a validação....................................................... 42

4.3 Análise de sensibilidade.................................................................................... 43

4.3.1 Parâmetros e sistemas envolvidos na análise de sensibilidade........................... 43

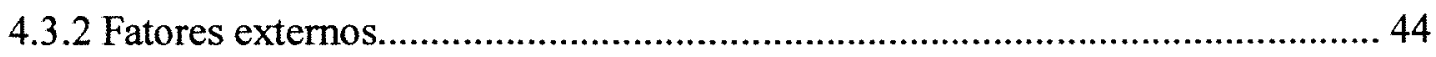

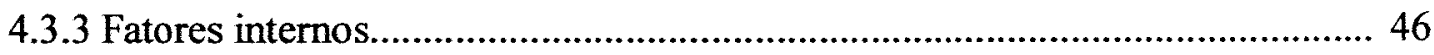

4.3.3.1 Eficiência de gerenciamento de sistemas mecanizados............................... 48

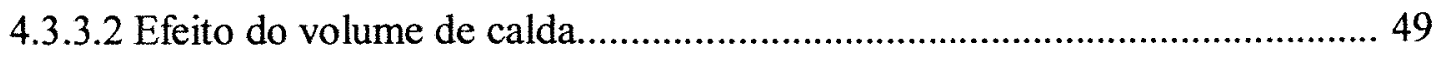

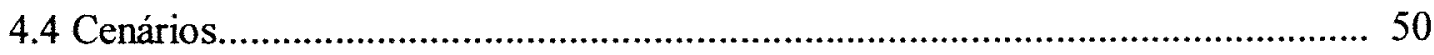

4.4.1 Necessidade de sistemas mecanizados (NSM) x fatores climáticos............... 50

4.4.2 Necessidade de sistemas mecanizados (NSM) x jornada de trabalho............ 51

4.4.3 Acréscimo do custo com máquinas $\mathrm{x}$ distância do ponto de abastecimento... 52

4.4.4 Acréscimo do custo com máquinas $\mathrm{x}$ formato dos talhões.............................. 54

4.4.5 Situações propostas.................................................................................. 55

4.4.5.1 Necessidade de sistemas mecanizados...................................................... 55

4.4.5.2 Capacidade de campo operacional........................................................... 57

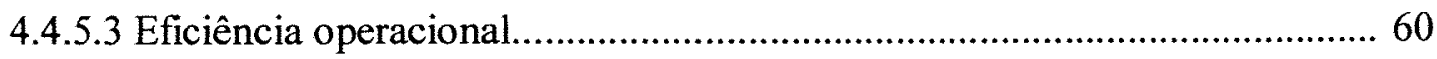




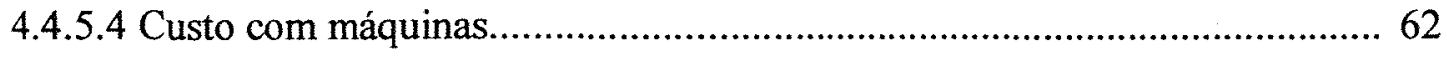

4.4.5.5 Custo com produtos fitossanitários....................................................... 65

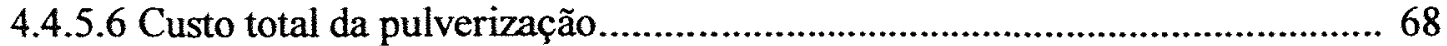

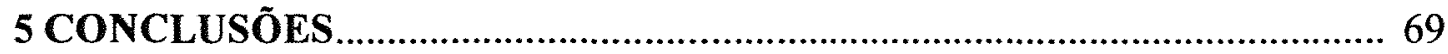

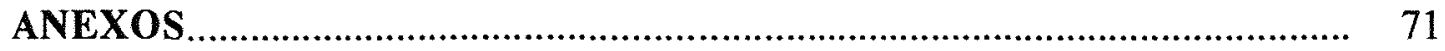

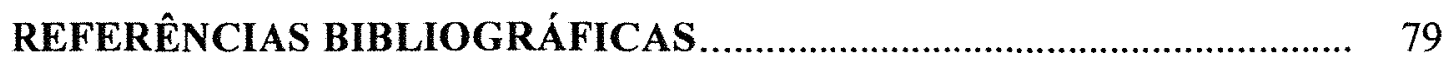




\section{LISTA DE FIGURAS}

1 Curvas de consumo específico de combustível dos ensaios realizados no CENEA (Milan, 1992); consumo através da fórmula da ASAE(1997); e equação obtida através da regressão polinomial de $2^{\circ}$ grau (Tachibana, 1998) ...................... 14

2 Esquema comparativo do pulverizador convencional com um pulverizador do tipo "cortina de ar". Adaptado de Whitney \& Salyani (1990)............... 20

3 Fluxograma do modelo............................................................................ 22

4 Comparação dos custos horários dos tratores MF-250x e MF 275,

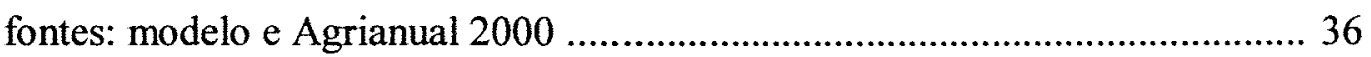

5 Comparação do custo horário em função da utilização anual do trator MF-250x. Fontes: modelo e Agrianual 2000......................................... 37

6 Comparação do custo horário em função da utilização anual do trator MF-275. Fontes: modelo e Agrianual 2000........................................... 38

7 Comparação dos tempos de pulverização dos talhões da série $\mathrm{A}$ e $\mathrm{C}$, obtidos a campo e fornecidos pelo modelo................................................. 39

8 Comparação dos tempos de manobra de cabeceira dos talhões da série A e C, obtidos a campo e fornecidos pelo modelo.

9 Comparação dos tempos de abastecimento dos pulverizadores dos talhões da série A e C, obtidos a campo e fornecidos pelo modelo

10 Comparação dos tempos de deslocamento para o abastecimento dos talhões da série $\mathrm{A}$ e $\mathrm{C}$, obtidos a campo e fornecidos pelo modelo

11 Variações no custo da pulverização, em porcentagem, devido às mudanças realizadas nos fatores externos, para o sistema $\mathrm{A}$

12 Variações no custo da pulverização, em porcentagem, devido às mudanças realizadas nos fatores externos, para o sistema $B$

13 Variações no custo da pulverização, em porcentagem, devido às mudanças realizadas nos fatores internos, para o sistema $\mathrm{A}$ 
14 Variações no custo da pulverização, em porcentagem, devido às mudanças realizadas nos fatores internos, para o sistema $\mathrm{B}$.

15 Acréscimos nos custos da operação em função dos valores da eficiência de gerenciamento. $100 \%$ é considerado como o sistema ideal

16 Variação no custo (\%) em função do volume de calda (\%), considerando $100 \%$ como 22 L.planta ${ }^{-1}$

17 Variação mensal da necessidade de sistemas mecanizados em função dos fatores climáticos da propriedade. Para 3 modelos de pulverizadores realizando a mesma operação (sistema $\mathrm{A}$ ).

18 Variação da necessidade de sistemas mecanizados em função da jornada de trabalho da propriedade. Para 3 modelos de pulverizadores realizando a mesma operação (sistema A)....................................................... 52

19 Variação no custo com máquinas, em porcentagem, em função da distância do ponto de abastecimento $(\mathrm{m})$....................................................... 53

20 Variação no custo com máquinas, em porcentagem, em função do formato dos talhões (Quantidade de fileiras. $\mathrm{ha}^{-1}$ )

21 Variação em porcentagem da NSM dos 3 conjuntos mecanizados em função das 9 situações elaboradas, sendo a situação 1 considerada como padrão....... 56

22 Necessidade de sistemas mecanizados para os 3 conjuntos na situação atual e na situação 9 denominada como final.

23 Variação da capacidade de campo operacional em porcentagem para os 3 modelos de conjuntos mecanizados, influenciada pelas 9 situações de trabalho, sendo a situação 1 considerada como padrão. 58

24 Capacidade de campo operacional para a situação atual e final (com todas as modificações). Para os 3 modelos de conjuntos

25 Variação da eficiência operacional para os três modelos de conjuntos nas situações de 1 a 9 , sendo a situação 1 adotada como padrão.

26 Eficiência operacional para os três modelos de pulverizadores na situação atual e na final 
27 Variação do custo com máquinas em porcentagem dos 3 modelos

de conjuntos mecanizados para as 9 situações, sendo a

situação 1 considerada como padrão................................................................ 63

28 Custo com máquinas para os 3 conjuntos mecanizados

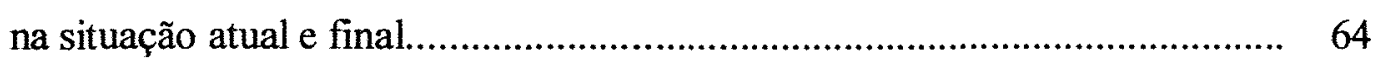

29 Variação do custo com defensivos para os 3 tipos de pulverizadores

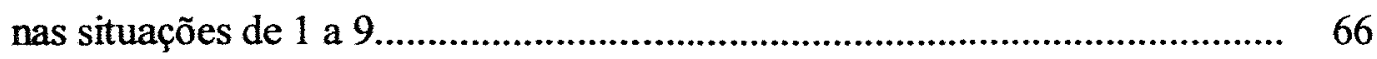

30 Custo com defensivos (US $\$ \times 1.000,00$ ) para os 3 modelos de

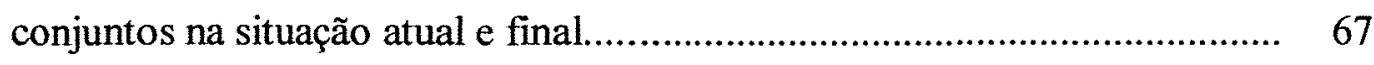

31 Variação do custo total da pulverização (US\$ x 1.000) dos 3 conjuntos na situação atual e final.................................................................. 68 


\section{LISTA DE TABELAS}

1 Principais características dos conjuntos mecanizados para

desenvolvimento dos cenários....................................................... 26

2 Principais características dos talhões da série A e C, utilizados para

a validação do modelo...............................................................................

3 Custo com máquinas e produtos para uma operação de pulverização de controle ao ácaro da leprose, para os sistemas A (3.000 ha) e B (500 ha)... $\quad 43$

4 Custo operacional (US\$. ha ${ }^{-1}$ ) dos 3 modelos de conjuntos

na situação atual e final........................................................................ 65

5 Custo de uma pulverização para a situação 1 , dividida em

custo com máquinas e com produtos....................................................... 


\title{
UM MODELO PARA AVALIAR SISTEMAS MECANIZADOS PARA APLICAÇÃO DE DEFENSIVOS EM CULTURAS PERENES
}

\author{
Autor: Alexandre Tachibana \\ Orientador: Prof. Dr. Marcos Milan
}

\section{RESUMO}

Uma das culturas perenes de maior importância para o Brasil é a da laranja (Citrus sinensis L. Osbeck). O país ocupa a liderança na produção mundial, com 19,4 milhões de toneladas em 1999, produzindo cerca de 1,2 milhão de toneladas de suco concentrado congelado, rendendo ao país US\$ 2,15 bilhões. Um dos aspectos de fundamental importância econômica, para essa cultura, é o controle de pragas e doenças, que pode ultrapassar $40 \%$ do custo total de produção. O objetivo deste trabalho foi desenvolver e aplicar um modelo computacional para simular sistemas mecanizados utilizados na aplicação de defensivos em culturas perenes, visando a redução de custos. O modelo, desenvolvido em Visual Basic 6.0, tem as rotinas de cálculos com base em dados encontrados na literatura e de observações obtidas em campo. A validação foi realizada através de comparações dos dados fornecidos pelo modelo com os da literatura e os levantados em uma propriedade agrícola produtora de laranja, mostrando que o mesmo está apto para realizar simulações de sistemas mecanizados auxiliando os produtores nas tomadas de decisões. Através da análise de sensibilidade foi possível observar que os fatores como volume de calda, velocidade de aplicação, preços de aquisição das máquinas e do óleo diesel são os que mais influenciam o custo da 
maquinaria. Baixas taxas de eficiência operacional podem elevar o custo da operação em até $200 \%$. Com a elaboração dos cenários pôde-se observar que os fatores climáticos podem dobrar a necessidade de sistemas mecanizados e que o aumento da jornada de trabalho de $8 \mathrm{~h}$ para $10 \mathrm{~h}$ por dia pode reduzir em $21 \%$ a necessidade de sistemas. O aumento da velocidade de aplicação de $0,55 \mathrm{~m} . \mathrm{s}^{-1}$ para $1 \mathrm{~m} \cdot \mathrm{s}^{-1}$ foi a que mais influenciou na necessidade de sistemas mecanizados, na capacidade de campo operacional e no custo com máquinas. Reduções de até $51 \%$ no custo das máquinas e de 20 a $25 \%$ nos produtos fitossanitários foram obtidos com a associação de alternativas do sistema básico. No total contabilizam uma redução no custo total da operação em até $30 \%$, cerca de US\$ 117 mil. 


\section{A MODEL TO EVALUATE MACHINERY SYSTEMS FOR APPLYING OF PESTICIDES ON PERENNIAL GROWINGS}

Author: Alexandre Tachibana

Adviser: Prof. Dr. Marcos Milan

\section{SUMMARY}

One of the perennial cultures of major importance for brazil is that of the orange. The country occupies the leadership in the world production, of 19,4 tons of million in 1999, producing about 1,2 tons of million of frozen concentrated juice, yielding for the country US\$2,15 billion. One of the aspects of the fundamental economic importance for this crop, is the control of insects and diseases, which may surpass $40 \%$ of the total production cost. The objective of this work was to develop and apply a computer model to simulate machinery systems utilized in the application of chemical products, aiming at the cost reduction. The model, developed in Visual Basic 6.0 , has the calculation routines based on data of the literature and field observations. The validity was realized through the comparisons of data supplied by the model with those of and the literature and those made up in an agricultural propriety of an orange producer, showing that same is apt to realize simulations of the machinery systems, giving assitance to the producer when taking decisions. Trough the sensibility analysis it was possible to observe that the factors such as the application volume and velocity, prices of the machinery and fuel have a major influence in the costs of the machinery 
systems. Low rate of operational efficiency may raise operational cost up to $200 \%$. With the elabotation of the scenarios one can observe that the climatic factors may double the machinery number and that the increase of working period from 8 to $10 \mathrm{~h}$ per day may reduce with $21 \%$ the necessity. The increase of the application velocity from $0,55 \mathrm{~m} \cdot \mathrm{s}^{-1}$ to $1 \mathrm{~m} \cdot \mathrm{s}^{-1}$ which influenced most the necessity of machinery, operational capacity and costs. Reductions up to $51 \%$ with the cost of machinery and $20 \%$ to $25 \%$ with the products were obtained with the association of alternatives regarding the basic system. Totally a reduction of the total cost of the operation is calculated up to $30 \%$, about US\$ 117 thousands. 


\section{INTRODUÇÃO}

Como em todos os setores da economia brasileira, a agricultura está passando por um processo de mudanças não só no aumento da competitividade no mercado interno como também e principalmente no externo. Dessa forma, o produtor agrícola precisa conhecer detalhadamente o seu custo de produção e estar apto para tomada de decisões que melhorem a eficiência de seu sistema.

Uma das culturas perenes de maior importância para o Brasil é a da laranja (Citrus sinensis L. Osbeck). O país ocupa a liderança na produção mundial, com 19,4 milhões de toneladas em 1999, correspondendo a terça parte da laranja produzida no mundo (58,7 milhões de toneladas) segundo a FAO - Food and Agriculture Organization (1999). De açordo com a ABECITRUS - Associação Brasileira de Exportadores de Cítricos (2000), a produção de suco concentrado congelado de laranja foi de aproximadamente 1,2 milhão de toneladas para a safra de 1999-2000, sendo apenas $2 \%$ desse montante consumido no mercado interno e os $98 \%$ excedentes destinados à exportação, rendendo ao pais o montante de US\$ 2,15 bilhões (considerando o preço do suco em US\$ 0,811 por libra).

Um dos aspectos de fundamental importância econômica para essa cultura é o controle de pragas e doenças; com a tecnologia disponível, são efetuadas no mínimo 5 pulverizações ao longo do ano, incluindo as adubações foliares para frutas destinadas à industria de suco. Esse controle é de extrema importância econômica podendo ultrapassar $40 \%$ do custo total de produção (Rigolin \& Tersi, 1999). Já o Agrianual (1999) estimou que para a safra de 1998 o custo das operações de pulverização, incluindo máquinas e produtos fitossanitários, representou $31 \%$ do custo de produção da laranja na árvore, sem considerar a colheita. O Agrianual (2000) estima que, para a safra 
de 1999 , o percentual foi de $37 \%$, como reflexo da variação cambial que incide diretamente nos produtos e em alguns equipamentos com preços vinculados ao dólar.

O alto custo da operação aliado com a necessidade das empresas reduzirem suas despesas, abriram mercado para pulverizadores com alta tecnologia. Com valor de aquisição superior a US\$ $50.000,00$, eles visam reduzir o volume de calda aplicado em até 3 vezes e a distribuição do produto (g.ha ${ }^{-1}$ ) em cerca de $20 \%$, quando comparados com os equipamentos utilizados tradicionalmente. $\mathrm{O}$ custo horário desses sistemas é elevado, e estudos sobre o desempenho operacional das máquinas visando o aumento de sua eficiência, podem reduzir o custo operacional (US\$. ha ${ }^{-1}$ ) e o número de conjuntos necessários de uma empresa.

Segundo Salyani (1994), a aplicação de defensivos em pomares tem possibilidade de melhorias, através do uso de equipamentos apropriados, seleção de bicos adequados, melhoria nos parâmetros operacionais, calibração correta e boas condições climáticas.

A dificuldade para o dimensionamento dos conjuntos mecanizados para a pulverização aliada ao cálculo do custo operacional, bem como a importância dos ganhos com defensivos e sua aplicação na cultura da laranja, constituíram-se nos motivos fundamentais para a elaboração desse trabalho, que tem como objetivo o desenvolvimento e aplicação de um modelo para simular sistemas mecanizados utilizados na aplicação de defensivos em culturas perenes. 


\section{REVISÃO DE LITERATURA}

\subsection{Cultura da laranja (Citrus sinensis, L. Osbeck)}

De acordo com Vieira (1976), no início do século praticamente toda a produção de citros no Brasil era destinada ao consumo de subsistência, sendo comercializado apenas o excedente em mercados e feiras livres. Com o aumento da área cultivada o volume excedente foi se tornando significativo, tanto que em 1911, foi realizada a primeira exportação de laranja, destinada à Argentina.

Segundo Moreira \& Moreira (1991), o início do processo para que o Brasil detenha hoje o primeiro lugar como produtor e exportador de suco concentrado ocorreu em 1952 com a viagem do pesquisador Sylvio Moreira aos EUA. Lá, percebeu que o nosso país tinha condições climáticas favoráveis para a cultura da laranja e, quando do seu retorno, passou a disseminar esse conceito. Em 1962/63 com a ocorrência de uma forte geada na Flórida (EUA), abriu-se a oportunidade para a exportação brasileira do suco concentrado congelado de laranja (FCOJ - Frozen Concentrated Orange Juice), ocasionando um aumento das áreas plantadas principalmente no Estado de São Paulo.

A expansão que vinha sendo rápida até 1965, passou a ser "febril" após o ano de 1970, quando alguns milhões de árvores por ano foram plantadas (Moreira \& Moreira, 1991). De acordo com Maia (1996), isto ocorreu devido à chegada das indústrias processadoras de laranja na década de 70 , quando $90 \%$ instalaram-se no Estado de São Paulo, chegando a consumir até $80 \%$ da produção.

De acordo com Amaro et al. (1991), a cultura citrícola encontra-se disseminada por todo o território nacional, com grande importância econômica e social para diversos estados, onde situa-se entre as dez principais culturas, sendo o Estado de 
São Paulo (SP) responsável por, pelo menos, 75\% da produção nacional de laranja. Reis (1995) afirmou que SP detinha $85 \%$ da produção brasileira em 1995, aumentando em 10 pontos percentuais a sua participação no mercado em relação à década de 80 .

Neves et al. (1995) foram além, denominando o Estado de São Paulo como o maior produtor mundial de laranja, detendo ao redor de $1 / 4$ da produção mundial. Os autores explicam este "boom" da citricultura paulista pela oferta insatisfatória de suco concentrado congelado nas décadas de 70 e 80 , desencadeando um processo rápido do plantio da cultura. Silva (1994) relata que a oferta insatisfatória de FCOJ deveu-se as sucessivas geadas na Flórida durante a década de 80; desta forma, o EUA que era um exportador de suco de laranja tornou-se um importador.

Neves et al. (1991) afirmam que no início da década de 90, houve um aumento muito grande da oferta e consequentemente os preços do FCOJ ficaram em baixa no mercado. A recuperação da produção de laranja na Flórida (EUA) foi segundo Silva (1994), a responsável por essa queda nos preços no início da década de 90.

Neves (1996) destaca que o Brasil é o maior produtor de suco concentrado de laranja, pois de acordo com um levantamento na safra de 93/94, o mundo inteiro produziu cerca de 2,13 milhões de toneladas, sendo que deste montante o Brasil foi responsável por 1,13 milhão, ou seja, cerca de $53 \%$ da produção mundial.

A ABECITRUS - Associação Brasileira de Exportadores de Cítricos (2000) afirma que a produção de FCOJ foi de aproximadamente 1,2 milhão de toneladas para a safra de 1999-2000. Um dado interessante é que apenas $2 \%$ desse montante são consumidos no mercado interno brasileiro e os $98 \%$ excedentes são destinados à exportação. Somente a produção de FCOJ rendeu ao país o montante de US\$2,15 bilhões.

Portanto, uma das culturas perenes de maior importância para o Brasil é a da laranja (Citrus sinensis L. Osbeck), que ocupa a liderança na produção mundial, com 19,4 milhões de toneladas em 1999, correspondentes a terça parte da laranja produzida no mundo (58,7 milhões de toneladas) segundo a FAO - Food and Agriculture Organization (1999). 
2.2 Modelos computacionais aplicados à agricultura

Os modelos computacionais são utilizados como ferramentas para auxiliar a tomada de decisão. No caso da agricultura o seu uso vem aumentando e uma das aplicações é no dimensionamento e cálculo do custo de conjuntos mecanizados. Um trabalho clássico na área é o de Burrows \& Siemens (1974), que desenvolveram um modelo computacional para determinar o menor custo, tamanho e a necessidade de sistemas mecanizados para fazendas produtoras de milho e soja. Esse modelo foi desenvolvido para auxiliar os produtores agrícolas nas decisões de aquisição da maquinaria, sendo que os autores consideraram como maquinaria ideal àquela que proporcionasse o menor custo. Foi utilizada a análise de sensibilidade para avaliar o impacto que alguns fatores causariam no custo da maquinaria em uma propriedade de 162 ha, tais como: taxa de juros, preço de aquisição, reparos e manutenção, combustível e a produtividade das máquinas. Para os autores esta análise consiste em variar um fator de cada vez observando-se as alterações causadas no custo final dos conjuntos mecanizados. Concluíram que o preço de aquisição foi um dos fatores que mais influenciaram o custo das máquinas, seguido pela taxa de juros e a produtividade.

Singh and Holtman (1979) desenvolveram um algoritmo para selecionar sistemas mecanizados em fazendas que utilizam o sistema de rotação de cultura. $\mathrm{O}$ programa baseia-se em dados como: especificações de campo, restrições de calendário, capacidade operacional das máquinas e condições de trabalho no campo. Os autores utilizaram dados climáticos na forma de porcentagem de dias úteis por mês para determinar o tempo disponivel para trabalho; porém, para a operação de colheita os dados climáticos não foram considerados. Para o cálculo do custo horário dos conjuntos, os autores utilizaram o método da linha reta para a depreciação; taxa de juros de $9 \%$ ao ano; $1 \%$ do preço de aquisição da máquina para alojamento e seguros; porcentagem do valor de aquisição da máquina para reparos e manutenção; mão-de-obra de US $\$ 3,25$ por hora; $15 \%$ do custo total de óleo diesel para óleos lubrificantes e filtros. Neste trabalho não foram consideradas as taxas porque estas não eram cobradas no campo. $\mathrm{O}$ número 
de implementos necessários foi calculado considerando que os tratores estivessem sempre disponiveis.

Um modelo para incluir os riscos causados por adversidades climáticas foi desenvolvido por Whitson et al. (1981). O objetivo desse trabalho foi maximizar os lucros levando em conta limitações da terra, tempo disponivel para o trabalho e características das máquinas. Os dias aptos ao trabalho foram estimados pela evapotranspiração (ET) do solo. O modelo foi utilizado em larga escala, ou seja, para uma propriedade (1.000 ha), e foi avaliada para três níveis de probabilidade, $50 \%, 75 \%$ e $90 \%$. Os autores relatam que conforme aumenta o nível de probabilidade climática, aumenta o investimento com a maquinaria por hectare, como prova disto um trator de $131 \mathrm{~kW}(179 \mathrm{cv})$ pode suprir a necessidade de 973 ha quando a probabilidade é de $50 \%$, para $75 \%$ este mesmo trator pode realizar o trabalho de 412 ha e para $90 \%$ somente 215 ha, portanto a área trabalhada por um trator pode ser reduzida para $22 \%$.

Um algoritmo desenvolvido por Rotz et al. (1983) foi utilizado para selecionar sistemas mecanizados de preparo de solo convencional e conservacionista. De acordo com este modelo pode-se adquirir e operar os equipamentos de preparo conservacionista com custos menores que o convencional. A análise de sensibilidade foi utilizada pelos autores com a finalidade de verificar as reações do modelo às mudanças e avaliar os efeitos que as mudanças causavam na maquinaria selecionada. Neste estudo a análise de sensibilidade mostrou que com a diminuição de condições climáticas favoráveis, havia a necessidade de complementar o sistema com máquinas menores, de qualquer forma, isto causava pequenas alterações de custo. Concluíram ainda que mudando de um solo argiloso para arenoso seria possível utilizar um conjunto de máquinas menores, e que propriedades maiores permitem uma utilização da maquinaria com maior eficiência e menor custo operacional.

Um modelo linear desenvolvido por Al-Soboh et al. (1986) teve como objetivo principal avaliar e comparar diferentes sistemas de produção para maximizar os lucros. O programa calcula o custo total das máquinas, tratores e caminhões da fazenda, subdivididos em depreciação, taxa de juros, seguros, alojamentos, taxas, reparos, manutenção, combustivel e lubrificantes. O custo anual levou em consideração as horas 
trabalhadas em cada operação. A potência requerida para acoplar o implemento num trator adequado foi calculada com base na largura do implemento, velocidade de deslocamento e resistência à penetração em solo de textura média. Neste trabalho foram considerados os custos com fertilizantes e defensivos agrícolas. Para os autores a situação ideal seria a que fornecesse um custo menor que o padrão determinado por eles.

Chen (1986) desenvolveu um modelo em microcomputador para auxiliar o produtor a agendar as operações agrícolas, determinar o número ótimo de conjuntos e modificar seu sistema de trabalho. $O$ funcionamento desse modelo se dá em duas etapas. A primeira refere-se a coleta de dados sobre tratores, equipamentos, número de culturas a serem conduzidas e os tipos de operações necessárias para cada cultura. Com os dados o programa inicia a segunda etapa referente ao cálculo de dias disponiveis para o trabalho, a rotina do programa e sua execução. O produtor poderá utilizar este modelo para tomar decisões sobre fazer ou não um empréstimo para investir na sua frota de máquinas, embora, o autor não considere o conceito da pontualidade de operações agrícolas ("timeliness").

O trabalho de McClendon et al. (1987) teve por objetivo desenvolver um modelo de simulação para a cultura da soja (Glycine Max (L.)) e trigo (Triticum aestivum L.) para avaliar componentes de maquinaria de campo alternativos. Os custos das máquinas foram calculados pela metodologia sugerida pela Oklahoma State Budget Generator, sendo o custo dividido em fixo e variável; e as capacidades de campo das máquinas foram calculadas através das relações da ASAE Yearbook (1983). Este modelo calcula o lucro líquido da cultura, classificado como baixo e alto em função das alterações que podem ocorrer nos parâmetros ou estratégias envolvidos no cálculo.

Um modelo denominado de "TERMS", desenvolvido por Colvin et al. (1989), foi elaborado com a finalidade de melhorar a precisão das estimativas de capacidade de campo das máquinas estimando o consumo de combustivel e o tempo requerido para cada operação, através de teorias básicas e equações aplicadas à movimentação dos sistemas mecanizados para parâmetros de campo. O tempo total da operação é a somatória dos tempos produtivos e improdutivos. Os tempos produtivos são aqueles em que a máquina está operando no campo, assumindo que metade do tempo a 
máquina está operando subindo um aclive e a outra descendo, devido à diferença de velocidade nessas situações. Os tempos improdutivos referem-se ao tempo de manobras e abastecimento do tanque. Já a capacidade de campo foi calculada como sendo a relação entre a área total pelo tempo total da operação. A validação dos fatores para capacidade de campo teve uma correlação de 0,91 e para o consumo de combustivel 0,90 . Este experimento não foi validado em terrenos com declividades acentuadas e nem para utilização de tratores $4 \times 4$.

Matuo (1990) desenvolveu um modelo para racionalização de uma aplicação de defensivos agrícolas baseado nos procedimentos utilizados por Mialhe (1974). Nesse trabalho, parâmetros como largura da faixa de aplicação, capacidade do tanque, distância para o reabastecimento e comprimento da faixa, foram os que mais influenciaram a capacidade de campo operacional da maquinaria. Para o autor, a análise operacional e econômica permite a seleção do equipamento mais apropriado para o trabalho, porém, afirma que aplicações mais rápidas e baratas não devem provocar maiores riscos ao operador e ao meio ambiente.

$\mathrm{Na}$ colheita do algodão fatores como chuva e vento influenciam na qualidade do produto, portanto, quando a cultura estiver no ponto de colheita, deve-se iniciá-la o mais rápido possível. Baseados neste fato, Chen et al. (1992) desenvolveram um modelo matemático chamado "COTSIM" com a finalidade de elaborar estratégias de trabalho para a colheita de algodão, para aumentar a eficiência operacional das máquinas ou para determinar o número ideal de sistemas mecanizados, relacionando-os com a qualidade do algodão. Este modelo faz estudos interativos entre número de colhedoras, capacidade de campo, tamanho da fazenda, data inicial da colheita e estágio de maturidade do algodão em função da produtividade e do lucro. De acordo com os resultados obtidos, pode-se observar que a data inicial de colheita é o fator que mais afeta a renda total. Como o objetivo do trabalho foi determinar qual o sistema de colheita que fornecesse o maior lucro, o programa foi executado sucessivamente até que um sistema atendesse a essas condições.

O trabalho desenvolvido por Milan (1992), teve como objetivo desenvolver um modelo que representasse a produção de cana-de-açúcar, considerando 
os quatro subsistemas básicos e suas inter-relações. Os subsistemas foram definidos como colheita, mecanização, transporte e agronomia. A utilização do modelo teve a finalidade de identificar estratégias que pudessem reduzir os custos envolvidos na produção de cana-de-açúcar, e para isso foi necessária a utilização sucessiva do programa. Através de situações hipotéticas em termos de área e tecnologia disponivel, o autor analisou as variáveis criticas para o sistema, levando em consideração dois parâmetros para a análise: os fatores externos e internos. Os fatores externos são aqueles que afetam o custo da maquinaria embora o gerente não possa controlar. Os fatores internos são os que influenciam o custo e que podem ser controlados pelo gerente. Para o estudo, as mudanças nos parâmetros foram realizadas uma de cada vez e acrescidas sempre em $10 \%$. Os resultados obtidos para uma área de 15.000 ha e uma distância de $50 \mathrm{~km}$ da indústria, indicaram que dos 12 fatores externos avaliados, os que mais influenciaram no custo foram o preço de aquisição dos caminhões utilizados no transporte da cana-de-açúcar, seguido pelo custo de reparo e manutenção dos mesmos e o preço do combustível; o fator de menor importância foi o valor de sucata da carregadora. Considerando-se a mesma área e distância, foram analisados 9 fatores internos e observou-se que os fatores de menor importância para esta situação foram o tempo de descarregamento dos caminhões, tempos auxiliares dos caminhões e vida útil da carregadora. $O$ fator de maior importância foi a capacidade de carga dos caminhões. $\mathrm{O}$ autor fez a mesma análise para outras situações onde modificou o tamanho da área e a distância da propriedade até a indústria, observando que os fatores criticos - que mais alteravam o custo - eram diferentes, indicando que para propriedades diferentes deve ser realizada outra análise de sensibilidade.

Outro trabalho realizado para a cultura da cana-de-açúcar foi o de Soffner et al. (1993), que desenvolveram um modelo através da programação linear. O número de conjuntos foi determinado pela relação entre o ritmo operacional necessário e a capacidade operacional do sistema. Os autores consideraram como fator determinante o custo operacional (custo por hectare) do conjunto, salientando que o ideal é obter uma alta capacidade operacional aliado a um baixo custo horário. 
O objetivo do estudo de Haffar \& Ee (1992) foi o de desenvolver um modelo que pudesse prever o crescimento diário do pepino, num período de 10 dias, predizendo então: a distribuição da colheita, a renda (US\$), a necessidade de equipamentos e o custo da colheita. Para tanto, desenvolveram um modelo matemático denominado "CHUCHARV", que forneceu tais informações através da simulação de dados como: tamanho da fazenda, estágio da cultura, quantidade e tipo de equipamentos. Baseados nestas informações, o modelo construiu gráficos de análise de sensibilidade variando-se algumas condições iniciais em função do lucro (US\$ ha $^{-1}$ ). Desta forma, promoveu um gerenciamento total da cultura determinando a data ideal para o início da colheita, em função de um conjunto de condições ou dados específicos.

Parmar et al. (1994) desenvolveram um modelo de simulação computacional, a fim de auxiliar o gerenciamento de máquinas no ato de tomar decisões quanto a mudanças nas condições de trabalho. Este programa foi utilizado para a cultura do amendoim, onde foram realizadas simulações de produtividade, custos com máquinas, lucro, entre outras. Porém, para que estas simulações fossem realizadas, foi necessário anteriormente estimar os dias disponíveis para trabalho em função da quantidade de água contida no solo. Para isto utilizou-se um modelo denominado "PNUTGRO v1.02", que estima também a maturidade da cultura e sua produtividade. Segundo o autor, o objetivo do gerenciamento de máquinas é utilizar equipamentos que proporcionem o maior lucro.

Em outro trabalho, Parmar et al. (1996) utilizaram algoritmos genéticos e simulações para selecionar máquinas agricolas com o objetivo de maximizar o lucro líquido sobre os custos da maquinaria. Algoritmo genético é um método para selecionar máquinas onde cada máquina é representada por 12 bits e a cada 2 bits tem-se uma característica da máquina, adaptando a frota de conjuntos mecanizados às diversas condições de trabalho até o equilibrio, desta forma, obtém-se a frota mínima para a cultura. Este método foi utilizado para procurar o conjunto de máquinas mais próximo possível do ótimo para uma fazenda de 150 ha. Comparando o algoritmo genético com as simulações sucessivas (método exaustivo), os autores concluiram que o algoritmo 
genético é capaz de selecionar um conjunto em $10 \%$ do tempo que o método exaustivo, além de melhorar a qualidade das soluções.

Sogaard \& Sorensen (1996) desenvolveram um modelo para ser utilizado como ferramenta para tomada de decisões na análise de sistemas mecanizados utilizando um modelo não-linear, desenvolvido pelo software GAMS. Os autores buscaram a seleção de um sistema, baseando-se nos custos fixos e variáveis e incluindo a pontualidade - penalidade econômica que os produtores pagam indiretamente quando as operações não são executadas num cronograma estimado como ideal -, em função de um dado tamanho de uma propriedade e de um determinado cronograma de operações. Os resultados fornecem o tamanho dos implementos, potência requerida e o número de tratores, sendo considerado como ótimo o sistema que tivesse o menor custo.

Stulp \& Mattuella (1997) desenvolveram um algoritmo, para cultura de arroz, que teve como objetivo principal determinar a relação econômica ótima entre o número de tratores e a área da propriedade, onde foi considerada a hipótese que o produtor desejasse maximizar o lucro médio ao longo dos anos e não em um ano específico. Para que seja possível determinar o número de conjuntos mecanizados para uma operação é de fundamental importância, o levantamento de dados meteorológicos e os tempos disponíveis de cada máquina nas operações

Um sistema integrado de custos, denominado "CUSTAGRI", desenvolvido por Martin et al. (1998) tem o objetivo de estimar custos de um conjunto de máquinas agrícolas, ou de atividades agropecuárias num determinado período. Além dos custos que envolvem a maquinaria, ele calcula todos os custos envolvidos com a produção. No setor de máquinas agrícolas, o custo é calculado em custo horário (RS. $\left.\mathrm{h}^{-1}\right)$ e por área $\left(\mathrm{R} \$ \mathrm{ha}^{-1}\right)$.

Ferguson \& Israel (1998), realizaram um estudo envolvendo propriedades agrícolas produtoras de laranja na Flórida, onde constataram que 49\% dos produtores utilizavam computadores para gerenciar seus pomares, e que as operações mais importantes utilizavam computadores e softwares relacionados à automação, à tomada de decisões no campo e aos fatores climáticos. 
Dahab \& O’Callaghan (1998) desenvolveram dois modelos de simulação, um para determinar o crescimento da cultura do trigo e outro para simular o desenvolvimento da doença causada por Septoria tritici. Os autores utilizaram os modelos para predizer as perdas na cultura e posteriormente comparar e analisar o custo beneficio de diferentes estratégias de pulverização para o controle da doença. Foram avaliadas 3 estratégias de pulverização: a primeira, consistia em aplicar 4 tratamentos na cultura baseados apenas no calendário; a segunda, 3 aplicações de acordo com estágios da cultura; e a terceira, baseada em um controle integrado de pragas. Os resultados obtidos mostraram que a primeira e a segunda estratégia têm um custo extra de $44 \%$ e $17 \%$, respectivamente. A terceira estratégia proporcionou um retorno médio de $30 \%$, para que esse tratamento seja viável, é necessário que a produtividade tenha um acréscimo de $10 \%$, no mínimo.

Tachibana et al. (1999) trabalhando com a cultura do limão Siciliano (Citrus limon, Burm.), encontrou custos de pulverização que variaram desde US\$24,00 a US\$ 59,00 por hectare o que demonstra a importância da avaliação correta do sistema mecanizado; o autor relata que $80 \%$ dos talhões da propriedade avaliada encontravam-se na faixa de US\$28,00 a US\$36,00 por hectare.

O trabalho desenvolvido por Ferreira (2000) teve por objetivo verificar a validade do modelo matemático proposto por Matuo (1983), a fim de utilizá-lo em simulações para determinar sistemas de otimização da capacidade operacional de turboatomizadores em citros. Os dados obtidos revelam que do tempo disponível, em média, os pulverizadores gastam cerca de $51 \%$ para pulverização, $17,4 \%$ para preparo dos equipamentos, $27,1 \%$ para o reabastecimento dos tanques, $2 \%$ para manobras de cabeceira e $2,5 \%$ com outros tempos. O autor concluiu que a capacidade do tanque foi o fator que mais interferiu no custo da operação, e que distâncias de abastecimentos superiores a $500 \mathrm{~m}$, justificam a presença de uma equipe de apoio para o transporte de água 


\subsubsection{Consumo de combustivel;}

Milan (1992) desenvolveu um trabalho para cultura da cana-de-açúcar, e para tanto, precisou desenvolver um modelo para determinação do consumo de combustivel para tratores agricolas em diferentes cargas na TDP, utilizando-se dados de ensaios reaiizados no CENEA durante o periodo de 1981 a 1986. A potência dos tratores analisados variaram de 22 a $106 \mathrm{~kW}$. O modelo empírico obtido tem um coeficiente $\left(\mathrm{r}^{2}\right)$ de $91,3 \%$.

$$
S F C t=0,288+\frac{0,0847}{\operatorname{Pr}}
$$

Onde: $\mathrm{SFCt}=$ consumo especifico de combustível $\left[\mathrm{L} .\left(\mathrm{kW} \mathrm{W}^{*} \mathrm{~h}\right)^{-1}\right]$;

$\mathrm{Pr}=$ razão de potência (disponivel/total na TDP);

De acordo com o boletim da ASAE STANDARDS (1997), a equação de consumo de combustivel apresenta valores $15 \%$ maiores que a média dos ensaios publicados no Nebraska Tractor Test, para refletir a perda de eficiência sob condições de campo. A equação sugerida pela ASAE é:

$$
C=2,64 X+3,91-0,203 \sqrt{738 X+173}
$$

Onde: $\mathrm{C}=$ consumo específico em L. $(\mathrm{kW} . \mathrm{h})^{-1}$;

$\mathrm{X}=$ razão de potência (disponivel/total na TDP);

Para se estimar o consumo de combustivel de tratores agrícolas, Tachibana (1998)* adotou uma equação empírica obtida a partir dos dados de ensaios realizados pelo CENEA (Centro Nacional de Engenharia Agricola) no periodo de 1980 a 1991, a potência dos tratores avaliados estavam entre 36 e $86 \mathrm{~kW}$. Esta equação permite calcular o consumo de combustível de acordo com a porcentagem de carga atribuída à TDP (tomada de potência) do trator.

* Trabalho desenvolvido na disciplina de gerenciamento de sistemas mecanizados, curso de mestrado em máquinas agricolas - ESALQ-USP. 
$C$ comb $=\left\{\left[\left(0,728 * \frac{\operatorname{Pr} p}{P m * 0,86}\right)^{2}-\left(1,2109 * \frac{\operatorname{Pr} p}{P m * 0,86}\right)+0,8054\right] * 0,732 * \operatorname{Pr} p\right\} * V C$

Onde: $\mathrm{Ccomb}=$ custo do combustível US $\$ \cdot \mathrm{h}^{-1}$

$$
\begin{aligned}
& \operatorname{Prp}=\text { potência requerida na TDP pelo pulverizador }(\mathrm{kW}) \\
& \mathrm{Pm}=\text { potência máxima no motor do trator }(\mathrm{kW}) \\
& \mathrm{VC}=\text { valor do combustível }\left(\mathrm{US} \$ \mathrm{~L}^{-1}\right)
\end{aligned}
$$

Pode-se verificar na Figura 1, a equação obtida através de uma regressão polinomial do segundo grau que possui um $\mathrm{r}^{2}=0,94$. Essa equação forneceu valores de consumo de combustível cerca de 27 a 37\% menores que os da ASAE Standards (1997), e a equação sugerida por Milan (1992) forneceu valores intermediários às outras duas.

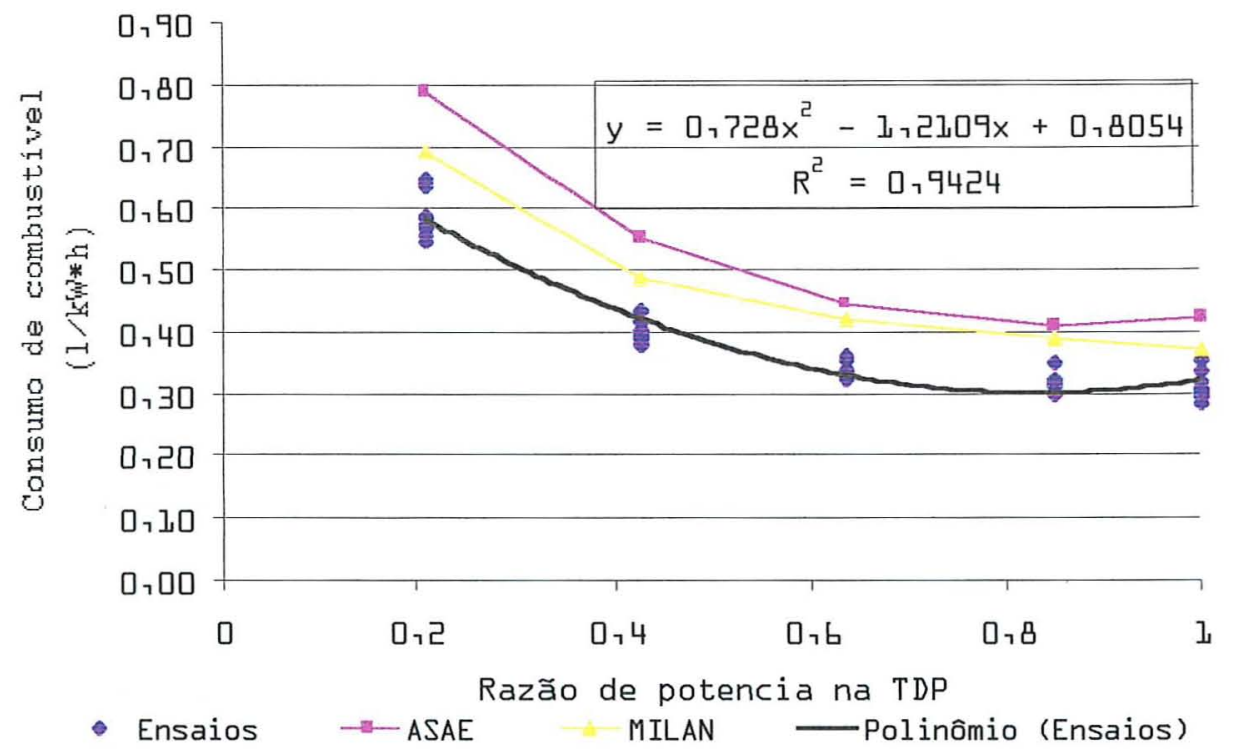

Figura 1 - Curvas de consumo específico de combustível dos ensaios realizados no CENEA (Milan, 1992); consumo através da fórmula da ASAE (1997); e equação obtida através da regressão polinomial de $2^{\circ}$ grau (Tachibana, 1998). 
2.3 Alguns fatores que influenciam a aplicação de produtos fitossanitários

2.3.1 Volume de calda

Monteiro (1970) desenvolveu equipamentos tratorizados para a aplicação de inseticidas em UBV (Ultra Baixo Volume), concluiu que é possivel realizar aplicações empregando-se atomizadores rotativos elétricos e utilizando-se discos metálicos para a subdivisão do líquido, com rotações entre 9.000 e 10.000 rpm; pode-se utilizar o sistema de alimentação a ar comprimido empregando-se baixas pressões para a alimentação dos atomizadores rotativos; e que não houve variação da deposição de gotas em função da altura de aplicação.

Hernandez \& Escobio (1986), estudando o efeito de diferentes formas de aplicação em citros, utilizando pulverizadores com ventiladores axiais, constataram que o volume de calda de 516 L.ha $^{-1}$ foi o método que proporcionou melhor qualidade de pulverização, aliada à alta produtividade.

Estudando a deposição de pulverização em cinco diferentes volumes de calda em citros, Salyani \& McCoy (1990), constataram que na medida que o volume aumentava, a média e a variabilidade da deposição reduzia na parte externa da copa, isto não era observado na parte interna da planta, portanto, quando o alvo é interno o simples aumento no volume de calda não é suficiente para controlar a praga.

Salyani (1994) e Hoffmann \& Salyani (1996) afirmam que volumes de calda menores proporcionam maiores deposições, porém, salientam que o coeficiente de variação $(\mathrm{CV})$ da deposição geralmente diminui com o aumento do volume pulverizado.

Rigolin \& Tersi (1999) desenvolveram um trabalho na Fazenda Cambuhy Agrícola Ltda., localizada no município de Matão-SP, com o objetivo de reduzir o custo no controle de ácaros. Desta forma, reduziram o volume de calda através da utilização de bicos que proporcionam gotas menores. Os autores relatam que com essa mudança conseguiram reduzir o volume de calda em $20 \%$, sem alterar a concentração de produtos 
no tanque do pulverizador. Porém, existem restrições para o sucesso desta pulverização, como tamanho da planta, tipo do ácaro e condições climáticas favoráveis.

Um estudo desenvolvido por Cunningham \& Harden (1999) comparou quatro modelos de pulverizadores, sendo um deles convencional que aplicava cerca de 10.000 L ha ${ }^{-1}$ e os outros variaram entre 500 e $6.000 \mathrm{~L}^{-h^{-1}}$. O estudo indica que o pulverizador com "torre de ar" aplicando 6.000 L.ha" produziu deposições semelhantes ao pulverizador de pistola que utiliza 10.000 L.ha ${ }^{-1}$, devido a menor perda de produto ocasionada pelo escorrimento. Para os volumes de calda inferiores os resultados não se mostraram satisfatórios, porém, salienta-se que as concentrações dos produtos no tanque não foram alteradas; este pode ter sido o motivo da inviabilidade das pulverizações com volumes inferiores a $6.000 \mathrm{~L} \cdot \mathrm{ha}^{-1}$.

\subsubsection{Dimensionamento de bicos}

Estudando o efeito de diferentes formas de pulverização, utilizando pulverizadores com ventiladores axiais em citros, Hernandez \& Escobio (1986) observaram que bicos hidráulicos com orificio de $1,2 \mathrm{~mm}$ de diâmetro realizaram uma pulverização mais uniforme.

Salyani (1988), analisando qual o tamanho ideal de gotas para pulverização em citros concluíram que o diâmetro ideal está na faixa de 240 a $340 \mu \mathrm{m}$ atribuindo a isso a influência da velocidade da gota (em função da velocidade do ar), volume aplicado (em função do tipo do alvo), propriedades da superficie da folha (tensão superficial). O autor verificou que gotas obtidas por bicos hidráulicos de orificios pequenos são as menos eficientes.

Para Palladini \& Matuo (1991), o arranjo ideal de bicos é aquele que libera $50 \%$ da calda na parte superior da planta e $50 \%$ na parte inferior, pois foi o tratamento que apresentou o melhor resultado de cobertura das folhas.

Em um estudo sobre a distribuição e a deposição de gotas nas pulverizações realizadas com turboatomizadores, Raetano (1996) determinou que um 
arranjo de 35 bicos JA-2 proporcionava o menor volume de calda dos bicos analisados, mostrando-se adequados para a aplicação de defensivos em citros à $300 \mathrm{psi}\left[\mathrm{lbf} .\left(\mathrm{pol}^{2}\right)^{-1}\right]$.

\subsubsection{Velocidade de deslocamento}

Whitney et al. (1988) estudaram o efeito da velocidade de deslocamento em dois tipos de pulverizadores no controle de Mycosphaerella citri e na deposição de cobre. Nas folhas da parte inferior da planta não foram observadas diferenças significativas na deposição de cobre, entretanto nas folhas superiores a deposição de cobre apresentou diferença. Isto pode ser explicado pela posição das zonas de amostragem. Também, o controle da doença não foi afetado por nenhum dos fatores envolvidos, ou seja, os mesmos não apresentaram diferenças significativas.

Segundo Salyani \& Whitney (1989) e Salyani (1994), velocidades de deslocamento situadas entre 1,6 e $6,4 \mathrm{~km} \cdot \mathrm{h}^{-1}$ não influenciaram na média de deposição dentro da copa das plantas de laranjas; entretanto a variabilidade aumenta com o acréscimo de velocidade. Os autores ainda afirmam que a disposição dos pontos de coleta na copa tem um efeito significante na deposição e mostrou interações com a velocidade de deslocamento.

Palladini \& Matuo (1991) avaliaram o efeito de condições operacionais de um turboatomizador na cobertura de folhas de citros. Os autores observaram que quanto menor for a velocidade de deslocamento, maior a cobertura das folhas, porém não foram encontradas diferenças significativas entre as velocidades de 3,0 e $5,3 \mathrm{~km} \cdot \mathrm{h}^{-1}$.

Para Boggio (1995), a velocidade de deslocamento está relacionada com o tipo de equipamento e a região da planta que se deseja alcançar - alvo. No caso das máquinas de pistola, se a velocidade de deslocamento for elevada os operadores não conseguirão promover uma boa cobertura de calda na planta e se a velocidade for muito baixa, haverá sobreposição da aplicação em partes da planta, causando um desperdício de produto. Para os pulverizadores de jato transportado, a velocidade de trabalho tem maior importância, pois, quando houver necessidade de atingir o interior da copa a 
velocidade deverá permitir que a cortina de ar consiga penetrar na planta. Caso se deseje uma aplicação externa à copa a velocidade pode ser maior.

Raetano (1996), estudando a distribuição e a deposição de gotas nas pulverizações realizadas com turboatomizadores, concluiu que as velocidades de $3,6 \mathrm{e}$ $5,1 \mathrm{~km} \cdot \mathrm{h}^{-1}$ são adequadas para a aplicação de defensivos na citricultura com os modelos Arbus 2000/Export e 2000/850 e para pressões de trabalho situadas entre 200 e 300 psi.

\subsubsection{Comparações entre modelos de pulverizadores}

Whitney et al. (1986) determinaram parâmetros de desempenho para pulverizadores para citros acionados pela TDP, onde a potência requerida pelos modelos ensaiados variaram de $12 \mathrm{~kW}$ a $46 \mathrm{~kW}$. Desse modo, por análise de regressão, determinaram equações para o dimensionamento de máquinas em função do consumo de combustivel e da rotação da TDP (540 ou $600 \mathrm{rpm}$ ) necessária para o acionamento do pulverizador, conforme Equações 4 e 5 .

$$
\begin{aligned}
& \mathrm{HP}_{540}=-38,4+70,6 *(\ln \mathrm{X}) \\
& \mathrm{HP}_{600}=-59,3+81 *(\ln \mathrm{X})
\end{aligned}
$$

Onde: $\mathrm{X}=$ consumo de combustivel, em galões por hora (gph).

$\mathrm{HP}_{540}=$ potência requerida por pulverizadores acionados pela TDP a $540 \mathrm{rpm}$.

$\mathrm{HP}_{600}=$ potência requerida por pulverizadores acionados pela TDP a $600 \mathrm{rpm}$.

Ainda no mesmo estudo, os autores determinaram que os pulverizadores de baixo volume, eletrostáticos ou não, apresentaram a maior variabilidade de deposição dentre os pontos amostrados nas copas das plantas de laranja valência, com valores de $105 \%$ e $115 \%$, respectivamente.

Comparando pulverizadores convencionais de médio e alto volume e pistolas manuais com o de "cortina de ar" para o controle de Guignardia citricarpa 
Keily em laranja valência, Beattie et al. (1989) salientam que o pulverizador de "cortina de ar" apresentou a mesma eficiência na pulverização que a pistola manual, com um volume de calda $72 \%$ menor e consequentemente com o menor custo.

Com a finalidade de encontrar alternativas de trabalho que tenham a mesma eficiência e menor custo que os métodos convencionais de pulverização, Juste et al. (1990), avaliaram quatro máquinas de aplicação de defensivos (pistola manual, bicos oscilantes, jato transportado - convencional - e pulverizadores à baixa pressão), para os parâmetros: penetração, tamanho de gotas, escorrimento e controle de pragas. Os volumes de calda utilizados pelas máquinas variaram de $1,26 \mathrm{~L}_{\text {planta }}{ }^{-1}$ até 16,2 L.planta $^{-1}$ em função do tipo da máquina e da praga a ser controlada. Os autores detectaram um escorrimento foliar muito maior para o pulverizador com osciladores $(20,8 \%)$ e para a pistola manual $(9,1 \%)$, enquanto para o pulverizador convencional e para o pulverizador à baixa pressão, as perdas foram as menores constatadas, $5,2 \% \mathrm{e}$ $1,5 \%$, respectivamente. No tocante ao controle de pragas, os pulverizadores convencionais e à baixa pressão obtiveram um controle superior a $95 \%$ para pragas localizadas na parte externa a copa, porém, quando o alvo é o interior da copa somente o pulverizador à baixa pressão obteve um desempenho razoável, com $75 \%$ de controle. Os resultados indicam que seria necessário um aumento de volume de ar para os pulverizadores convencionais obterem um melhor alcance dentro da copa das plantas, através da utilização de ventiladores maiores.

Ensaiando um pulverizador com sistema de "cortina de ar" e outro convencional, visando comparar as características da deposição da pulverização em plantas de citros quando pulverizadas apenas de um lado, Whitney \& Salyani (1990) não encontraram diferenças significativas nos coeficientes de variação para árvores de grapefruit ou laranja, embora a média de deposição nas folhas tenha sido significativamente menor, cerca de $35 \%$, para os pulverizadores "cortina de ar". A Figura 2 demonstra as diferenças básicas entre um pulverizador convencional e um com "cortina de ar". 


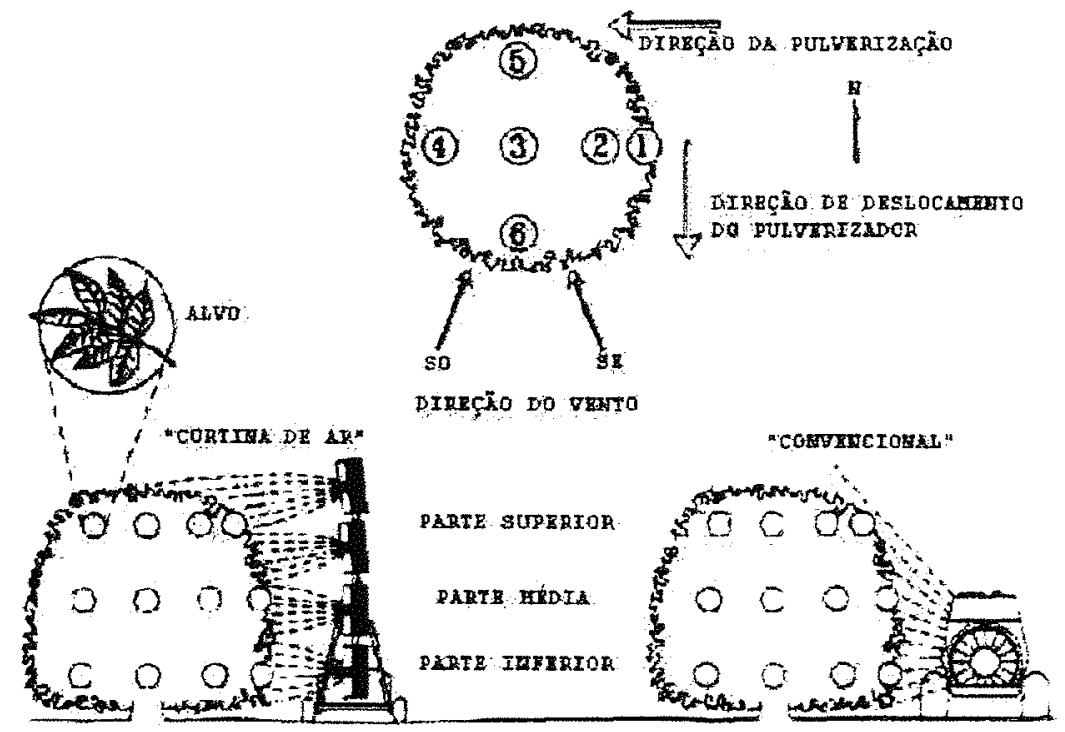

Figura 2 - Esquema comparativo do pulverizador convencional com um pulverizador do tipo "cortina de ar". Adaptado de Whitney \& Salyani (1990).

Whitney \& Salyani (1991), realizando ensaios entre um pulverizador de jato transportado e um pulverizador de "cortina de ar" (com 4 ventiladores transversais), concluíram que a razão do volume de ar movimentado por lado é de $25 \mathrm{~m}^{3} . \mathrm{s}^{-1}$ e 14,8 $\mathrm{m}^{3} \cdot \mathrm{s}^{-1}$, respectivamente. Além disso, a deposição realizada pelo pulverizador convencional foi maior que o de "cortina de ar".

$\mathrm{Na}$ comparação de duas máquinas terrestres e duas aéreas (pulverizadores à alto e baixo volume, helicóptero e avião), Salyani \& Cromwell, (1992) concluíram que não existe diferença substancial entre os pulverizadores terrestres e os aéreos no tocante à deriva, e que aplicações a baixo volume aparentam ser mais susceptíveis à deriva. Já a seleção de bicos e o volume pulverizado em máquinas terrestres têm uma influência significativa na deriva.

Bayat et al. (1994), analisando a deposição de pulverização de três pulverizadores convencionais e um com carga eletrostática, afirmam que o pulverizador eletrostático aumentou a deposição, mas não conseguiu reduzir a variabilidade no sentido vertical das zonas de amostragem das plantas. 


\section{MATERIAL E MÉTODOS}

Para o desenvolvimento do modelo utilizou-se um microcomputador com processador Pentium II $-450 \mathrm{MHz}, 64 \mathrm{Mb}$ de memória RAM, HD de $6.0 \mathrm{~Gb}$, marca Microtec, e o programa Visual Basic 6.0.

\subsection{Desenvolvimento do algoritmo}

Algoritmo é um processo de cálculo ou de resolução de um grupo de problemas semelhantes em que se estipulam com generalidades e sem restrições regras formais para a obtenção do resultado ou da solução do problema.

O desenvolvimento do algoritmo pode ser visualizado no fluxograma, apresentado na Figura 3. O modelo inicia com a introdução de informações gerais pelo usuário (1)** como jornada de trabalho (h), período em que ocorre a operação, quantidade de jornadas diárias, salário dos trabalhadores (US\$), preço do combustível (US\$. $L^{-1}$ ), volume de calda (L), velocidades de trabalho $\left(\mathrm{m} . \mathrm{s}^{-1}\right)$, entre outras.

$\mathrm{Na}$ entrada de dados referentes à caracterização da base fisica (2), cadastram-se os talhões no banco de dados com as seguintes informações: nome, data de plantio, número de plantas, número de covas, número de fileiras, área (ha), espaçamento (m), variedade, distância do ponto de abastecimento (m) e vazão do ponto de abastecimento $\left(\mathrm{m}^{3} \mathrm{~h}^{-1}\right)$. Para execução do modelo, é necessário selecionar a área a ser pulverizada (4), que pode ser realizada em função da idade, variedade, talhões ou em área total.

Na entrada de dados "Produtos Fitossanitários" (3) discrimina-se o nome do produto, a quantidade de produto utilizado por tanque (em $\mathrm{L}$ ou $\mathrm{kg}$ ) e o preço unitário

** Os números entre parénteses referem-se aos conteúdos da Figura 3. 
do produto (US\$. $\mathrm{kg}^{-1}$ ou L $\mathrm{L}^{-1}$ ). Desta forma, é possível determinar o custo total com produtos e a quantidade total necessária para a operação (6), com base na quantidade de plantas a serem pulverizadas e no volume de calda (L.planta ${ }^{-1}$ ).

Escolhidos os talhões, determinam-se os tempos operacionais (5) da pulverização em função do sistema mecanizado selecionado e de informações existentes no cadastro de talhões, como: a quantidade de plantas, vazão e distância do ponto de abastecimento, espaçamento da cultura, entre outros. Os tempos são classificados como: pulverização, manobras, abastecimento, deslocamento para abastecimento, manutenção e gerenciais, sendo agrupados em três modalidades: produtivos, auxiliares e perdidos.

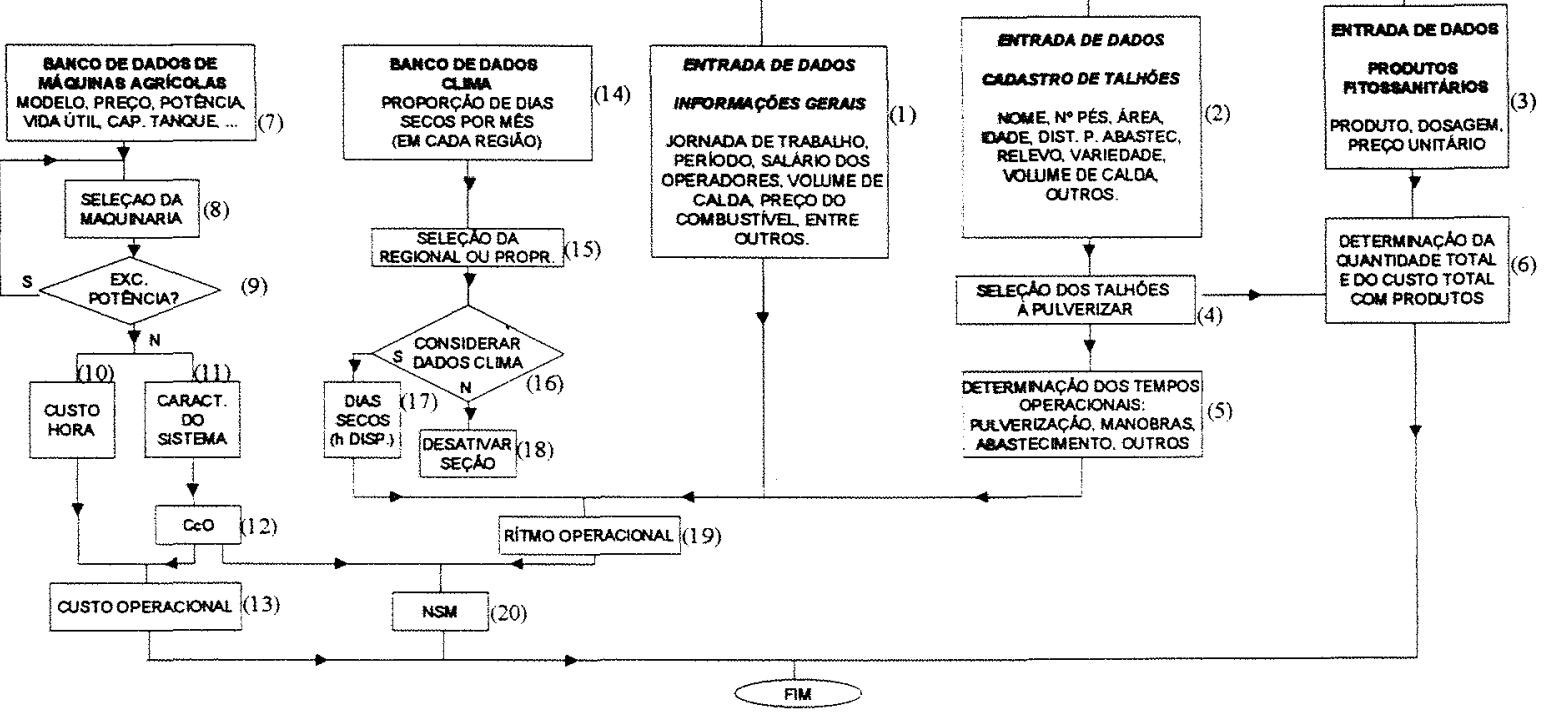

Figura 3 - Fluxograma do modelo.

Os tempos produtivos são aqueles em que o sistema mecanizado está efetivamente operando, no caso, o tempo de pulverização. Os auxiliares são os despendidos com tarefas que são necessárias para que seja realizada a operação, como os tempos de manobra, abastecimento, deslocamento para abastecimento e manutenção. Os 
perdidos referem-se àqueles que não são necessários para a execução do trabalho, como os tempos de espera, quebra, deslocamento de funcionários, entre outros.

$\mathrm{O}$ banco de dados de máquinas agrícolas (7) é dividido em duas partes. A primeira refere-se aos tratores onde são armazenadas as informações básicas sobre os modelos disponiveis no mercado. As informações referem-se ao modelo, potência no motor (cv), preço de aquisição (US\$) e vida útil (h). A segunda armazena os dados sobre os pulverizadores que são: modelo, preço de aquisição (US\$), vida útil (h), capacidade do tanque (L), quantidade de defletores, potência requerida (cv), e no caso de máquinas tracionadas por tratores, mas acionadas por motores próprios, a potência máxima do motor (cv). Se houver a necessidade da introdução de uma nova máquina ou a alteração de dados já existentes, é possivel alterar este banco de dados.

O próximo passo é a seleção da maquinaria (8), onde o usuário faz a opção do conjunto trator / pulverizador que deseja utilizar. Na sequêencia, o modelo informa ao usuário se o acoplamento foi adequado (9), comparando a potência requerida pelo pulverizador com a disponível no motor do trator, possibilitando uma nova seleção da maquinaria, caso a potência requerida do pulverizador não esteja adequada à do trator, com base na potência fornecida nos catálogos dos fabricantes.

Com o conjunto selecionado, o modelo calcula o custo horário (10), e com base nas caracteristicas técnicas (11) determina a capacidade de campo operacional dos conjuntos (12), que aliado ao item (10) fornece o custo operacional (13).

$\mathrm{O}$ banco de dados de informações climáticas (14) contém informações referentes à proporção de dias secos e sem vento em cada mês, que são inseridas pelo usuário em função de suas anotações climáticas de campo. Como padrão o modelo traz dados climáticos para as regiões de Campinas, Piracicaba, Limeira, Jaú e Ribeirão Preto (Mialhe, 1974).

Em seguida, seleciona-se uma região ou propriedade (15) para determinação dos dias aptos à pulverização (17). Para este cálculo é necessário que o usuário indique se a operação será realizada durante os sábados, domingos e feriados, para que possam ser descontados do cálculo. A seguir, multiplicam-se os dias restantes 
pela proporção de dias secos e com condições de vento adequado do mês escolhido para a pulverização.

Se o usuário não quiser utilizar dados climáticos na modelagem do seu sistema (16), é possivel desativar esta parte do modelo (18) selecionando a região "Sem clima", onde o modelo considera a proporção como sendo 1 para todos os meses, ou seja, $100 \%$ dos dias referentes àquele periodo estão aptos ao trabalho. Esta sub-rotina é necessária quando o usuário não está utilizando o modelo para o planejamento da operação, mas para o gerenciamento diário da propriedade que consiste em disponibilizar a quantidade ideal de conjuntos mecanizados para realização de uma determinada tarefa.

Para a determinação do ritmo operacional (19), utiliza-se os tempos operacionais (5), os dias aptos à pulverização (17) e informações gerais (1). Caso o usuário não queira considerar fatores climáticos, o ritmo operacional será dado em função dos dias de calendário. A necessidade de conjuntos (20) é fornecida pela razão do ritmo operacional e a capacidade operacional do sistema. Parte da rotina de programação pode ser observada no Anexo 1.

3.2 Rotinas de cálculo

3.2.1 Custo horário

A determinação do custo horário dos sistemas mecanizados foi realizada com base na metodologia fornecida pela ASAE (American Society of Agricultural Engineers) Standards (1997), onde se subdivide o custo horário em duas partes: custo fixo e variável.

Somente para se estimar o consumo de combustivel dos tratores utilizados para a pulverização foi utilizada uma equação empirica obtida a partir dos dados de ensaios do CENEA (Centro Nacional de Engenharia Agricola), sugerida por Tachibana 
(1998). Esta equação $n^{0} 3$ pg.14 permite calcular o consumo de combustivel de acordo com a porcentagem de carga atribuida a TDP (tomada de potência) do trator.

\subsubsection{Dias aptos à pulverização}

Para estimar corretamente a necessidade de sistemas mecanizados para uma determinada operação, é preciso descontar os dias que não estão disponiveis para o trabalho devido ao clima. No presente caso, as restrições impostas ao trabalho referemse a precipitação e a velocidade do vento. Segundo manual da British Crop Protection Council (1991) velocidades de vento entre 3,2 e $9,6 \mathrm{~km} \cdot \mathrm{h}^{-1}$ são adequadas para a aplicação de defensivos agrícolas.

\subsection{3 - Parâmetros operacionais}

Neste trabalho, os parâmetros operacionais envolvem o ritmo operacional, a capacidade de campo operacional, a necessidade de sistemas mecanizados e custo operacional. A metodologia utilizada para determinação deste foi a sugerida por Mialhe (1974).

\subsection{Conjuntos mecanizados avaliados}

Com a finalidade de avaliar o modelo em diversas situações de trabalho, utilizou-se neste trabalho 3 modelos de conjuntos mecanizados, que podem ser visualizados na Tabela 1.

O conjunto 1 é composto por um trator de $53,9 \mathrm{~kW}(75 \mathrm{cv})$ utilizado para tracionar e acionar através da TDP a bomba hidráulica e o ventilador de um pulverizador de jato transportado (pulverizador convencional). 
O conjunto 2 é composto por um trator de $36,6 \mathrm{~kW}(50 \mathrm{cv})$ utilizado apenas para tracionar um pulverizador de "baixo" volume, semelhante à máquina "torre de ar" utilizada no estudo de Cunningham \& Harden (1999).

O conjunto 3 é composto por um trator de $53,9 \mathrm{~kW} \mathrm{(75} \mathrm{cv)} \mathrm{utilizado} \mathrm{para}$ tracionar e acionar através da TDP a bomba hidráulica e os ventiladores de um pulverizador de "cortina de ar", semelhante ao citado por Whitney \& Salyani (1990). Dados mais detalhados sobre estes conjuntos podem ser visualizados nos Anexos 2, $3 \mathrm{e}$ 4 , respectivamente.

Tabela 1 - Principais características dos conjuntos mecanizados para desenvolvimento dos cenários.

\begin{tabular}{lrrr}
\hline \multicolumn{4}{c}{ Principais características dos conjuntos mecanizados } \\
\hline & \multicolumn{3}{c}{ Conjunto mecanizado } \\
\cline { 2 - 4 } Características & 1 & 2 & 3 \\
\hline Volume de calda (L/planta) & 22 & 7,33 & 11 \\
Velocidade de aplicação $(\mathrm{m} / \mathrm{s})$ & 0,81 & 0,55 & 0,81 \\
Velocidade de manobras $(\mathrm{m} / \mathrm{s})$ & 0,60 & 0,55 & 0,60 \\
Velocidade de deslocamento $(\mathrm{m} / \mathrm{s})$ & 2,00 & 2,00 & 2,00 \\
Capacidade do tanque $(L)$ & 2.000 & 2.100 & 2.000 \\
\hline
\end{tabular}

\subsection{Verificação e validação}

A verificação da rotina é realizada para analisar a possibilidade de erros durante a construção do programa. Ela foi efetuada através da comparação dos valores obtidos com calculados em cada etapa da rotina.

Já com a validação, procura-se analisar a consistência dos resultados obtidos pelo programa, confrontando-os com valores em literatura e, no presente caso, com dados fornecidos por uma empresa agrícola. A validação foi feita para o custo horário e tempos operacionais. 


\subsubsection{Custo horário}

Neste item foram avaliados os custos horários dos tratores utilizados pelos conjuntos, sendo um de $54,9 \mathrm{~kW}$ (75 cv) (MF-275) e outro de $36,6 \mathrm{~kW}(50 \mathrm{cv})$ (MF-250). Comparou-se o custo horário calculado pelo modelo com os fornecidos pelo Agrianual 2000.

Para o cálculo do custo horário considerou-se uma utilização anual de $1.200 \mathrm{~h}$ por trator, e o preço de aquisição das máquinas foi fornecido pela empresa agrícola, como pode-se observar nos Anexos 1 e 2.

Ainda analisou-se o custo desses tratores por tempo de utilização anual, que variou de 400 a $1.500 \mathrm{~h}$ anuais, sendo esses comparados com os dados do Agrianual 2000.

Neste trabalho foi utilizada a moeda norte-americana para todos os parâmetros que utilizam valores monetários, a taxa de cambio utilizada na conversão da moeda foi de R\$ 1,80 por US\$.

\subsubsection{Tempos operacionais}

Para aferição dos tempos operacionais foram levantados os tempos despendidos em pulverização, manobra, abastecimento e deslocamento para o abastecimento numa pulverização realizada em 7 talhões da fazenda, sendo estes dados comparados com os fornecidos pelo modelo.

O tempo de pulverização no campo foi levantado através da medição da velocidade média de aplicação, para tanto, foram marcados 5 trechos de $50 \mathrm{~m}$ e anotouse o tempo necessário para o conjunto se deslocar nestes espaços. O cálculo foi realizado multiplicando-se o número de plantas do talhão pelo espaçamento entre plantas e por dois, em seguida, dividiu-se o total obtido pela média da velocidade de aplicação.

Num pomar de laranja existem dois tipos de manobras realizados pelas máquinas: as que contornam a mesma fileira de plantas e as que mudam de fileira. $\mathrm{O}$ 
levantamento do tempo de manobras no campo foi realizado anotando-se o tempo gasto para o conjunto mecanizado realizar a manobra de cabeceira. Foram observadas 5 manobras de cada tipo e multiplicou-se a média das duas pelo número de manobras necessárias para pulverizar cada talhão, obtendo-se o tempo de manobras de campo.

O tempo de abastecimento dos pulverizadores foi levantado através de medições de tempo para o abastecimento de um conjunto. $\mathrm{Na}$ fazenda em questão os pulverizadores são abastecidos de duas maneiras, na primeira o caminhão já abastece os tanques com os produtos previamente misturados e na segunda o caminhão abastece os pulverizadores somente com água, sendo os produtos fitossanitários adicionados posteriormente.

O tempo de deslocamento para abastecimento dos pulverizadores foi levantado em campo através da anotação do tempo total de pulverização subtraído do tempo de pulverização, manobras e abastecimento. Também foram desconsideradas algumas paradas ocasionadas por quebra, regulagens, entre outras.

A validação foi realizada para 2 métodos diferentes de pulverização, na primeira os talhões da série $A$, cujas iniciais do nome são a letra "A" (A31, A32, A33A e A36), foram pulverizados com 7 conjuntos do tipo 1 , utilizando-se um volume de calda de $16 \mathrm{~L}_{\text {ha }}{ }^{-1}$, uma velocidade de aplicação de $0,87 \mathrm{~m} \cdot \mathrm{s}^{-1}$ e trabalhou-se com o sistema de "calda pronta" onde utiliza-se um caminhão pipa com os produtos misturados no tanque previamente, desta forma, não perde-se tempo para misturar os defensivos nos tanques dos pulverizadores.

Na outra, os talhões da série C (C20, C20A e C20E), foram pulverizados com 3 conjuntos do tipo 2, Utilizando-se nesta aplicação um volume de calda de aproximadamente $11 \mathrm{~L}^{\mathrm{h}} \mathrm{ha}^{-1}$, a uma velocidade de trabalho de $0,55 \mathrm{~m} . \mathrm{s}^{-1}$ e utilizou-se apenas um caminhão tanque trazendo somente água, sem misturar os produtos previamente no tanque do caminhão, sendo a mistura realizada após o abastecimento do tanque dos pulverizadores. As principais características dos talhões podem ser observadas na Tabela 2. 
Tabela 2 - Principais características dos talhões da série A e C, utilizados para a validação do modelo.

\begin{tabular}{lccccc}
\hline Talhão & Variedade & $\begin{array}{c}\text { Idade } \\
\text { (anos) }\end{array}$ & $\begin{array}{c}\text { Quantidade } \\
\text { plantas }\end{array}$ & $\begin{array}{c}\text { Área } \\
\text { (ha) }\end{array}$ & $\begin{array}{c}\text { Espaçamento } \\
\text { (m) }\end{array}$ \\
\hline A31 & Valência & 7 & 813 & 2,77 & $7,5 \times 4$ \\
A32 & Valência & 7 & 1.374 & 4,69 & $7,5 \times 4$ \\
A33A & Valência & 7 & 192 & 0,65 & $7,5 \times 4$ \\
A36 & Valência & 7 & 147 & 0,51 & $7,5 \times 4$ \\
C20 & Valência & 19 & 440 & 2,11 & $8 \times 6$ \\
C20A & Valência & 19 & 516 & 2,48 & $8 \times 6$ \\
C20E & Valência & 19 & 581 & 2,79 & $8 \times 6$ \\
\hline
\end{tabular}

3.5 Análise de sensibilidade

Esta é uma ferramenta de análise utilizada por muitos autores, que auxilia na deteç̧ão dos fatores que mais influenciam no custo de uma operação, desta forma é possivel atuar diretamente nos pontos críticos do sistema.

Para tanto, foram escolhidos alguns fatores subdivididos em internos e externos para a realização desta análise, todos os fatores foram acrescidos em $10 \%$ do seu valor normal e observou-se o quanto isso afetou o custo operacional da maquinaria. Cada fator foi mudado individualmente, e a metodologia empregada nesta análise foi a mesma utilizada por Milan (1992).

Para a realização da análise de sensibilidade, adotou-se duas situações, onde são definidas algumas características básicas que podem influenciar a aplicação. A propriedade "A" possui uma área de aproximadamente 3.000 ha com plantas de idades iguais ou superiores a 7 anos. Nesta propriedade existem caminhões tanques auxiliando no transporte de água, e a distância média até o ponto de abastecimento é de $300 \mathrm{~m}$.

A propriedade " $\mathrm{B}$ " possui uma área de aproximadamente 500 ha com plantas de idades iguais ou superiores a 7 anos. Nesta propriedade não existem caminhões tanques auxiliando no transporte de água, dessa forma, os pulverizadores 
precisam se deslocar até o ponto de abastecimento que pode estar a até $3 \mathrm{~km}$ da área de trabalho.

Analisou-se uma pulverização hipotética contra ácaro da leprose em plantas "adultas" (idade mínima 7 anos), os conjuntos mecanizados utilizados foram do tipo 1 operando com um volume de calda médio de 22 L.planta ${ }^{-1}$. Uma descrição detalhada dos sistemas A e B podem ser visualizados nos Anexos 5 e 6, respectivamente.

3.5.1 Parâmetros e sistemas envolvidos na análise de sensibilidade

A análise de sensibilidade foi desenvolvida levando em conta duas categorias: os fatores externos e os fatores internos.

Os fatores externos são aqueles que influenciam o custo da operação, porém não podem ser controlados pelo gerente. Foram selecionados 8 fatores externos:

- Preço de aquisição do pulverizador;

- Preço de aquisição do trator;

- Preço do óleo diesel;

- Salário do tratorista;

- Salário do auxiliar;

- Taxa de juros anual;

- Vida útil do pulverizador;

- Vida útil do trator.

Os fatores internos são aqueles que influenciam o custo da operação e que podem ser controlados pelo gerente. Foram selecionados 13 fatores externos:

- Volume de calda (L.planta ${ }^{-1}$ );

- Distância do ponto de abastecimento (m);

- Tempo gerencial (min);

- Tempo de manutenção (min);

- Quantidade de produtos utilizado no tanque; 
- Quantidade de turnos;

- Jornada de trabalho(h);

- Velocidade de manobra de cabeceira $\left(\mathrm{m} . \mathrm{s}^{-1}\right)$;

- Velocidade de deslocamento $\left(\mathrm{m} \cdot \mathrm{s}^{-1}\right)$;

- Velocidade de aplicação $\left(\mathrm{m} \cdot \mathrm{s}^{-1}\right)$;

- Vazão do ponto de abastecimento $\left(\mathrm{m} 3 \cdot \mathrm{h}^{-1}\right)$;

- Utilização anual do trator (h);

- Utilização anual do pulverizador (h);

\subsection{Cenários}

Outra ferramenta para auxiliar a tomada de decisão são os cenários, pois torna possível visualizar como a operação funcionaria com algumas modificações adotadas, observando o custo operacional e a eficiência do sistema.

Para definir quais as modificações são necessárias, pode-se utilizar os fatores mais críticos indicados pela análise de sensibilidade, procurando montar situações que sejam possiveis de realizar no campo, por exemplo, substituir um modelo de pulverizador ou trator por outro existente no mercado.

Serão desenvolvidos diversos cenários associados com estratégias de gerenciamento, técnicas de aplicação de defensivos, modelos e acessórios de equipamentos. Uma propriedade e suas metodologias de trabalho foram consideradas como padrão e os cenários foram desenvolvidos em sua função.

A propriedade padrão é a apresentada na seção 4.3 , denominada como situação A (propriedade A) e suas principais características podem ser visualizadas no Anexo 5 .

Neste estudo apenas os custos diretos da situação serão analisados, portanto não foram incluídos os investimentos necessários para realização de cada situação. 
3.6.1 Necessidade de sistemas mecanizados (NSM) x fatores climáticos

Esta análise quantifica a influência dos fatores climáticos na variação da necessidade de sistemas mecanizados. Para o cálculo foi considerado o período do $1^{\circ}$ ao $30^{\circ}$ dia de cada mês do ano 2.000 , com exceção de fevereiro que foi até o dia 29 , descontando-se os sábados e domingos, e utilizou-se a probabilidade de dias úteis fornecida pela própria empresa que está sediada no município de Matão - SP.

A necessidade de sistemas mecanizados foi calculada para os três modelos de conjuntos ao realizarem uma pulverização na situação A em cada mês.

3.6.2 Necessidade de sistemas mecanizados (NSM) x jornada de trabalho

Neste item quantificou-se a influência da jornada de trabalho na variação da necessidade de sistemas mecanizados. Para o cálculo foram consideradas jornadas variando de 8 até 24 horas.

A necessidade de sistemas mecanizados foi calculada para os três modelos de conjuntos ao realizarem uma pulverização na situação A em 30 dias, sem considerar os fatores climáticos.

3.6.3 Acréscimo do custo com máquinas $\mathrm{x}$ distância do ponto de abastecimento

Avaliou-se a influência da distância do ponto de abastecimento no custo com máquinas na propriedade $\mathrm{A}$, considerando os conjuntos mecanizados 1 e 2 . Para tanto, alterou-se as distâncias até o ponto de abastecimento de $300 \mathrm{~m}$ para 500, 1.000 , $1.500,2.000,2.500$ e $3.000 \mathrm{~m}$, observando-se as variações do custo com máquinas. 
3.6.4 Acréscimo do custo com máquinas $\mathrm{x}$ formato dos talhões

A influência do formato dos talhões no custo com máquinas foi determinada reduzindo-se a quantidade de fileiras por área (ha), observando-se as alterações ocorridas no custo. Foram avaliadas as proporções de 1,$9 ; 2,2 ; 2,8 ; 3,8 ; 5,7 \mathrm{e}$ 11,4 fileiras ha $^{-1}$.

Considerou-se para esta análise a propriedade $\mathrm{A}$ e os conjuntos 1 e 2 .

\subsubsection{Situações propostas}

Foram sugeridas algumas alterações no sistema A com a finalidade de observar as mudanças ocorridas em alguns parâmetros, que são: necessidade de sistemas mecanizados (NSM), capacidade de campo operacional $(\mathrm{CcO})$, eficiência operacional (EO), custo com máquinas (CM), custo com produtos fitossanitários (CPF), custo total da pulverização (CT).

A elaboração das situações foi baseada a partir de algumas melhorias nas estratégias de gerenciamento e tecnologia de aplicação de defensivos. Todas foram criadas visando sempre um mínimo investimento, se possível nenhum. Foram desenvolvidas 9 situações de trabalho:

Situação 1: sistema atual de trabalho;

Situação 2: realização da pulverização com velocidade de trabalho de 1 $\mathrm{m} . \mathrm{s}^{-1}$. Segundo Raetano (1996), pode-se trabalhar com velocidades de até $1,42 \mathrm{~m} . \mathrm{s}^{-1} \mathrm{sem}$ afetar o controle de pragas. A velocidade na situação atual é de $0,81 \mathrm{~m} \cdot \mathrm{s}^{-1}$ para o conjunto 1 e 3 , e de $0,55 \mathrm{~m} \cdot \mathrm{s}^{-1}$ para o 2 .

Situação 3: Utilização do sensor de plantas nos pulverizadores, pois os equipamentos atuais não possuem esses dispositivos.

Situação 4: Redução de $10 \%$ do volume de calda médio das pulverizações. Segundo um estudo de Hernandez \& Escobio (1986), o volume de calda 
de 516 L.ha ${ }^{-1}$ foi o método que proporcionou maior qualidade da pulverização. Atualmente, o menor volume de calda que se trabalha é de 2.000 L.ha ${ }^{-1}$.

Situação 5: Redução do tempo de manutenção diária para 0 min, realizando o serviço após o expediente de trabalho, quando as máquinas estiverem no galpão.

Situação 6: Redução do tempo gerencial diário de 60 min para $30 \mathrm{~min}$, através de mudanças no planejamento, visando um menor deslocamento das máquinas e operadores até a área de trabalho.

Situação 7: Aumento da velocidade de manobras para $1 \mathrm{~m} \cdot \mathrm{s}^{-1}$, utilizando cardans especiais que possibilitam a manobra de cabeceira com a tomada de potência (TDP) acionada.

Situação 8: Jornadas de trabalho de $10 \mathrm{~h}$. Para isto é necessário que os auxiliares substituam os operadores no horário de almoço e café.

Situação 9: Somatória das situações 2 até 8.

Todas as situações foram estudadas para os 3 conjuntos mecanizados. 


\section{RESULTADOS E DISCUSSÃO}

\subsection{Verificação da rotina}

A rotina foi avaliada durante as etapas de desenvolvimento do modelo não se verificando erros. Considera-se que o modelo pode ser utilizado para a análise de sistemas.

\subsection{Validação}

A validação do modelo é um método que comprova a veracidade dos dados, portanto, foi utilizada para comparar os resultados fornecidos pelo modelo com dados existentes na literatura e/ou com dados fornecidos por uma propriedade agrícola.

\subsubsection{Custo horário}

$\mathrm{Na}$ citricultura paulista os tratores mais utilizados são os de pequeno e médio porte (até $55 \mathrm{~kW}$ ou $75 \mathrm{cv}$ ), portanto foram escolhidos dois modelos de tratores para essa análise: o MF-275 e o MF-250x. Comparou-se os custos horários obtidos no modelo com os publicados no Agrianual 2000. 
A Figura 4 compara os custos horários dos tratores MF-275 e MF-250x considerando uma utilização anual de $1.200 \mathrm{~h}$, observa-se que a diferença entre os resultados fornecidos pelo modelo e Agrianual não ultrapassa a faixa de $10 \%$. A diferença de US\$ $0,48 \cdot \mathrm{h}^{-1}$ para o MF-250 e de US\$ $0,50 \cdot \mathrm{h}^{-1}$ para o MF-275 pode ser explicada pelo preço de aquisição dos tratores, pois no modelo utilizou-se o preço fornecido pela fazenda que por ser uma grande empresa compra tratores como frotista, já o Agrianual considera o preço médio de mercado.

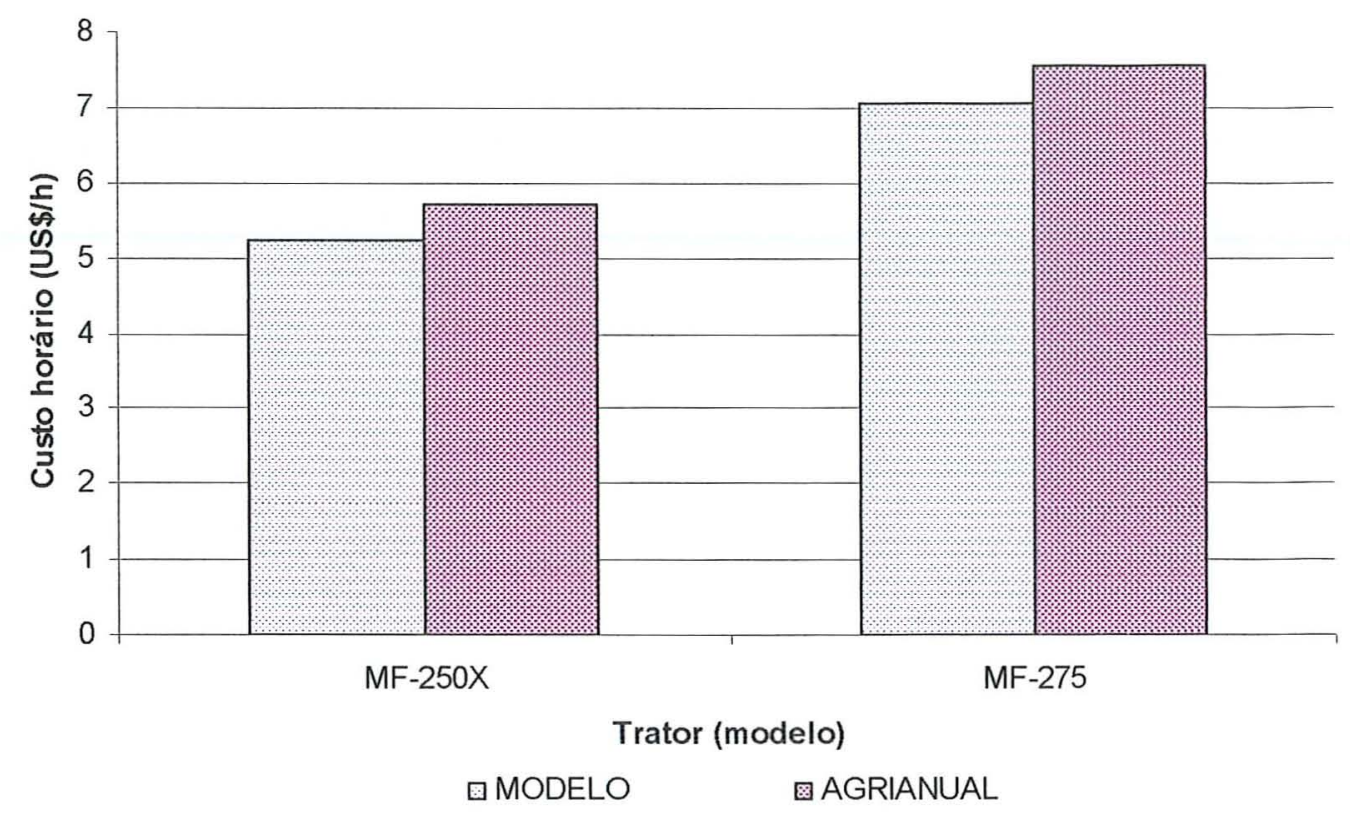

Figura 4 - Comparação dos custos horários dos tratores MF-250x e MF 275, fontes: modelo e Agrianual 2000.

O custo horário das máquinas é influenciado pela sua utilização anual. Para tanto, o modelo foi utilizado sucessivas vezes com a finalidade de obter o custo horário das máquinas quando utilizadas por $400 \mathrm{~h}, 600 \mathrm{~h}, 800 \mathrm{~h}, 1.000 \mathrm{~h}$ e $1.500 \mathrm{~h}$ anuais, por conseguinte comparou-se esses custos fornecidos pelo modelo com os encontrados no Agrianual 2000. 
A Figura 5 apresenta os custos horários em função do tempo de utilização anual para o trator MF-250x. Observa-se nas duas curvas que o custo horário diminui com o aumento da utilização anual. No caso do modelo, o custo para $400 \mathrm{~h}$ anuais é de US $\$ 8,56$ hora $^{-1}$, enquanto que para $1.500 \mathrm{~h}$ anuais o custo decresce para US $\$ 5,23 . \mathrm{h}^{-1}$, ou seja, uma redução no custo horário de aproximadamente 39\%. Para o Agrianual 2000 esta redução é de $46 \%$. Ainda, nota-se que a diferença entre as duas curvas é maior (cerca de 20\%) quando a utilização anual é menor (400 h anuais), já com 1.500 h anuais esta diferença fica abaixo dos $10 \%$.

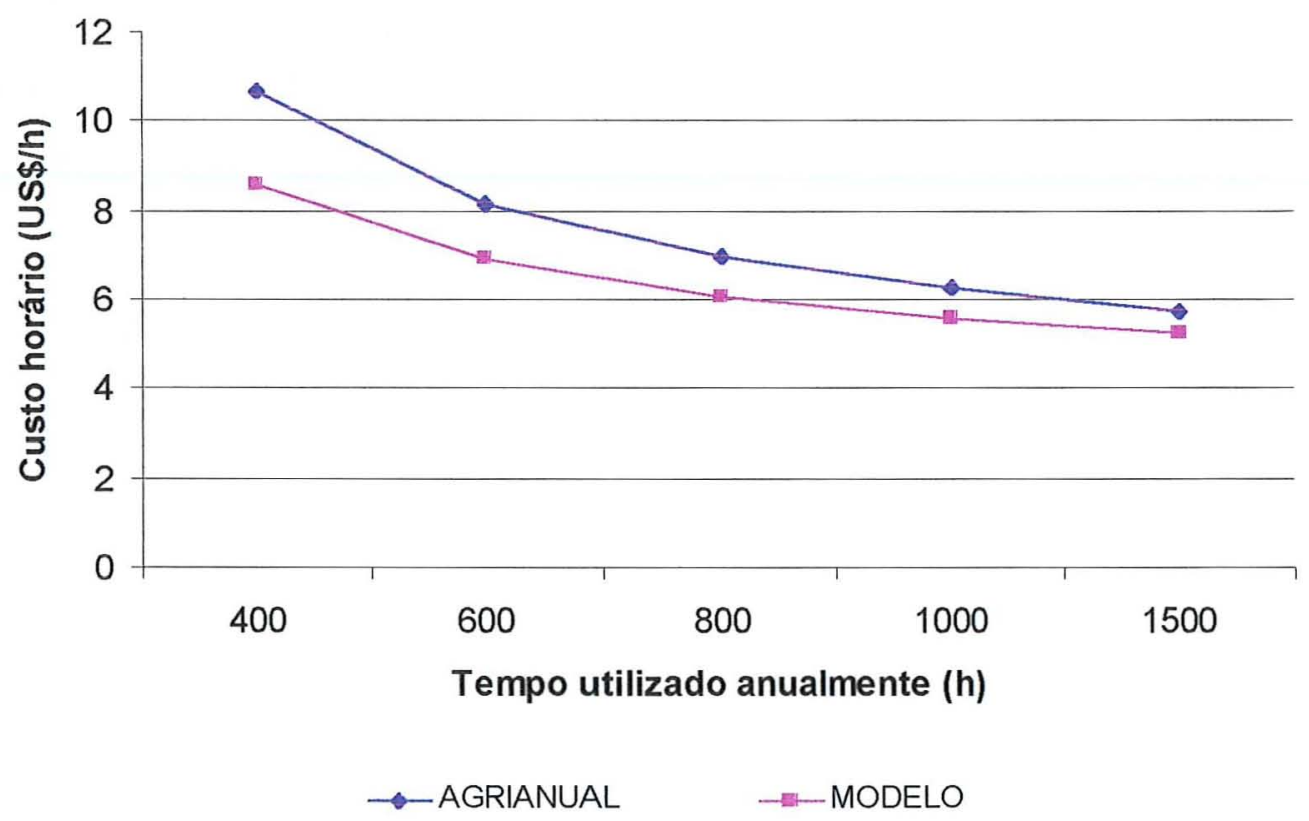

Figura 5 - Comparação do custo horário em função da utilização anual do trator MF250x. Fontes: modelo e Agrianual 2000.

A mesma comparação foi realizada para o trator MF-275, como pode-se observar na Figura 6. Novamente, nota-se a tendência nas curvas em diminuir o custo horário conforme eleva-se a utilização anual. A redução de custo apontada pelo modelo, quando aumenta-se a utilização de $400 \mathrm{~h}$ para $1.500 \mathrm{~h}$ anuais, é de $39,8 \%$, enquanto para o Agrianual é de $41,6 \%$. 
A diferença entre as duas curvas é maior em $400 \mathrm{~h}$ anuais, atingindo 9,5\% entre as duas fontes de dados, a menor diferença foi detectada à $1.500 \mathrm{~h}$ anuais $(6,6 \%)$. Portanto, pode-se afirmar que a diferença entre as duas curvas é praticamente constante.

Deve-se lembrar que o modelo considera que o custo horário fica constante a partir de $1.200 \mathrm{~h}$ anuais, pois de acordo com a ASAE standards (1997), a vida útil de um trator é de 12.000 h ou 10 anos, logo se um trator for utilizado mais de $1.200 \mathrm{~h}$ anuais a vida útil em anos vai diminuir. Isto pode ser uma das causas da redução das diferenças entre as duas curvas conforme o aumento das horas utilizadas.

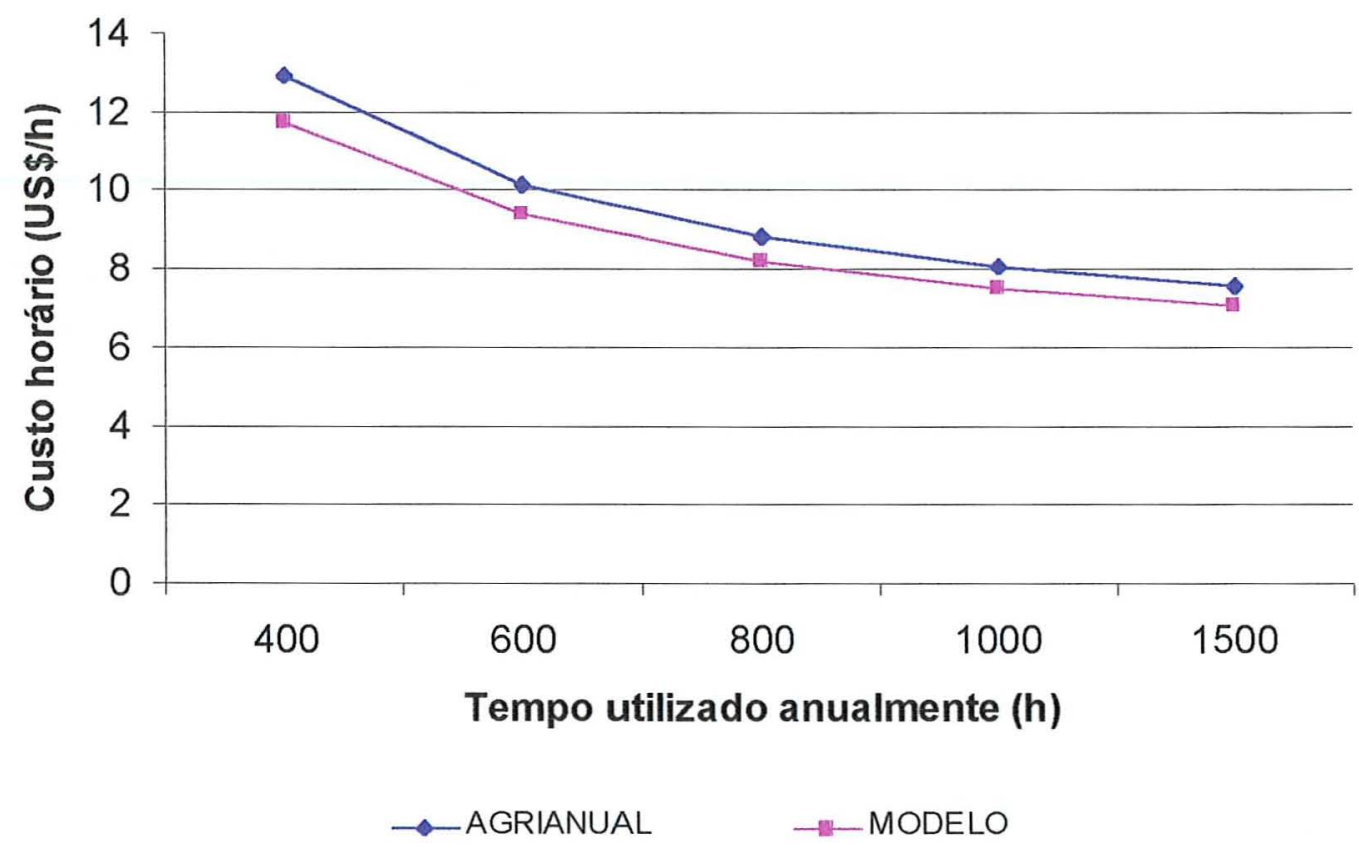

Figura 6 - Comparação do custo horário em função da utilização anual do trator MF-275. Fontes: modelo e Agrianual 2000.

\subsubsection{Tempos operacionais}

Para aferição dos tempos operacionais comparou-se os tempos de pulverização, manobra, abastecimento e deslocamento para o abastecimento 
despendidos numa pulverização aplicada em 7 talhões da fazenda com os fornecidos pelo modelo.

Na Figura 7 observa-se a comparação entre o tempo de pulverização calculado pelo modelo e o obtido no campo. Nota-se que praticamente não houve diferenças entre os dados, devido ao fato da velocidade de aplicação utilizada no modelo ser a mesma que foi obtida com medições de campo.

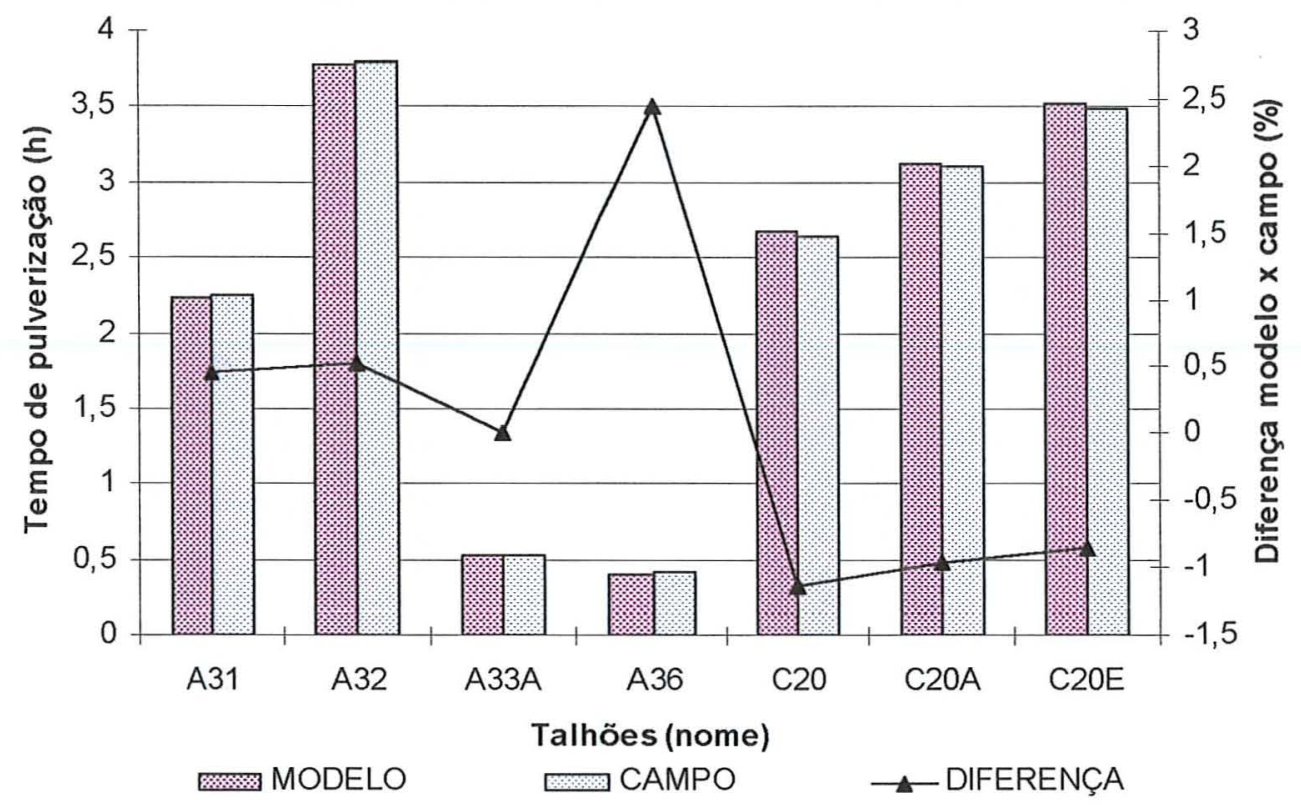

Figura 7 - Comparação dos tempos de pulverização dos talhões da série A e C, obtidos a campo e fornecidos pelo modelo.

A Figura 8 compara o tempo de manobras de cabeceiras fornecidas pelo modelo e obtidas no campo, observa-se que nos talhões de série A os tempos de manobra de campo foram cerca de $20 \%$ maiores do que os tempos do modelo. Uma das possíveis causas desta diferença é que os pulverizadores do conjunto 1 não possuíam árvores cardans que possibilitassem a realização de manobras com eles acionados, portanto o tratorista tinha que parar o conjunto e desengatar a TDP (tomada de potência) para fazer a manobra, fato esse que demandou mais tempo que o esperado pelo modelo. Ferreira (2000) observou o mesmo problema, encontrando diferenças entre 14 e 54\%. 
Nos talhões da série $\mathrm{C}$ ocorreu o inverso, os tempos de manobra fornecidos pelo modelo foram cerca de 20 a $25 \%$ maiores que os tempos anotados a campo. Uma possível justificativa para o fato é que os pulverizadores do conjunto 2 não necessitam da TDP do trator para serem acionados, pois possuem motor próprio. Ferreira (2000) observou diferenças de 4 a 40\%.

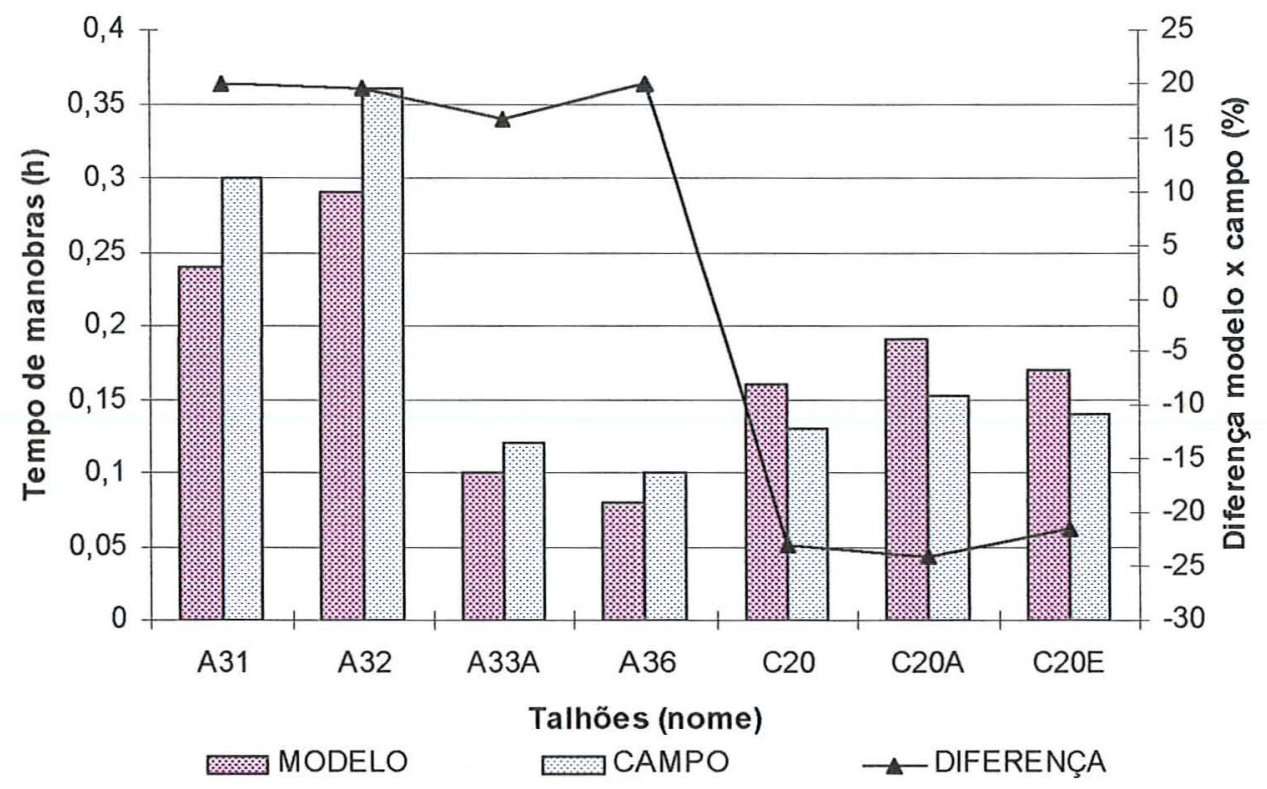

Figura 8 - Comparação dos tempos de manobra de cabeceira dos talhões da série A e C, obtidos a campo e fornecidos pelo modelo.

Atualmente as propriedades têm se preocupado com o aumento da eficiência de trabalho visando a redução de custos. Na fazenda em questão os pulverizadores são abastecidos de duas maneiras. Na primeira o caminhão já abastece os tanques com os produtos previamente misturados e a segunda o caminhão abastece os pulverizadores somente com água, sendo os produtos fitossanitários adicionados posteriormente.

Na Figura 9 observa-se o tempo de abastecimento dos pulverizadores fornecidos pelo modelo e anotados a campo. Os tempos fornecidos pelo modelo são cerca de 15 a 20\% maiores para os talhões da série A e isso deve-se ao fato de não haver a necessidade de misturar os produtos no tanque, logo, o tempo de abastecimento fica 
restrito ao tempo de encher o tanque. O modelo considera o tempo de mistura dos defensivos.

Para os talhões de série $\mathrm{C}$, observa-se que os tempos de abastecimento obtidos a campo são de 25 a 30\% maiores que os calculados pelo modelo. O principal fator que pode explicar esta diferença é que neste caso existe o tempo de mistura de produtos, mas não havia um ajudante para abastecer os pulverizadores sendo os próprios tratoristas quem misturavam os produtos no tanque, ocasionando um tempo mais longo para o abastecimento. O modelo considera um ajudante para cada 3 pulverizadores.

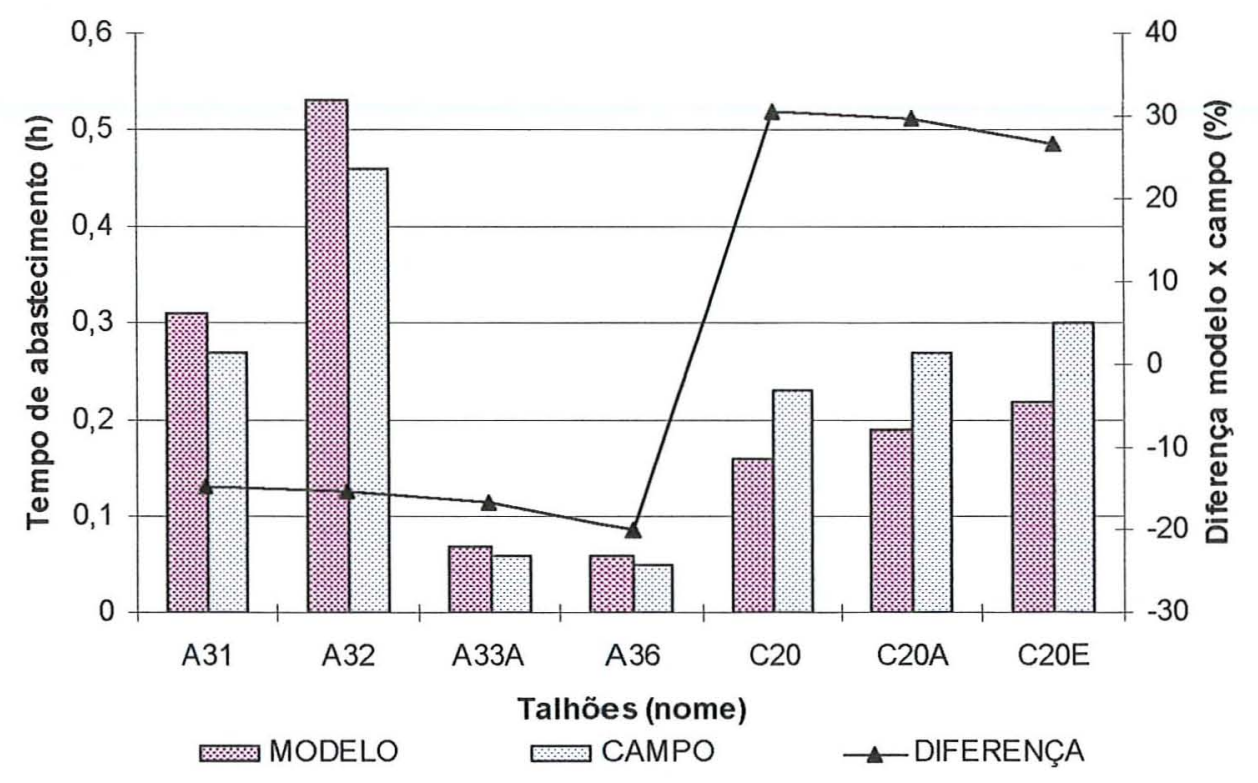

Figura 9 - Comparação dos tempos de abastecimento dos pulverizadores dos talhões da série $\mathrm{A}$ e $\mathrm{C}$, obtidos a campo e fornecidos pelo modelo.

O tempo de deslocamento para abastecimento dos pulverizadores pode tomar grande parte do tempo disponível das máquinas, dependendo da distância do ponto de abastecimento.

Observa-se na Figura 10 a comparação dos tempos de deslocamento para o abastecimento dos pulverizadores. Nota-se que os tempos levantados a campo sempre foram maiores que os calculados pelo modelo com uma variação de 5 a $25 \%$. Existem 
duas possíveis causas que explicam a diferença. A primeira é que o abastecimento dos pulverizadores é realizado com caminhões tanque, e esses locomovem-se para ficar o mais próximo possível das máquinas dificultando a determinação da distância média do ponto de abastecimento. A segunda causa pode ter sido a dificuldade de determinar a velocidade média de deslocamento, que pode ser influenciada por: tratoristas, modelos de trator, relevo, trecho em que se está deslocando (dentro do pomar ou carreador).

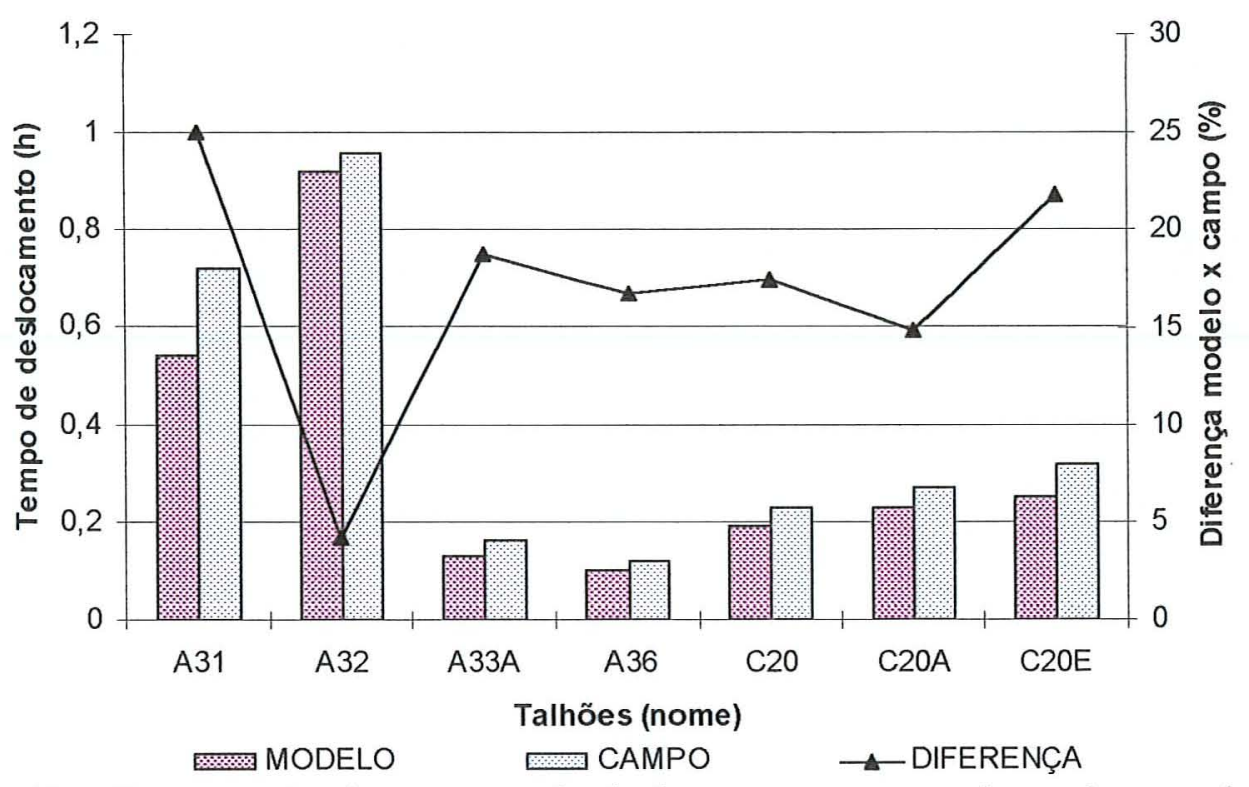

Figura 10 - Comparação dos tempos de deslocamento para o abastecimento dos talhões da série $\mathrm{A}$ e $\mathrm{C}$, obtidos a campo e fornecidos pelo modelo.

4.2.3 - Considerações gerais sobre a validação.

As diferenças obtidas para o custo horário e referente ao desempenho operacional dos conjuntos podem ser consideradas pequenas e adequadas à situação agrícola, sujeitas as mais diversas fontes de variação. Os resultados permitem afirmar que o modelo desenvolvido é adequado para simular as aplicações de defensivos para a cultura da laranja. 


\subsection{Análise de sensibilidade}

A cultura da laranja apresenta propriedades agricolas de diversos tamanhos e em função deste potencial pode-se encontrar diferenças entre conjuntos de equipamentos, tecnologia de aplicação, preço de aquisição das máquinas, entre outros. Para o desenvolvimento do presente estudo adotou-se duas propriedades de tamanhos diferentes, levando em consideração as condições de trabalho disponiveis em cada uma.

\subsubsection{Parâmetros e sistemas envolvidos na análise de sensibilidade}

Dois sistemas foram analisados para verificar a importância de cada parâmetro em diferentes tamanhos de área e suas tecnologias. Na Tabela 3, pode-se verificar o custo atual (US\$) das duas propriedades para realizar uma operação de pulverização em plantas "adultas". Nota-se que embora a área seja seis vezes maior o custo com máquinas aumenta em apenas 3,5 vezes. Isso ocorre devido ao melhor aproveitamento das máquinas e também às condições de negociação como exemplo, a aquisição da maquinaria e outros insumos em grande quantidade. Por esses motivos afirma-se ainda que o custo com máquinas do sistema A representa $17,42 \%$ do custo total da operação, enquanto no sistema B este índice passa para $21,13 \%$.

O custo com produtos é 4,3 vezes maior, neste caso deveria ser de 6 vezes não fosse a diversidade de espaçamentos entre plantas encontradas nas duas propriedades, pois, considerou-se o mesmo volume de calda e a mesma concentração de produtos no tanque.

Tabela 3: Custo com máquinas e produtos para uma operação de pulverização de controle ao ácaro da leprose, para os sistemas A (3.000 ha) e B (500 ha).

\begin{tabular}{cccccccc}
\hline \multicolumn{8}{c}{ Custo para uma operação de pulverização } \\
\hline $\begin{array}{c}\text { Área } \\
\text { (ha) }\end{array}$ & \multicolumn{2}{c}{ Custo com Máquinas } & \multicolumn{2}{c}{ Custo com Produtos } & \multicolumn{3}{c}{ Custo Total } \\
(US $\$$ ) & (\%) & (US\$) & (\%) & (US\$) & (\%) \\
\hline $\mathbf{3 . 0 0 0}$ & $66.202,17$ & 17,42 & $313.785,41$ & 82,58 & $379.987,58$ & 100,00 \\
$\mathbf{5 0 0}$ & $19.120,10$ & 21,13 & $71.382,67$ & 78,87 & $90.502,77$ & 100,00 \\
\hline
\end{tabular}




\subsubsection{Fatores externos}

As Figuras 11 e 12 apresentam as variações no custo da operação influenciadas por cada fator nos sistemas A e B, respectivamente.

Na Figura 11 o preço de aquisição do pulverizador foi o que mais onerou o sistema, seguido pelo preço de aquisição do trator e pelo preço do combustível, todos aumentaram em mais de $2,5 \%$ o custo da operação. A Figura 12 , que representa o sistema B, mostra como fator mais importante o preço do combustível, que aumentou o custo em aproximadamente $3,2 \%$, seguido pelos preços de aquisições do trator $(2,6 \%)$ e do pulverizador $(2,3 \%)$.

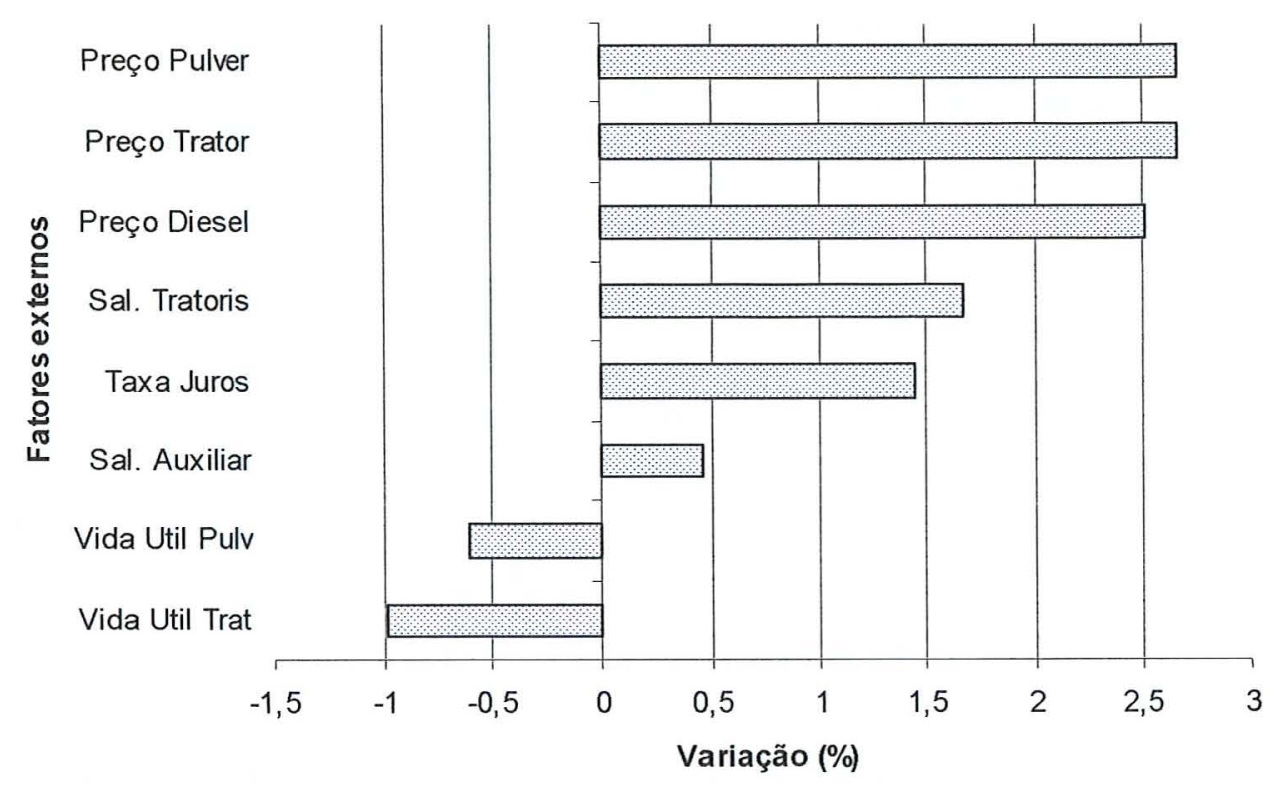

Figura 11 - Variações no custo da pulverização, em porcentagem, devido às mudanças realizadas nos fatores externos, para o sistema $\mathrm{A}$. 


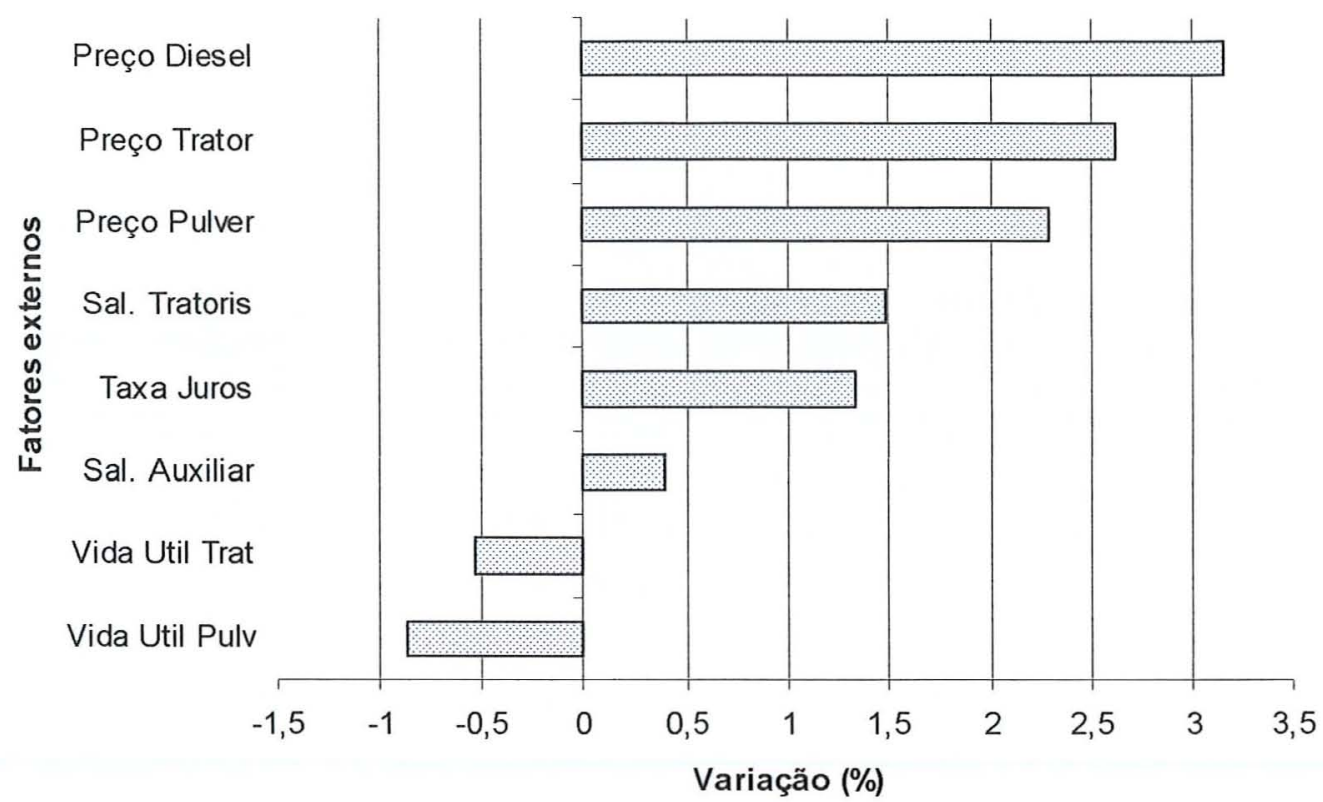

Figura 12 - Variações no custo da pulverização, em porcentagem, devido às mudanças realizadas nos fatores externos, para o sistema $\mathrm{B}$.

Nas Figuras 11 e 12, o salário do tratorista e a taxa de juros ficaram num nível intermediário onerando o sistema em cerca de $1,5 \%$. Os parâmetros: salário do auxiliar, vida útil do pulverizador e do trator foram os que menos influenciaram o custo, com alterações menores que $1 \%$.

Comparando as Figuras 11 e 12 nota-se que existem algumas diferenças na importância dos parâmetros, pois, como pode-se observar no sistema A, o preço do combustível é o terceiro fator que mais onera o custo da operação (cerca de 2,5\%), já no sistema B torna-se o que mais influencia no custo, aumentando-o em 3,2\%. Ainda o preço de aquisição do pulverizador que está como o fator mais importante no sistema $\mathrm{A}$, passa para terceiro lugar no sistema $\mathrm{B}$, sendo menos influente que o preço de aquisição do trator. 


\subsection{3 - Fatores internos}

As Figuras 13 e 14 apresentam as variações no custo da operação de pulverização influenciadas pelos fatores internos nos sistemas $\mathrm{A}$ e $\mathrm{B}$, respectivamente.

A Figura 13 apresenta as variações no custo causadas pelas mudanças realizadas em cada parâmetro para a situação A. Observa-se que o fator que mais onerou o custo foi o volume de calda, ocasionando um aumento de aproximadamente $3,25 \%$, seguido pela distancia do ponto de abastecimento $(1,68 \%)$ e pelos tempos gerenciais $(1,18 \%)$. A velocidade de aplicação foi o fator que mais reduziu o custo, chegando ao indice de $5,7 \%$.

As variações no custo causadas pelas mudanças realizadas em cada fator interno para a situação B podem ser visualizadas na Figura 14. Observa-se que o fator que mais onerou o custo foi o volume de calda, ocasionando um aumento de aproximadamente $5,37 \%$, seguido pela distância do ponto de abastecimento $(4,40 \%) \mathrm{e}$ pelos tempos gerenciais $(1,18 \%)$. As velocidades de aplicação e de deslocamento foram os fatores que mais reduziram o custo, chegando ao índice de 3,67\% e 3,64\%, respectivamente.

Comparando as Figuras 13 e 14, nota-se que em termos de ordem de importância dos fatores internos, mantiveram-se praticamente constantes tendo apenas uma alteração. Para a situação $\mathrm{A}$ a velocidade de deslocamento é o quinto fator de redução de custo, já na situação B torna-se o segundo fator mais importante. Isto ocorre por causa da maior distância até o ponto de abastecimento encontrada na situação $B$

Porém, observando-se as reduções ocasionadas por tais fatores, tem-se que o volume de calda em A aumenta o custo em 3,25\%, enquanto que em B passa para $5,37 \%$, ou seja, em B este fator é cerca de $65 \%$ mais importante que em A. Fazendo-se a mesma análise para a distância até o ponto de abastecimento, tem-se um acréscimo de $1,68 \%$ em A e $4,40 \%$ em $B$, logo em $B$ este influencia 2,6 vezes mais que em A. A velocidade de deslocamento que onera o sistema $\mathrm{A}$ em $1,54 \%$ é de $3,64 \%$ em B, ou seja, uma influencia 2,4 vezes maior. 


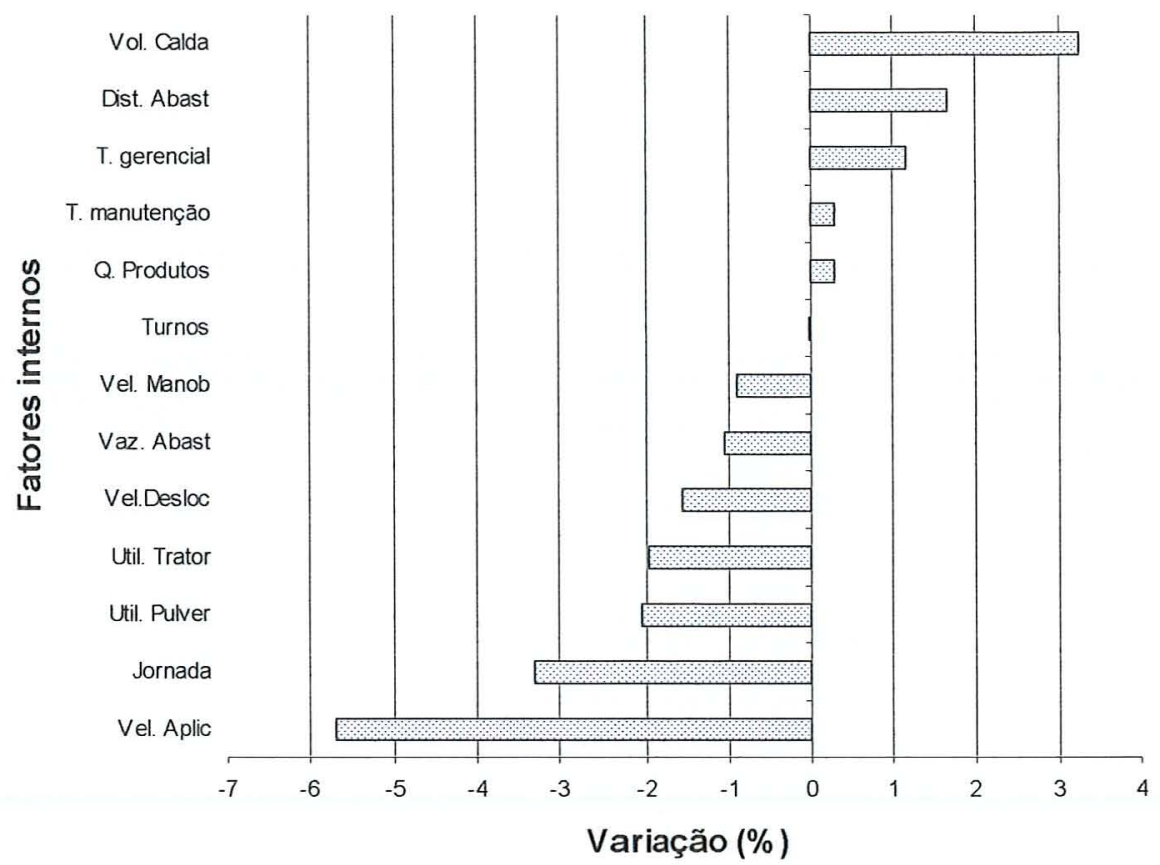

Figura 13 - Variações no custo da pulverização, em porcentagem, devido às mudanças realizadas nos fatores internos, para o sistema $\mathrm{A}$.

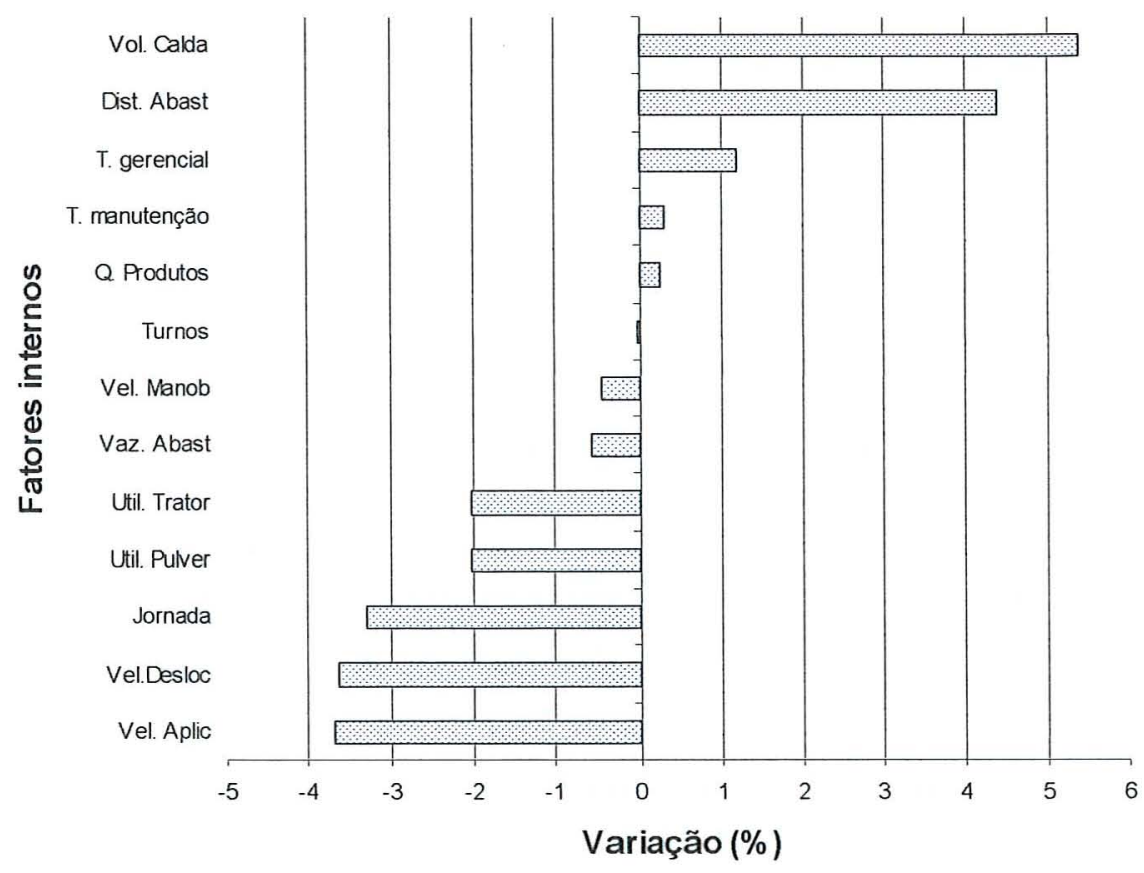

Figura 14 - Variações no custo da pulverização, em porcentagem, devido às mudanças realizadas nos fatores internos, para o sistema $\mathrm{B}$. 
Com o fator velocidade de aplicação ocorre o inverso em A é de 5,7\%, em B é de $3,68 \%$, portanto, perde $55 \%$ da capacidade de reduzir o custo na situação B.

\subsubsection{Eficiência de gerenciamento dos sistemas mecanizados}

No sistema A, a eficiência de gerenciamento utilizada foi de $85 \%$, portanto, $15 \%$ do tempo disponível é perdido devido a problemas gerenciais como aguardando ordens e com deslocamento até a área. Uma eficiência de $100 \%$ significa que não existe tempo perdido, ou seja, seria o sistema ideal.

A Figura 15 apresenta a variação no custo da operação (\%) em função da eficiência de gerenciamento, para valores de 30\% a 100\%. As simulações foram realizadas no sistema $A$.

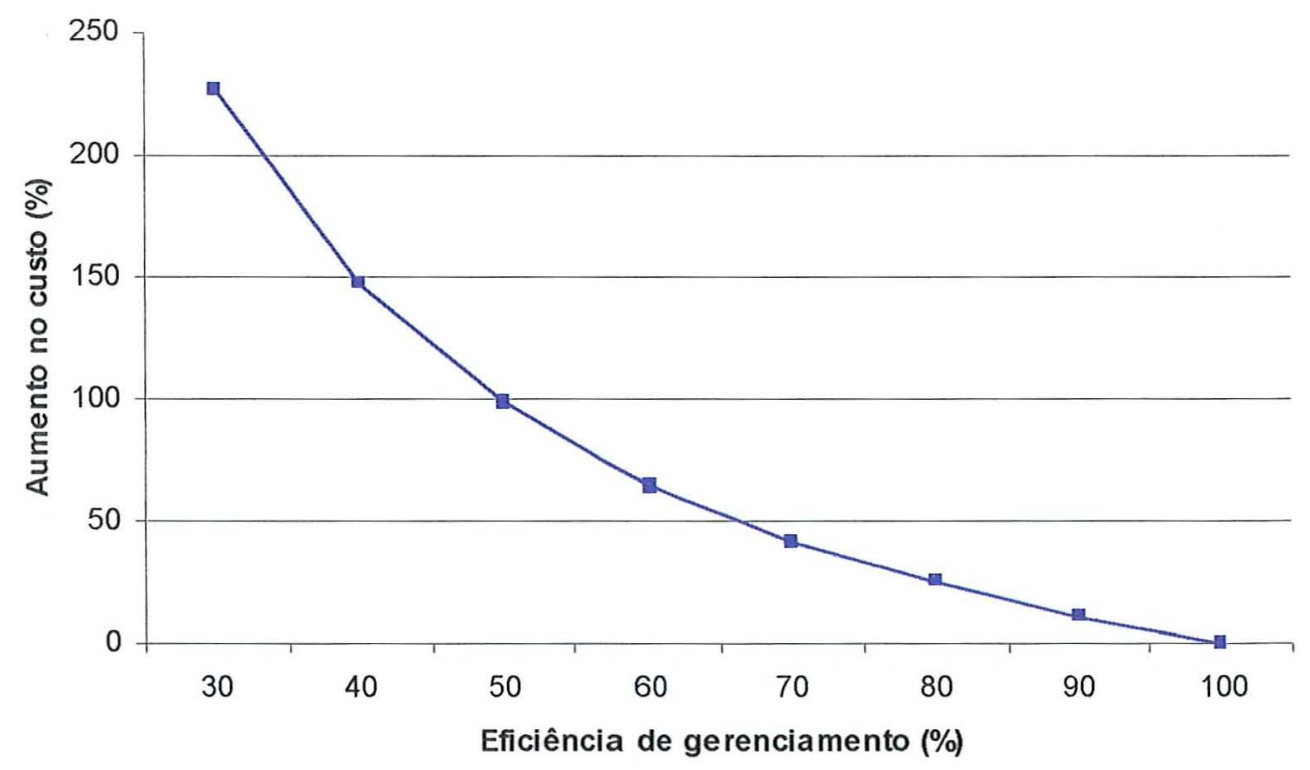

Figura 15 - Acréscimos nos custos da operação em função dos valores da eficiência de gerenciamento. $100 \%$ é considerado como o sistema ideal.

Observa-se na Figura 15 que quanto maior for a eficiência de gerenciamento menor será o custo da operação. Aumentar a eficiência de $80 \%$ para $90 \%$, 
causaria uma redução no custo total na faixa de $13,8 \%$ (US\$ 7.790,71). Porém, se o sistema operasse com $50 \%$ de eficiência o custo seria elevado em 74,3 pontos percentuais, ou seja, para realizar a mesma operação o custo total seria acrescido em US\$ $41.844,51$.

\subsubsection{Efeito do volume de calda}

Para avaliar o efeito do volume de calda considerou-se como $100 \%$ o volume de calda médio (22 L.planta ${ }^{-1}$ ), utilizado atualmente no sistema A.

Na Figura 16 observa-se o efeito no custo ocasionado pela variação do volume de calda, que variou de $50 \%$ até $150 \%$, portanto, variou de $11 \mathrm{~L}_{\text {planta }}{ }^{-1}$ até 33 L.planta ${ }^{-1}$.

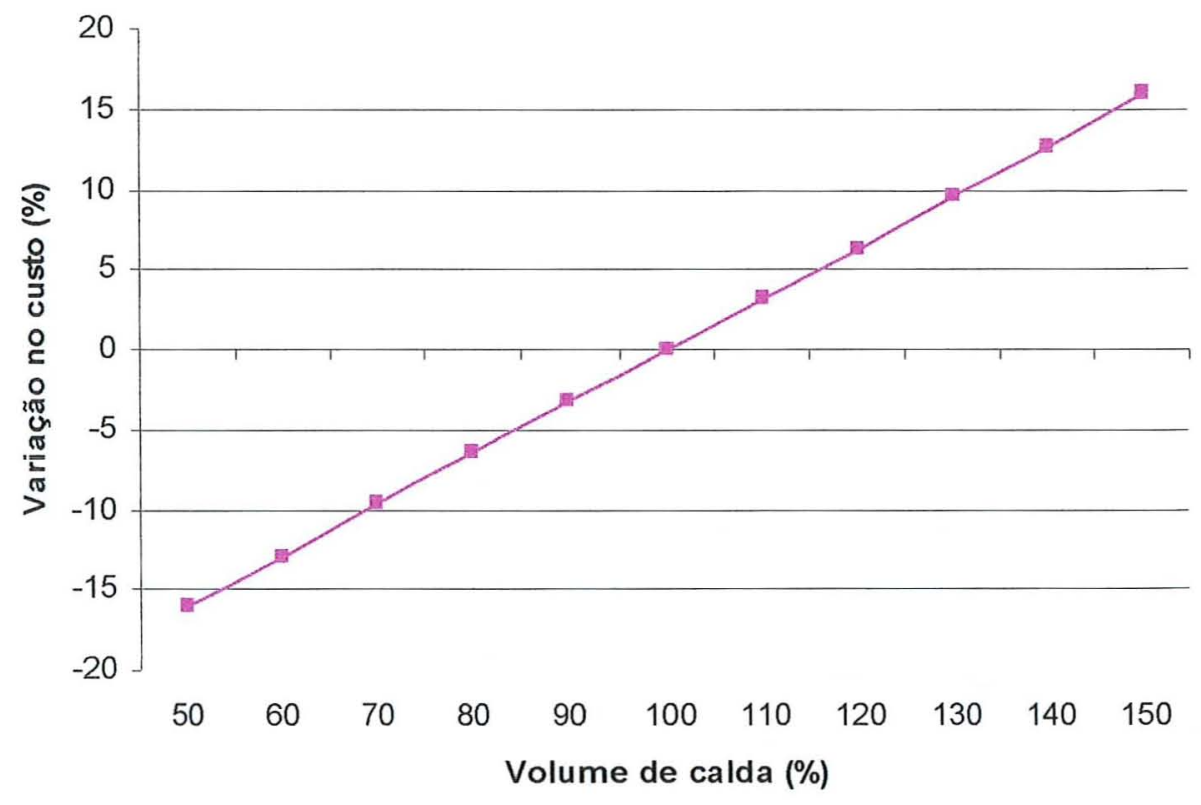

Figura 16 - Variação no custo (\%) em função do volume de calda (\%), considerando $100 \%$ como 22 L.planta $^{-1}$.

Pode-se notar na Figura 16 que os efeitos nos custos causados pela variação no volume de calda são lineares e podem reduzir o custo em aproximadamente 
$16 \%$ quando utilizado um volume de calda 50\% menor; ou um acréscimo de $16 \%$ para um volume $50 \%$ maior. Portanto, a variação no custo total com máquinas pode ser de US\$ 10.604,70 em uma única aplicação. Deve-se lembrar que não foram levados em conta o custo com produtos fitossanitários.

\subsection{Cenários}

Neste capítulo, foram desenvolvidos diversos cenários associados com estratégias de gerenciamento, técnicas de aplicação de defensivos, modelos e acessórios de equipamentos. Uma propriedade e suas metodologias de trabalho foram consideradas como padrão e os cenários foram desenvolvidos em sua função.

A propriedade padrão é a apresentada na seção 3.5 , denominada como situação A e as características detalhadas podem ser visualizadas no anexo 5.

Neste estudo apenas os custos diretos da situação serão analisados, portanto, não foram incluídos os investimentos necessários para realização de cada situação.

4.4.1 Necessidade de sistemas mecanizados (NSM) x fatores climáticos

Esta análise visa quantificar a variação na necessidade de sistemas mecanizados em função do tempo disponível para a realização do trabalho, que é influenciada por fatores climáticos.

A Figura 17 apresenta a variação mensal da NSM durante um ano em função dos fatores climáticos. Pode-se observar que nos meses de janeiro, fevereiro e dezembro utiliza-se aproximadamente o dobro de sistemas mecanizados do que no período de junho a agosto, para realizar a mesma operação em 30 dias. Neste estudo foram avaliados os 3 modelos de conjuntos mecanizados que foram apresentados na seção 3.3 e como pode ser notado, o conjunto 2 foi o que precisou de um maior número 
de conjuntos, seguido pelo 1 e em terceiro o 3 . O conjunto 1 utiliza cerca de $10 \%$ de conjuntos a mais que o 2 e $30 \%$ a mais que o 3 .

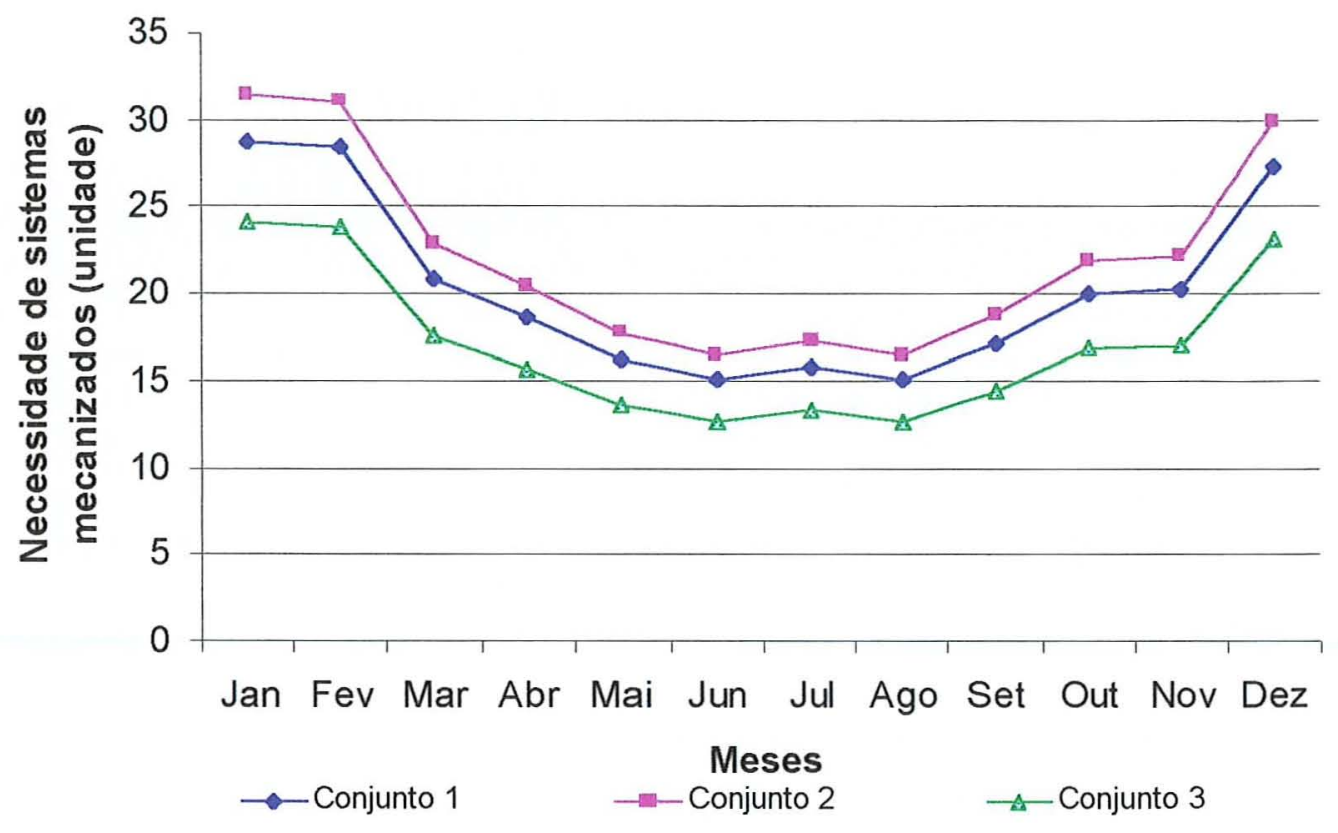

Figura 17 - Variação mensal da necessidade de sistemas mecanizados em função dos fatores climáticos da propriedade. Para 3 modelos de pulverizadores realizando a mesma operação (sistema A).

4.4.2 Necessidade de sistemas mecanizados (NSM) x jornada de trabalho

As empresas podem adotar diferentes períodos de jornada de trabalho diário. Na situação atual as jornadas de trabalho são de 8,8 h e trabalha-se 2 turnos por dia.

Esta análise tem por objetivo avaliar a NSM em função da variação da jornada de trabalho diária. Três modelos de pulverizadores foram estudados e os resultados podem ser visualizados na Figura 18.

Nota-se que trabalhando 16 horas por dia utiliza-se cerca de $50 \%$ a menos de conjuntos mecanizados quando comparado à jornada de $8 \mathrm{~h}$. Para qualquer que seja a 
duração da jornada, utiliza-se em maior número o conjunto 2 , seguido pelo 1 e por fim o 3.

Observa-se ainda, uma redução de aproximadamente $21 \%$ da necessidade de sistemas mecanizados quando a jornada passa de $8 \mathrm{~h}$ para $10 \mathrm{~h}$ por dia, para qualquer modelo de pulverizador.

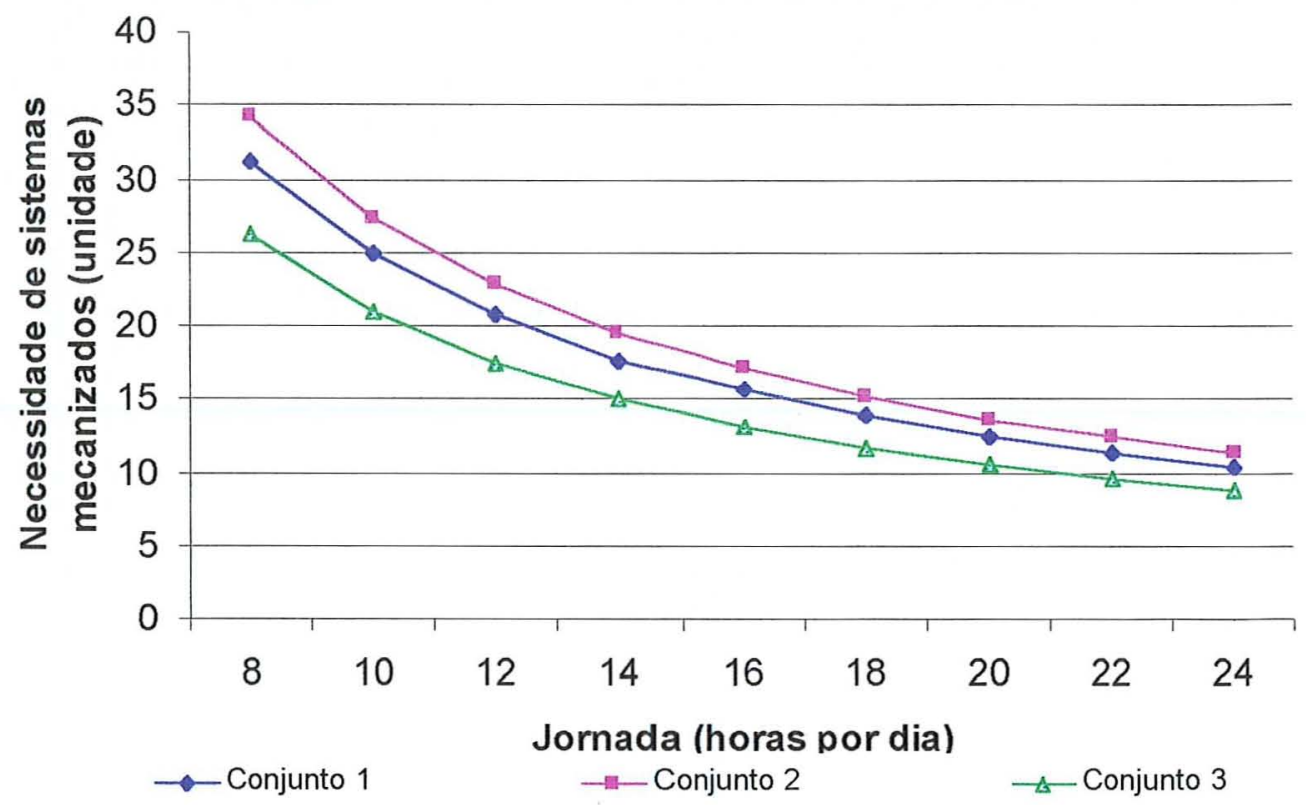

Figura 18 - Variação da necessidade de sistemas mecanizados em função da jornada de trabalho da propriedade. Para 3 modelos de pulverizadores realizando a mesma operação (sistema A).

4.4.3 Acréscimo do custo com máquinas $\mathrm{x}$ distância do ponto de abastecimento

Observa-se na Figura 19 a variação no custo com máquinas, para os conjuntos 1 e 2, ocasionada pelo aumento da distância do ponto de abastecimento.

Nota-se que o custo do conjunto 1 é mais susceptível a distância do ponto de abastecimento do que o do 2. Para uma distância de 2.000 m, o conjunto 1 sofre um 
acréscimo no custo de aproximadamente $95 \%$, enquanto que para o conjunto 2 esta não passa de 30\%. Logo o acréscimo sofrido pelo conjunto 1 é 3 vezes maior que no conjunto 2. A explicação é pelo fato de que o conjunto 1 utiliza um volume de calda maior que o 2 , conseqüentemente precisa deslocar-se mais vezes até o ponto de abastecimento.

Portanto, para o conjunto 1 , que possui um custo com máquinas de US\$ 66 mil para realizar uma aplicação em área total no sistema A, passaria para US\$165,5 mil caso a distância do ponto de abastecimento fosse de $3.000 \mathrm{~m}$, uma diferença de US\$ 99,5 mil por aplicação.

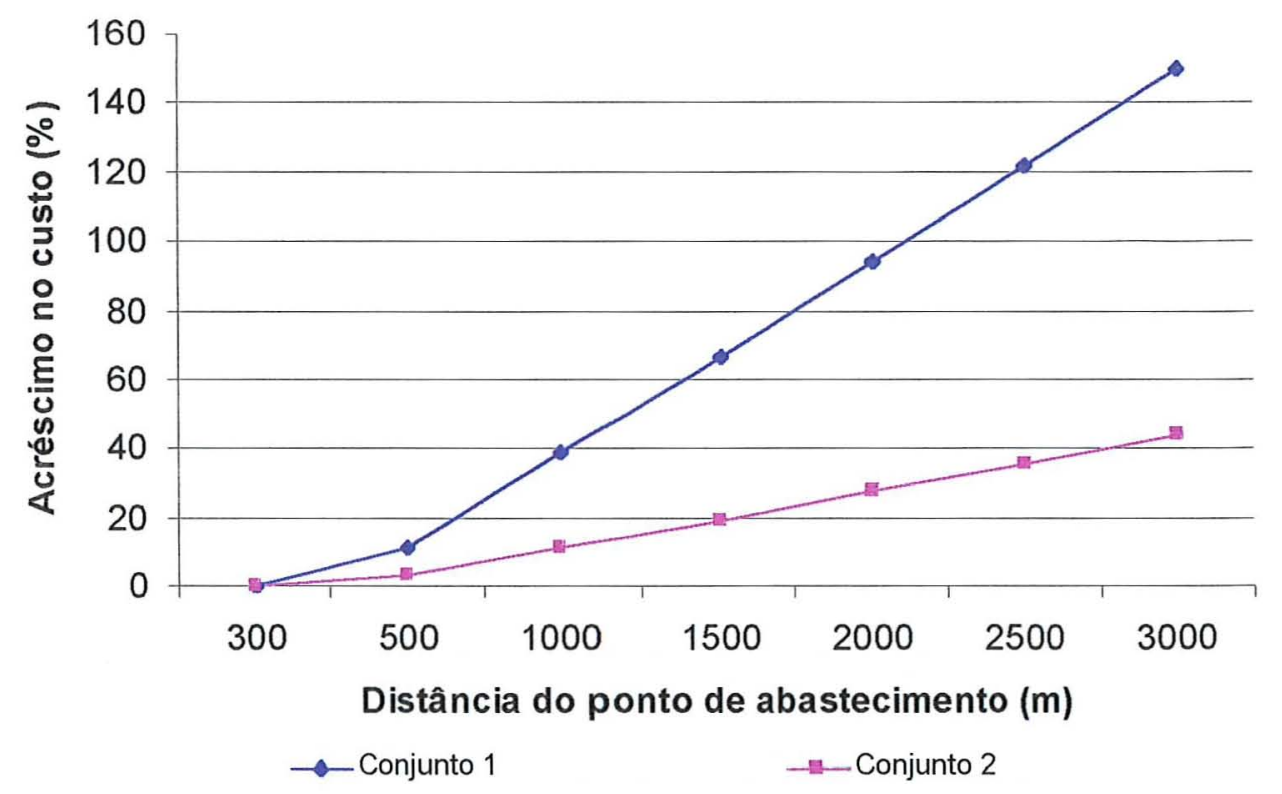

Figura 19 - Variação no custo com máquinas, em porcentagem, em função da distância do ponto de abastecimento (m). 
4.4.4 Acréscimo do custo com máquinas $\mathrm{x}$ formato dos talhões

Na Figura 20 observa-se a variação do custo com máquinas para os conjuntos 1 e 2 , ocasionada pela variação no formato dos talhões.

Pode-se notar que os custos de ambos os conjuntos são sensíveis ao formato do talhão, podendo chegar a um acréscimo de aproximadamente $15 \%$ no custo total com máquinas, caso a quantidade de fileiras passe de 1,9 para 11,4 por hectare.

Embora este fator não tenha tanta importância como o ponto de abastecimento, pode-se economizar cerca de US\$10 mil por aplicação para o conjunto 1 e US\$ 18 mil para o 2, apenas com o planejamento adequado dos talhões.

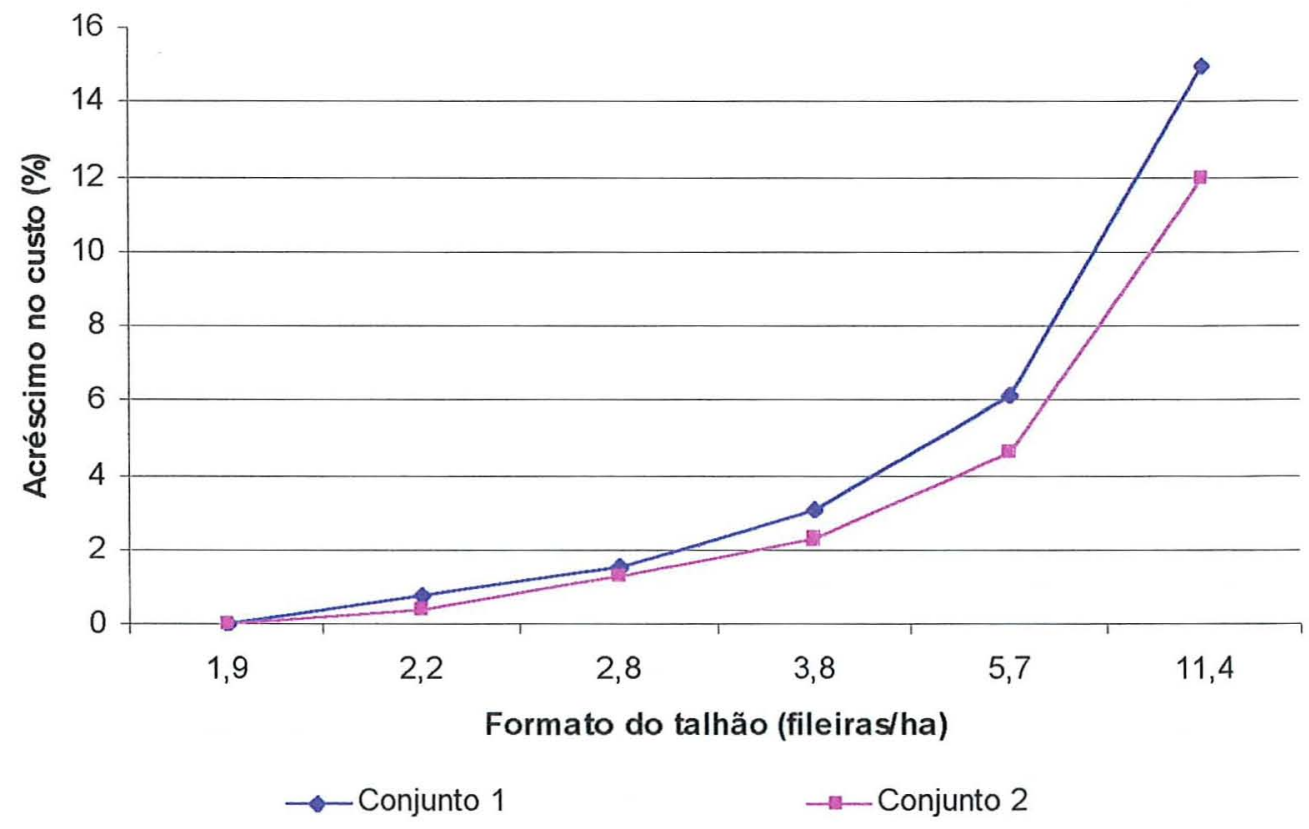

Figura 20 - Variação no custo com máquinas, em porcentagem, em função do formato dos talhões (Quantidade de fileiras.ha ${ }^{-1}$ ). 


\subsubsection{Situações propostas}

A elaboração das situações foi baseada a partir de algumas melhorias nas estratégias de gerenciamento e na tecnologia de aplicação de defensivos. Todas foram criadas visando sempre um mínimo investimento, se possivel nenhum. Foram desenvolvidas 9 situações de trabalho que podem ser visualizadas na seção 3.6.5.

\subsubsection{Necessidade de sistemas mecanizados (NSM)}

A quantidade de sistemas mecanizados é um fator muito importante para decisão de escolha dos equipamentos, pois, isto implica num investimento inicial elevado, uma vez que os conjuntos mecanizados podem custar até US\$46.500,00.

A Figura 21 apresenta a variação em porcentagem da NSM dos 3 conjuntos mecanizados em função das 9 situações elaboradas. A situação 1 é considerada padrão, portanto terá sempre o índice 0 .

Observa-se que para o conjunto 1 as situações 2 e 8 foram as que mais reduziram a NSM, com índices próximos a 12\%. A situação 6 proporcionou uma redução intermediária, cerca de 7\%, enquanto as demais reduziram a NSM em menos de $5 \%$ cada uma. No total, realizando-se todas as modificações sugeridas tem-se uma redução de aproximadamente $32 \%$ do parque de máquinas.

O conjunto 2 foi o que obteve a maior redução da NSM com as modificações sugeridas, podendo reduzir o parque de máquinas destinadas à pulverização em até $50 \%$. A situação 2 (velocidade de aplicação $=1 \mathrm{~m} . \mathrm{s}^{-1}$ ) foi responsável pela redução de $38 \%$, portanto, a velocidade de aplicação está sendo o fator limitante para viabilizar a utilização desta máquina. Em segundo lugar, está a jornada de trabalho de 10 h (situação 8) com uma redução de aproximadamente $12 \%$ e as demais situações com reduções inferiores a $10 \%$.

Para o conjunto 3 ocorrem as mesmas modificações que notadas para 0 conjunto 1. Ou seja, a situação 2 foi a que mais reduziu a NSM com indice de 
aproximadamente $14 \%$, seguida pela 8 com $12 \%$, a 6 com $7 \%$ e as demais com reduções inferiores a $5 \%$. No total, teve-se uma redução da NSM superior a $30 \%$.

Portanto, a situação 2 foi a que mais influenciou na redução da NSM dos 3 conjuntos, e o conjunto 2 foi o que mais se beneficiou com as mudanças.
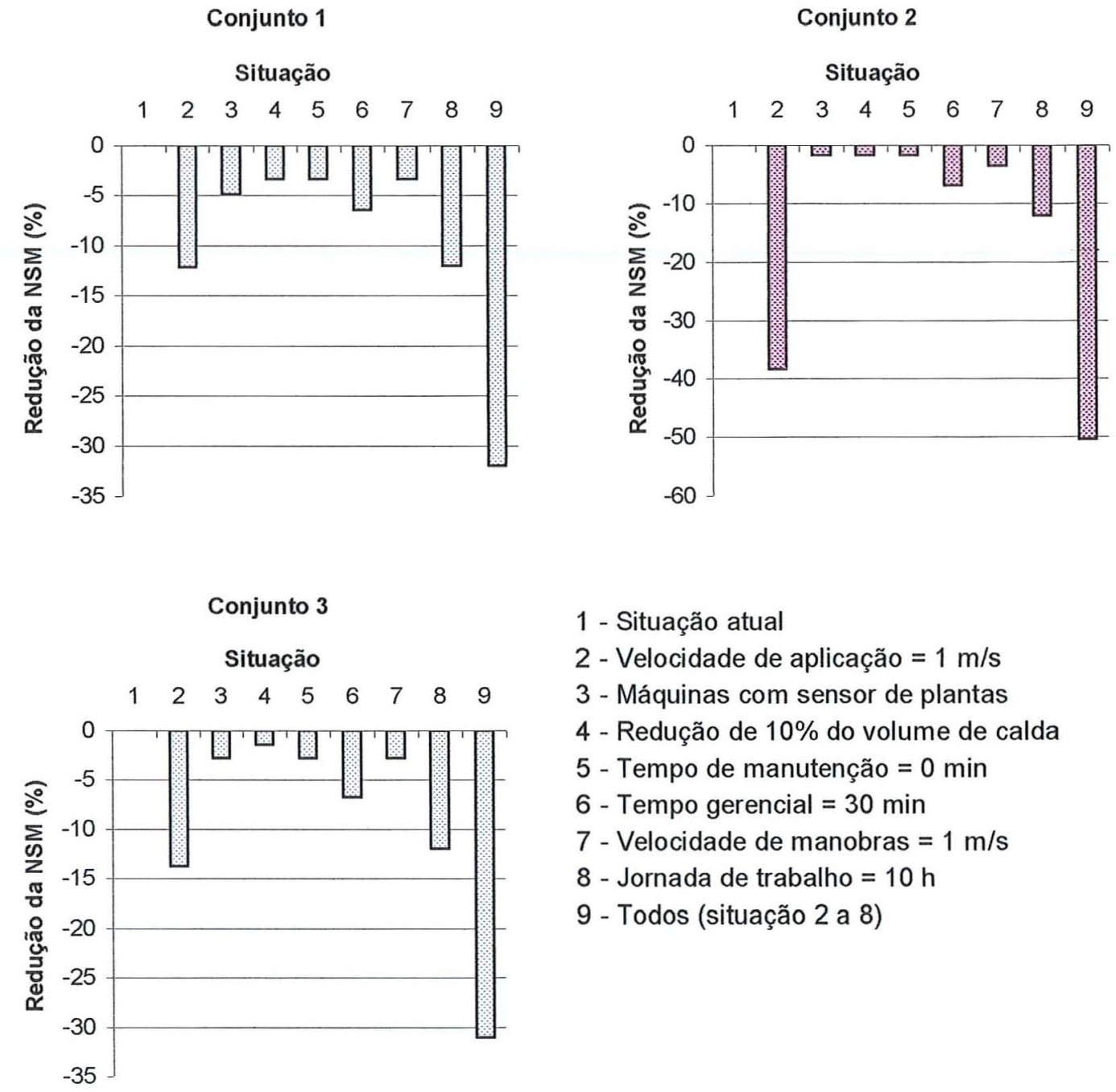

Figura 21 - Variação em porcentagem da NSM dos 3 conjuntos mecanizados em função das 9 situações elaboradas, sendo a situação 1 considerada como padrão. 
Na Figura 22 observa-se a NSM para os 3 conjuntos na situação atual e na situação 9 denominada como Final. Nota-se que todos os conjuntos reduziram a NSM, porém, deve-se ressaltar que o conjunto 2 que na situação atual é o que mais utiliza máquinas (aproximadamente 16), precisa de apenas 8 conjuntos na situação Final, sendo a menor NSM dos 3 modelos de máquinas.

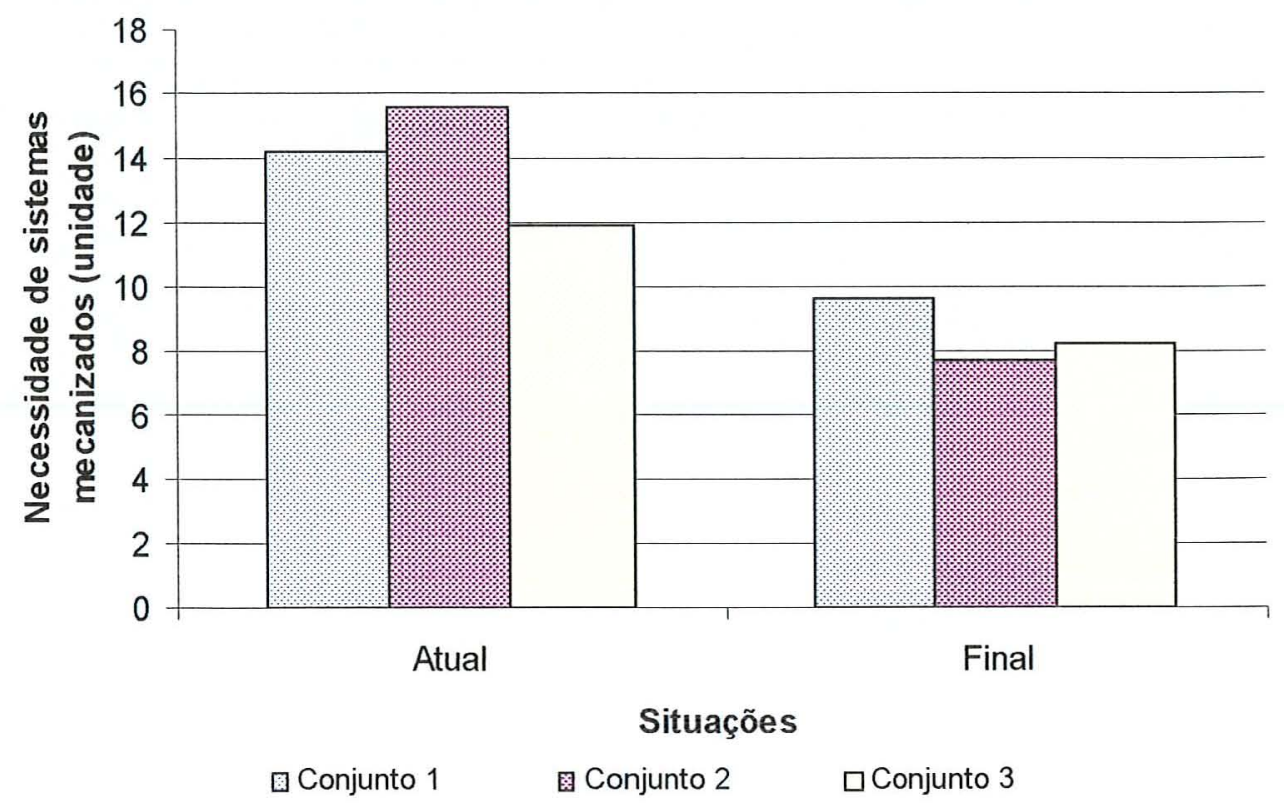

Figura 22 - Necessidade de sistemas mecanizados para os 3 conjuntos na situação atual e na situação 9 denominada como Final.

\subsubsection{Capacidade de campo operacional $(\mathrm{CcO})$}

A capacidade de campo operacional é um índice de produtividade que indica quanto uma máquina é capaz de produzir por hora. Para esse caso é indicada como ha. $h^{-1}$. A Figura 23 apresenta a variação da capacidade de campo operacional em porcentagem para os 3 modelos de conjuntos mecanizados, influenciada pelas 9 situações de trabalho, sendo a situação 1 considerada como padrão. 
Nota-se que a situação 2 foi a que mais influenciou a $\mathrm{CcO}$ dos 3 modelos de conjuntos, o 2 teve sua $\mathrm{CcO}$ aumentada em mais de $60 \%$, seguido pelo 3 com acréscimo de $16 \%$ e em terceiro lugar o 1 com aproximadamente $14 \%$.

Conjunto 1

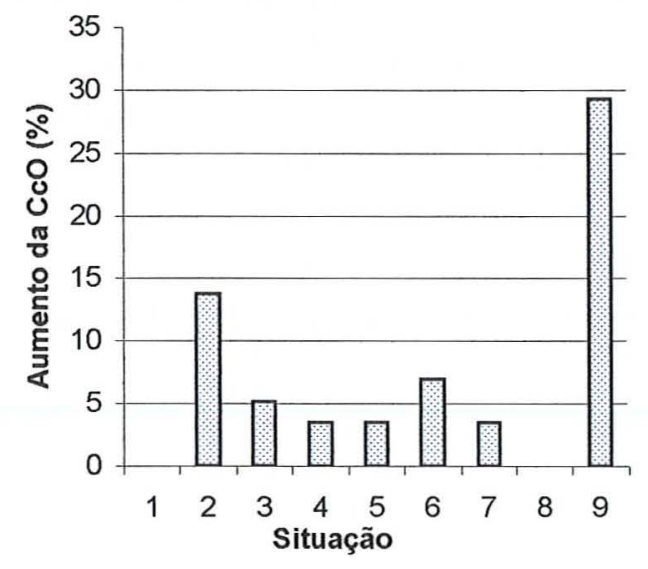

Conjunto 3

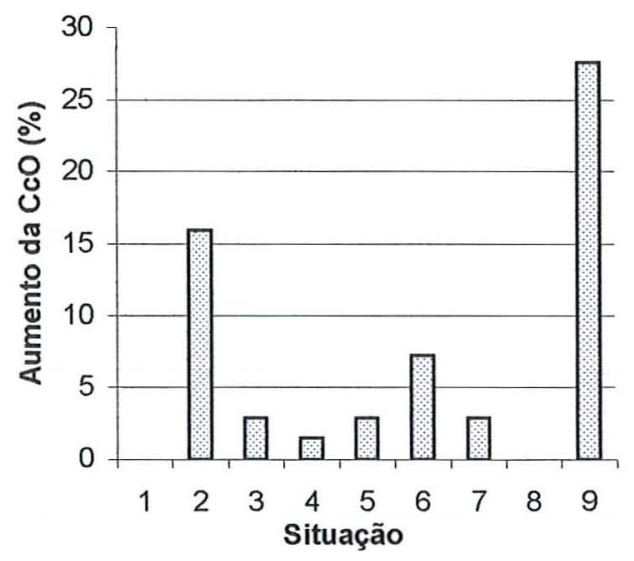

Conjunto 2

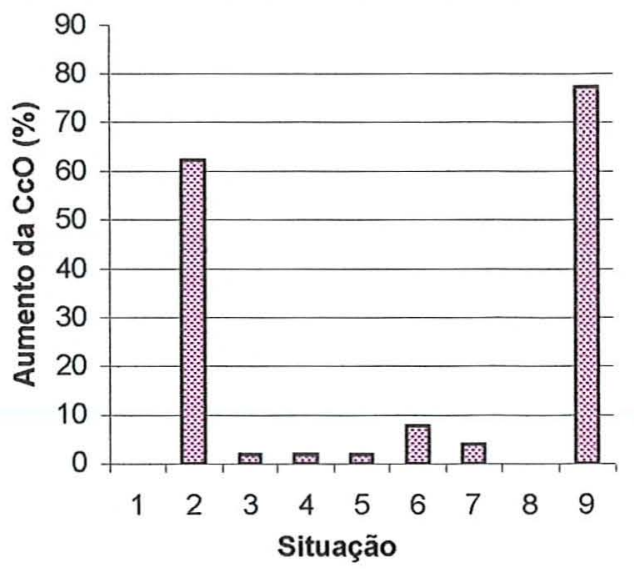

1 - Situação atual

2 - Velocidade de aplicação $=1 \mathrm{~m} / \mathrm{s}$

3 - Máquinas com sensor de plantas

4 - Redução de $10 \%$ do volume de calda

5 - Tempo de manutenção $=0 \mathrm{~min}$

6 - Tempo gerencial $=30 \mathrm{~min}$

7 - Velocidade de manobras $=1 \mathrm{~m} / \mathrm{s}$

8 - Jornada de trabalho $=10 \mathrm{~h}$

9 - Todos (situação 2 a 8)

Figura 23 - Variação da capacidade de campo operacional em porcentagem para os 3 modelos de conjuntos mecanizados, influenciada pelas 9 situações de trabalho, sendo a situação 1 considerada como padrão. 
A segunda situação foi a 6 , que aumentou a $\mathrm{CcO}$ dos 3 conjuntos em níveis de $6 \%$ a 7\%. As demais situações causaram um acréscimo de no máximo 5\%.

Deve-se lembrar, que a situação 8 não alterou em nada a capacidade de campo operacional pois a jornada de trabalho não tem relação alguma com este parâmetro.

Na Figura 24 observa-se a capacidade de campo operacional para a situação atual e final (com todas as modificações). Pode-se notar que todos os conjuntos obtiveram um acréscimo na $\mathrm{CcO}$, porém o conjunto 2 que tinha a menor $\mathrm{CcO}$, cerca de 0,5 ha. $\mathrm{h}^{-1}$, passa a ter a maior dos 3 conjuntos, com mais de 0,9 ha. $\mathrm{h}^{-1}$. Portanto, esse modelo obteve um acréscimo na $\mathrm{CcO}$ de aproximadamente $80 \%$, seguido por $29 \%$ do conjunto 1 e $27 \%$ do 3 .

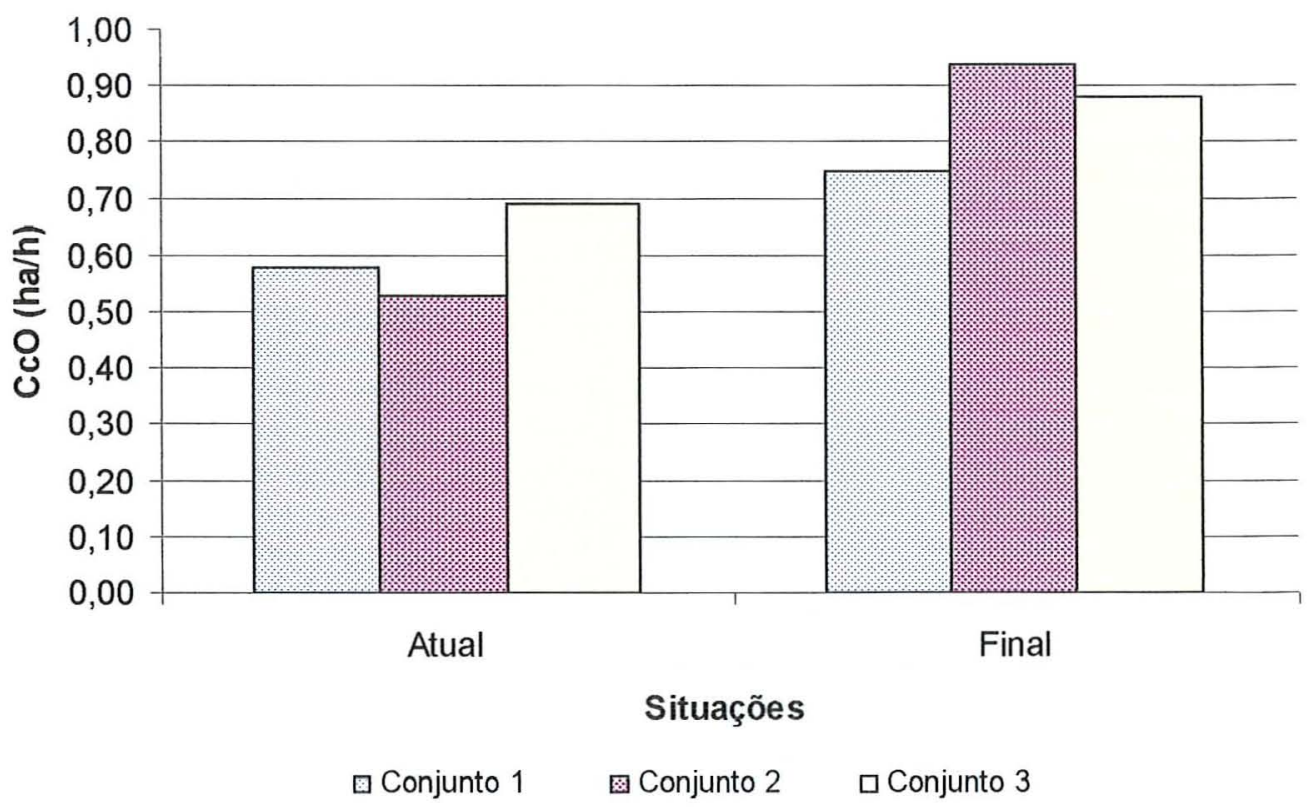

Figura 24 - Capacidade de campo operacional para a situação atual e final (com todas as modificações). Para os 3 modelos de conjuntos. 


\subsubsection{Eficiência operacional}

A eficiência operacional tem três classificações: Eficiência produtiva (Epro) que representa o tempo em que a máquina está efetivamente operando; Eficiência auxiliar (Eaux) indica a porcentagem do tempo em que a máquina está realizando serviços indispensáveis para a realização da operação; Eficiência perdida (Eper) representa os tempos perdidos.

A Figura 25 apresenta a variação da eficiência operacional para os três modelos de conjuntos nas situações de 1 a 9 , sendo a situação 1 adotada como padrão.

Observa-se que, para o conjunto 1 a eficiência produtiva é de aproximadamente $52 \%$ na situação 1 e que na situação 9 é de $60 \%$, logo todas as modificações sugeridas aumentaram em 8 pontos percentuais a Epro, e a Eper que era de $15 \%$ cai para cerca de $5 \%$.

Para o conjunto 2 a Epro na situação 1 é de $71 \%$ passa para $76 \%$ na situação 9 , neste caso o aumento é de apenas 5 pontos percentuais, porém, este indice mostra que de cada $10 \mathrm{~h}$ disponíveis a máquina está efetivamente trabalhando em $7,6 \mathrm{~h}$, esta eficiência é considerada muito boa para esta operação

O modelo 3 apresentou uma eficiência intermediária aos outros dois, tendo uma Epro de $62 \%$ na situação 1 e de $71 \%$ na situação 9 . Porém foi a que mais aumentou a Epro, com 9 pontos percentuais.

Uma característica interessante notada nos três modelos de conjuntos foi que a situação 2 diminuiu ao invés de aumentar a Epro. Isto pode ser explicado pelo fato do aumento da velocidade de aplicação diminuir o tempo gasto efetivamente na pulverização.

Todas as eficiências produtivas deste trabalho são consideradas elevadas pelo fato de terem caminhões pipas auxiliando no transporte de água, desta forma, os pulverizadores perdem menos tempo com deslocamento para o abastecimento. Segundo Tachibana et al.(1999), numa propriedade onde os pulverizadores se deslocam até o ponto de abastecimento este índice pode ser de $40 \%$ ou menos, dependendo da distância. 
Conjunto 1

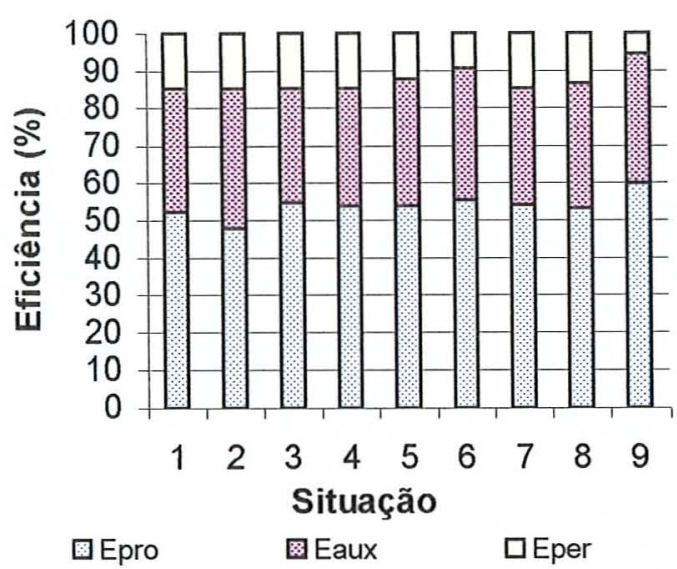

Conjunto 3

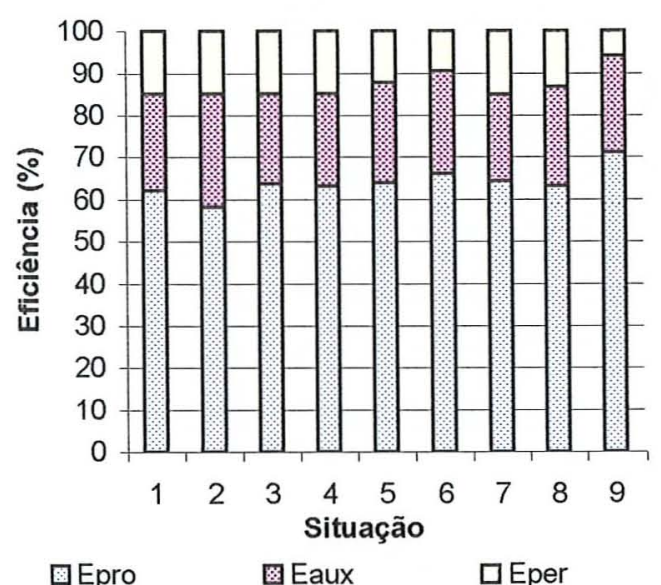

Conjunto 2

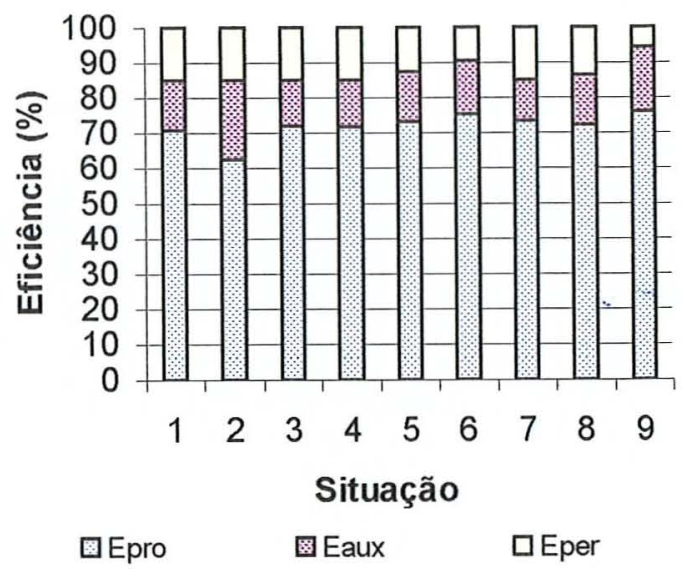

1 - Situação atual

2 - Velocidade de aplicação $=1 \mathrm{~m} / \mathrm{s}$

3 - Máquinas com sensor de plantas

4 - Redução de $10 \%$ do volume de calda

5 - Tempo de manutenção $=0 \mathrm{~min}$

6 - Tempo gerencial $=30 \mathrm{~min}$

7 - Velocidade de manobras $=1 \mathrm{~m} / \mathrm{s}$

8 - Jornada de trabalho $=10 \mathrm{~h}$

9 - Todos (situação 2 a 8)

Figura 25 - Variação da eficiência operacional para os três modelos de conjuntos nas situações de 1 a 9, sendo a situação 1 adotada como padrão.

Na Figura 26 observa-se a eficiência operacional para os três modelos de pulverizadores na situação atual e na final. Nota-se que, o conjunto 2 é o modelo que tem a maior Epro nas duas situações, seguido pelo modelo 3 e em terceiro o 1. 


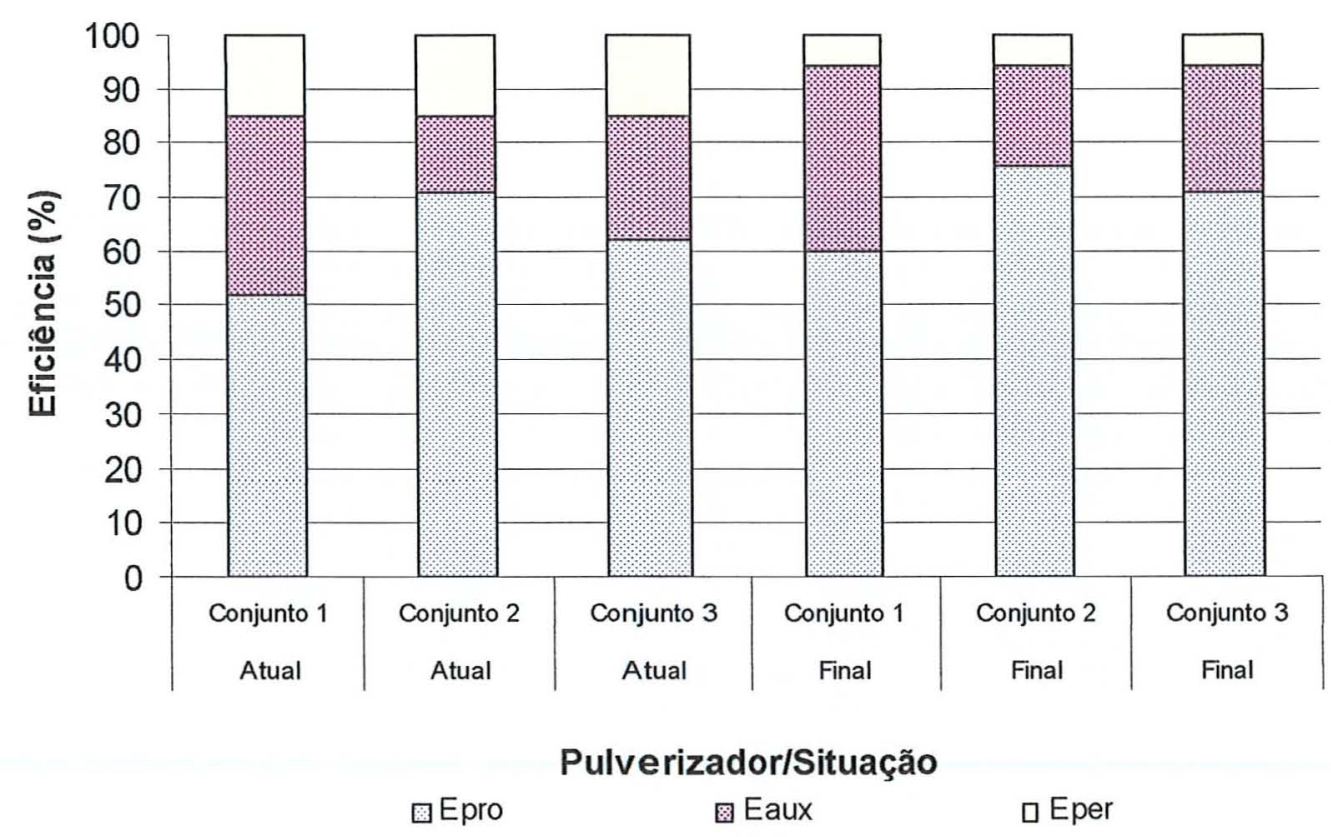

Figura 26 - Eficiência operacional para os três modelos de pulverizadores na situação atual e na final.

\subsubsection{Custo com máquinas}

O custo com máquinas é um dos fatores mais importantes na seleção de uma maquinaria, desde que elas realizem o serviço com a mesma qualidade.

Na Figura 27 observa-se a variação do custo com máquinas dos 3 modelos de conjuntos mecanizados para as 9 situações. Pode-se notar que para o conjunto 1 a situação 2 foi a que mais reduziu o custo (cerca de 12\%), seguida pela situação $6(6 \%)$ e as demais reduziram o custo em menos de $5 \%$. No total, com todas as modificações sugeridas, o custo foi reduzido em aproximadamente $32 \%$.

Analisando o conjunto 2, a mesma tendência pode ser notada, porém, com a diferença que a situação 2 reduziu cerca de $38 \%$ do custo, enquanto o conjunto 1 sofreu uma redução de apenas $12 \%$, isto significa que a redução foi superior a 3 vezes para este conjunto. No final, a redução do custo máquina ficou na faixa de $50 \%$. 
Com o conjunto 3 praticamente ocorreram as mesmas reduções obtidas com o 1. A situação 2 reduziu o custo em aproximadamente $14 \%$, obtendo uma redução total de $31 \%$.
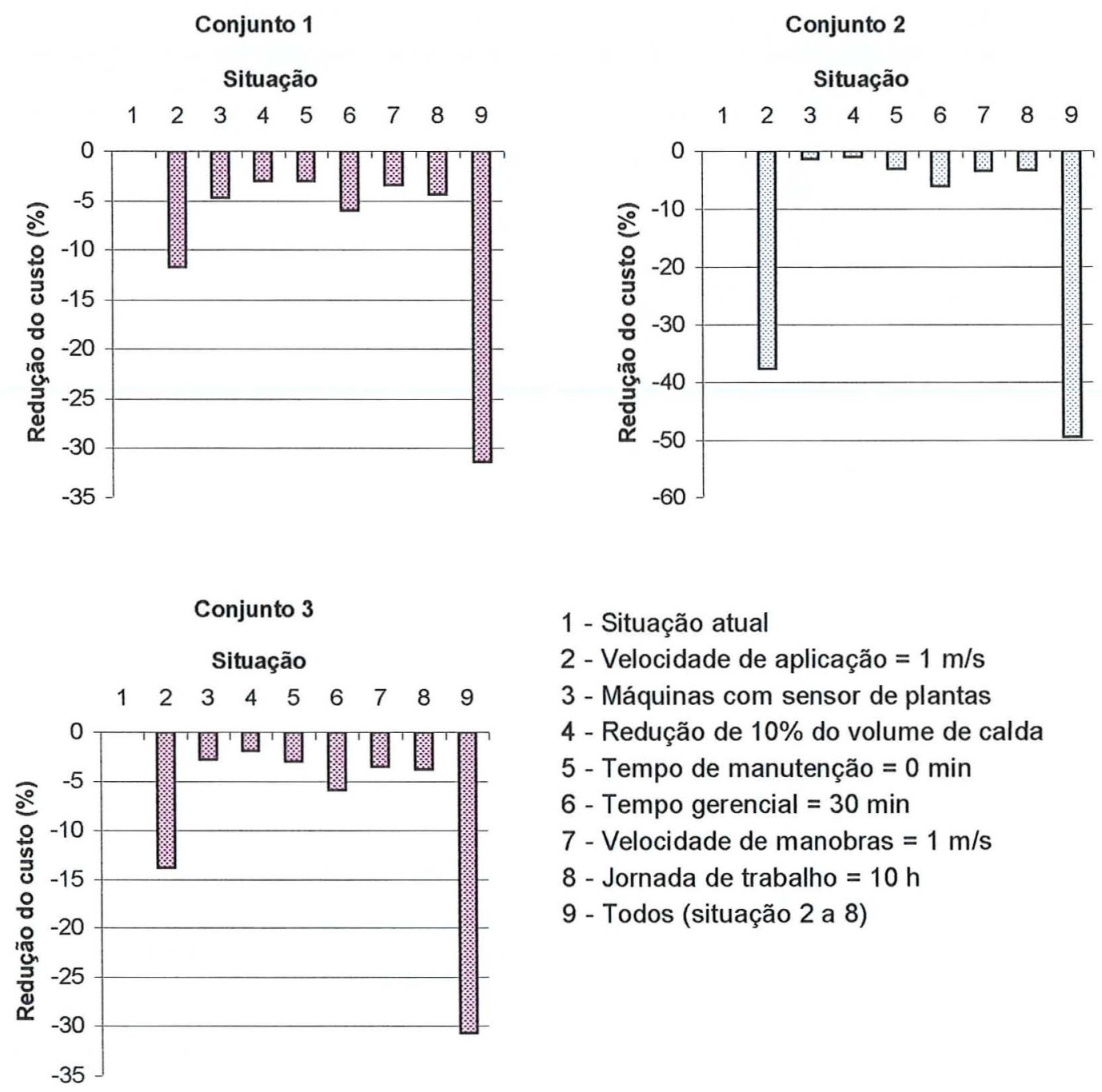

Figura 27 - Variação do custo com máquinas, em porcentagem, dos 3 modelos de conjuntos mecanizados para as 9 situações, sendo a situação 1 considerada como padrão.

Com relação à Figura 27, pode-se afirmar que a situação 2 foi a mais importante para a redução do custo com máquinas. 
A Figura 28 apresenta o custo com máquinas para os 3 conjuntos mecanizados na situação atual e final. Na situação atual, nota-se que o conjunto 2 tem um custo de aproximadamente US\$ $120.000,00$ o que seria quase duas vezes mais que os outros 2 conjuntos que estão com o custo entre US\$ 65.000,00 e US\$70.000,00.

Na situação final o custo do conjunto 2 é reduzido para US $\$ 60.000,00$ (uma redução de 50\%), enquanto os outros dois tem o custo entre US\$ 45.000,00 e US\$ $48.000,00$, portanto, a diferença que era de aproximadamente $80 \%$, cai para cerca de $35 \%$.

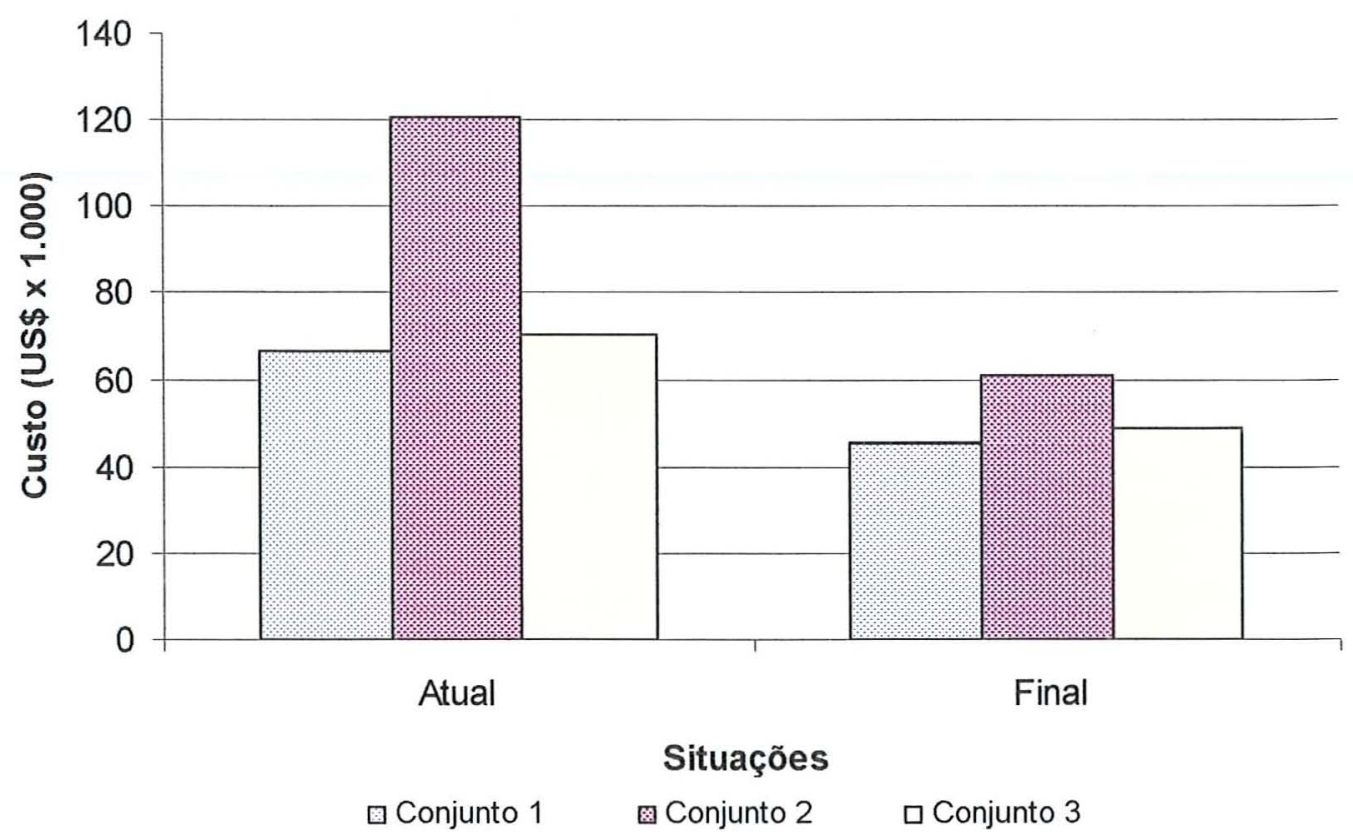

Figura 28 - Custo com máquinas para os 3 conjuntos mecanizados na situação atual e final.

A área total para ser pulverizada é de 3.065 ha, portanto, um outro índice de produtividade que pode ser calculado é o custo operacional (US $\$ . h a^{-1}$ ), A Tabela 4 apresenta o custo operacional dos 3 modelos de conjuntos na situação atual e final. 
Tabela 4 - Custo operacional (US $\$$ ha $^{-1}$ ) dos 3 modelos de conjuntos na situação atual e final.

\begin{tabular}{lcc}
\hline \multicolumn{3}{c}{ Custo operacional } \\
\hline Modelo de conjuntos & Atual & Final \\
\cline { 2 - 3 } & US\$/ha & US\$/ha \\
\hline Conjunto 1 & 21,60 & 14,83 \\
Conjunto 2 & 39,28 & 19,86 \\
Conjunto 3 & 23,02 & 15,94 \\
\hline
\end{tabular}

As reduções de custo obtidas neste índice são as mesmas citadas para o custo com máquinas, a diferença é que pode-se visualizar o custo com máquinas para pulverizar apenas 1 ha.

\subsubsection{Custo com produtos fitossanitários}

O custo envolvido com produtos fitossanitários é responsável pela maior parte dos custos totais de uma pulverização, representando de $67 \%$ a $82 \%$ do custo de uma aplicação, dependendo da maquinaria utilizada e da praga que está se controlando. Isto pode ser observado na Tabela 5, que apresenta a planilha de custo de uma pulverização, dividida em custo com máquinas e com produtos.

Tabela 5 - Custo de uma pulverização para a situação 1, dividida em custo com máquinas e com produtos.

\begin{tabular}{|c|c|c|c|c|c|c|}
\hline \multicolumn{7}{|c|}{ Custo Total da Operação de pulverização } \\
\hline \multirow[t]{2}{*}{ Sistema Mecanizado } & \multicolumn{2}{|c|}{ Custo com máquinas } & \multicolumn{2}{|c|}{ Custo com produtos } & \multicolumn{2}{|c|}{ Custo total } \\
\hline & US\$ & $\%$ & US\$ & $\%$ & US\$ & $\%$ \\
\hline Conjunto 1 & $66.199,01$ & 17,42 & $313.785,41$ & 82,58 & $379.984,42$ & 100,00 \\
\hline Conjunto 2 & $120.398,16$ & 32,43 & $250.914,36$ & 67,57 & $371.312,52$ & 100,00 \\
\hline Conjunto 3 & $70.542,94$ & 21,94 & $251.026,98$ & 78,06 & $321.569,92$ & 100,00 \\
\hline
\end{tabular}

Na Figura 29 pode-se observar a variação do custo com defensivos para os 3 tipos de pulverizadores nas situações de 1 a 9 . 
Nota-se que somente as situações 3 e 4 reduziram o custo com produtos, pois são as modificações ligadas diretamente à tecnologia de aplicação de defensivos. As situações 2 e de 5 a 8 não influenciam o custo com defensivos por estarem vinculadas somente a estratégia de gerenciamento, alterando somente o custo com a maquinaria.
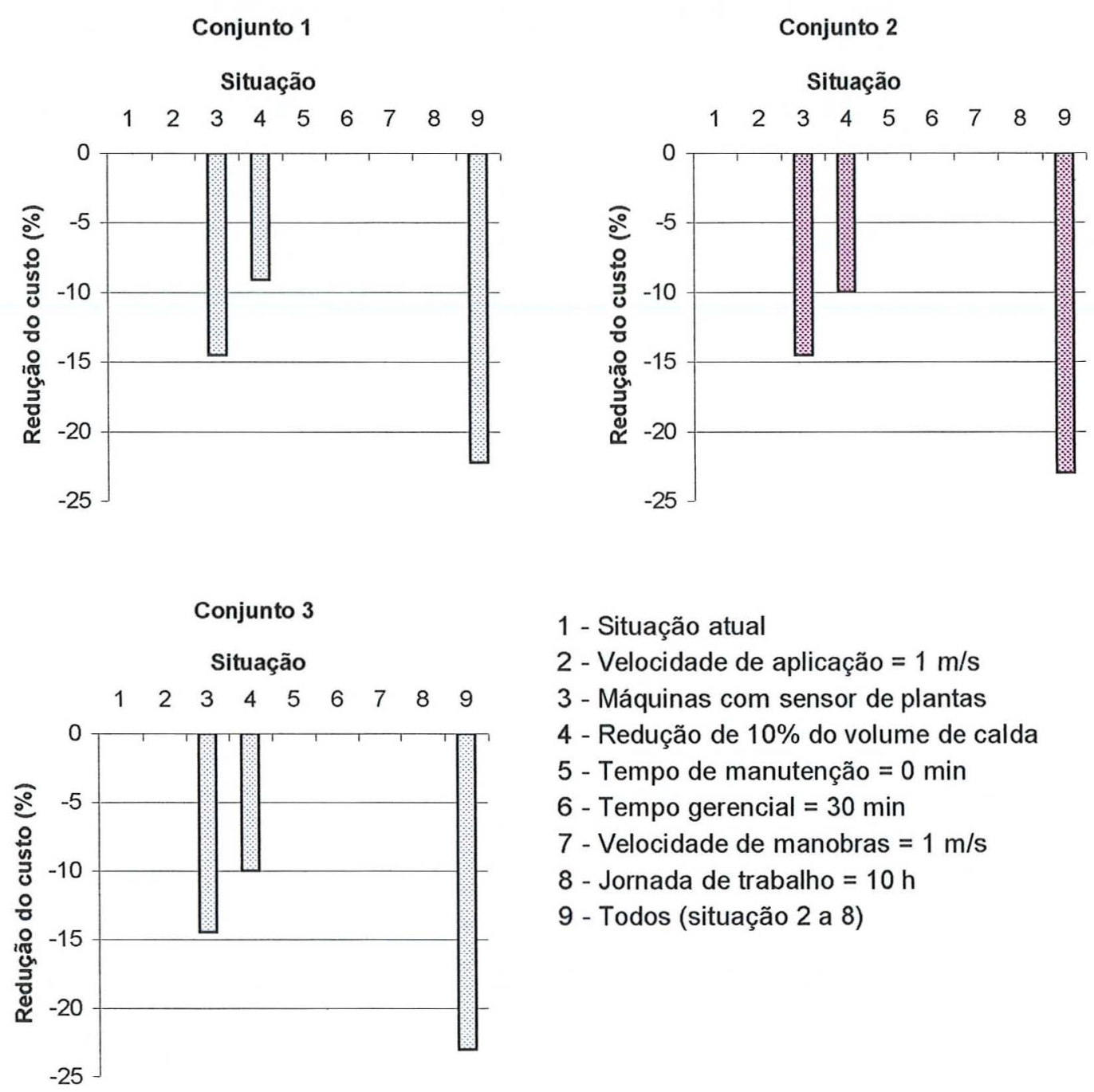

Figura 29 - Variação do custo com defensivos para os 3 tipos de pulverizadores nas situações de 1 a 9 . 
Ainda na Figura 29, pode-se notar que a situação 3 reduziu o custo com produtos em aproximadamente $14 \%$, porém, deve-se lembrar que esta redução está vinculada ao número de plantas mortas existentes no pomar, ou seja, isto vai variar de acordo com o estado de cada pomar.

A situação 4 reduziu de $8 \%$ a $10 \%$ o custo com produtos fitossanitários. No total, para o sistema A pode-se conseguir uma redução de $20 \%$ a $25 \%$ nos gastos.

A Figura 30 apresenta o custo com defensivos para os 3 modelos de conjuntos na situação atual e final. Nota-se que, o conjunto 1 gasta atualmente cerca de US\$ 315 mil para realizar uma pulverização contra o ácaro da leprose, enquanto os demais cerca de US\$250 mil, o que representa uma economia ao redor de $20 \%$.

Realizando somente as situações 3 e 4 pode-se reduzir o custo com produtos fitossanitários em US\$ 70 mil para o 1 e em US\$ 57 mil para os outros dois conjuntos.

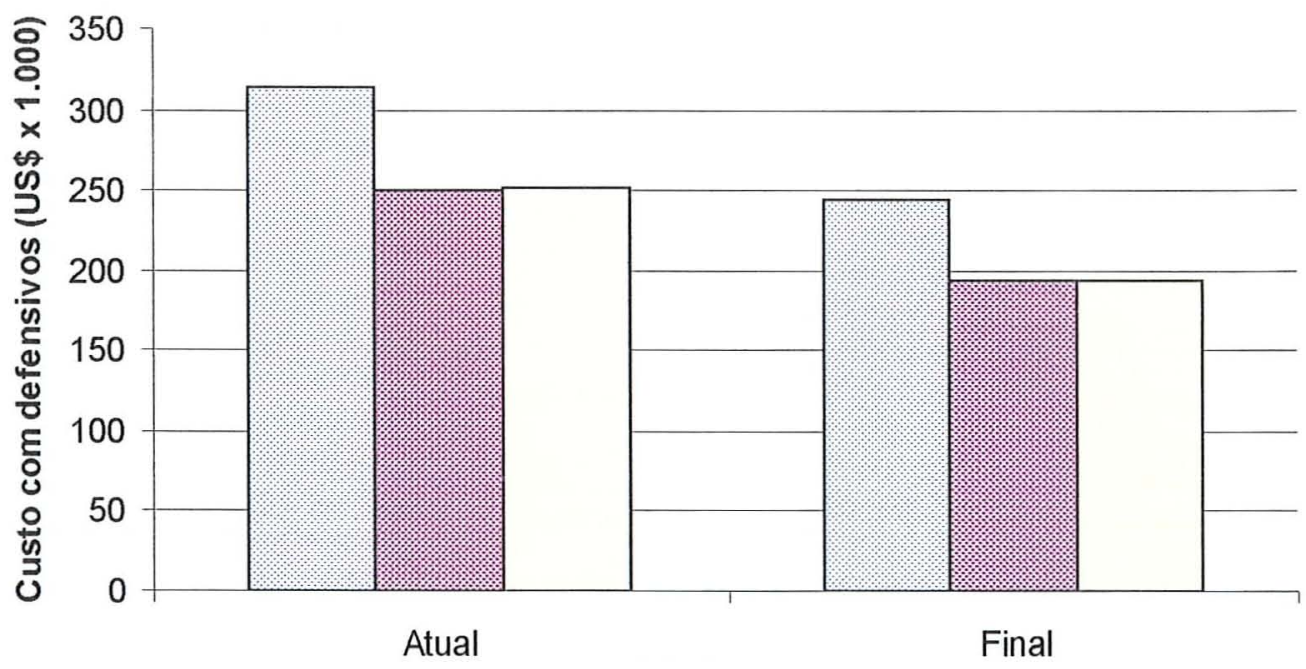

Situações

ㅁonjunto $1 \quad$ 응 Conjunto $2 \quad \square$ Conjunto 3

Figura 30 - Custo com defensivos (US\$ x 1.000,00) para os 3 modelos de conjuntos na situação atual e final. 


\subsubsection{Custo total da pulverização}

Para uma seleção correta de equipamentos deve-se analisar o custo total da pulverização, considerando que todas tenham a mesma qualidade de operação.

A Figura 31 demonstra a variação do custo total da pulverização dos 3 conjuntos na situação atual e final. Nota-se que para a situação atual os modelos 1 e 2 operam com um custo praticamente iguais (acima de US\$ 370 mil), a diferença entre eles é cerca de $2 \%$. Já o 3 consegue uma redução de $16 \%$ e 14\%, quando comparados aos outros dois modelos, respectivamente.

Na situação final observa-se que o "ranking" continua o mesmo, porém, com uma redução de $25 \%$ a $30 \%$ nos custos totais, portanto, tem-se uma economia de aproximadamente US\$ 90 mil para o 1 , US\$ 117 mil para o 2 e US\$ 79 mil para o 3 . Deve-se lembrar que nessas reduções não foram incluídos os investimentos necessários para a realização das mudanças sugeridas.

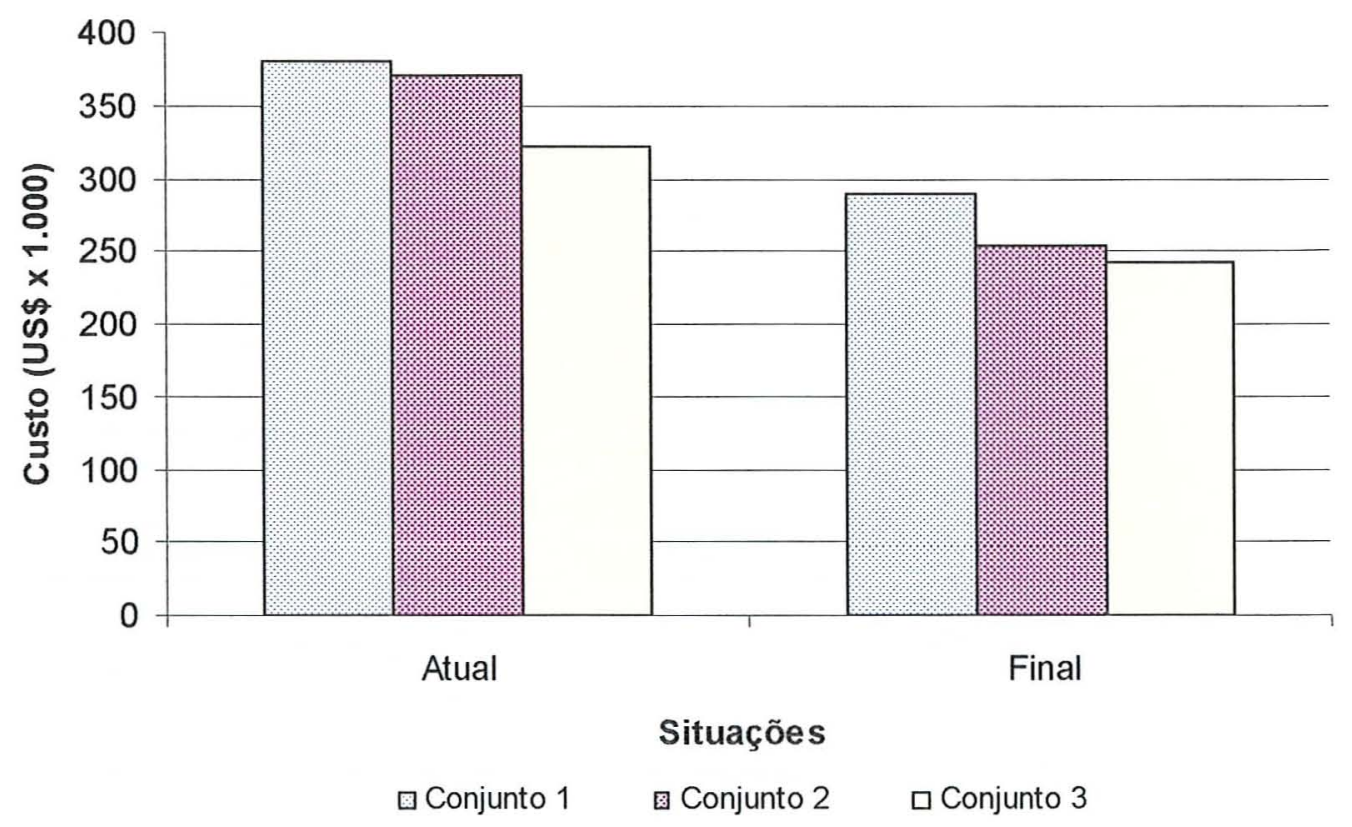

Figura 31 - Variação do custo total da pulverização (US\$ x 1.000) dos 3 conjuntos na situação atual e final. 


\section{CONCLUSÕES}

O modelo computacional desenvolvido neste trabalho mostrou-se adequado para auxiliar os produtores na tomada de decisão quando se trata da operação de pulverização, pois, conseguiu predizer os tempos operacionais com diferenças de no máximo $30 \%$.

Para o sistema $\mathrm{A}$, os fatores externos que mais influenciaram o custo foram o preço de aquisição do pulverizador, do trator e do combustivel, todos aumentaram em mais de $2,5 \%$ o custo da operação. No sistema $\mathrm{B}$, o fator mais importante foi o preço do combustível que aumentou o custo em aproximadamente $3,2 \%$, seguido pelos preços de aquisições do trator $(2,6 \%)$ e do pulverizador $(2,3 \%)$.

Analisando os fatores externos, os parâmetros que mais influenciaram no custo do sistema A foram: o volume de calda que ocasionou um aumento de aproximadamente $3,25 \%$; e a velocidade de aplicação que reduziu o custo em $5,7 \%$. No sistema B, o fator que mais onerou o custo foi o volume de calda, ocasionando um aumento de $5,37 \%$, enquanto as velocidades de aplicação e de deslocamento reduziram o custo em $3,67 \%$ e $3,64 \%$, respectivamente.

Nos meses de janeiro, fevereiro e dezembro, utiliza-se aproximadamente o dobro de sistemas mecanizados do que no período de junho a agosto para realizar uma mesma operação em 30 dias, isto deve-se ao fato dos fatores climáticos influenciarem o tempo disponivel para realização da operação.

Aumentar a jornada de trabalho de $8 \mathrm{~h}$ para $10 \mathrm{~h}$ por dia causa uma redução de aproximadamente $21 \%$ da necessidade de sistemas mecanizados, para qualquer modelo de pulverizador. 
Os conjuntos do tipo 1 são mais susceptiveis à distância do ponto de abastecimento.

A situação 2 sugere o aumento da velocidade de aplicação para $1 \mathrm{~m} \cdot \mathrm{s}^{-1}$, sendo a que mais influenciou na necessidade de sistemas mecanizados, na capacidade de campo operacional e no custo com máquinas.

Somente as situações 3 (máquinas equipadas com sensor de plantas) e 4 (redução de $10 \%$ do volume de calda) tiveram influencia no custo com produtos fitossanitários.

Realizando todas as mudanças sugeridas (situação 9), obteve-se uma redução no custo com máquinas de $32 \%$ para o conjunto $1,51 \%$ para o 2 e de $31 \%$ para o 3 .

Para o custo com produtos fitossanitários pode-se obter uma redução de $20 \%$ a $25 \%$ nos gastos quando se realiza as mudanças sugeridas pelas situações 3 (máquinas equipadas com sensor de plantas) e 4 (redução de 10\% do volume de calda), para os três modelos de equipamentos.

Pode-se obter uma redução nos custos totais na faixa de $25 \%$ a $30 \%$, obtendo uma economia de aproximadamente US\$90 mil para o conjunto 1, US\$ 117 mil para o 2 e US\$ 79 mil para o 3.

Este modelo não é capaz de calcular quantas horas o conjunto mecanizado trabalha anualmente, calcula somente o tempo necessário para a operação em questão. Também não é capaz de comparar as máquinas pela qualidade de seus serviços, somente pelos fatores operacionais e custos.

Como sugestão para um próximo trabalho pode-se comparar estes 3 modelos de equipamentos visando a qualidade da aplicação, através da utilização de técnicas de aplicação de defensivos, e se possível inserir estes dados no modelo para que este esteja apto a fazer uma avaliação completa das máquinas. 
Anexo 1 - Parte da rotina de programação do modelo.

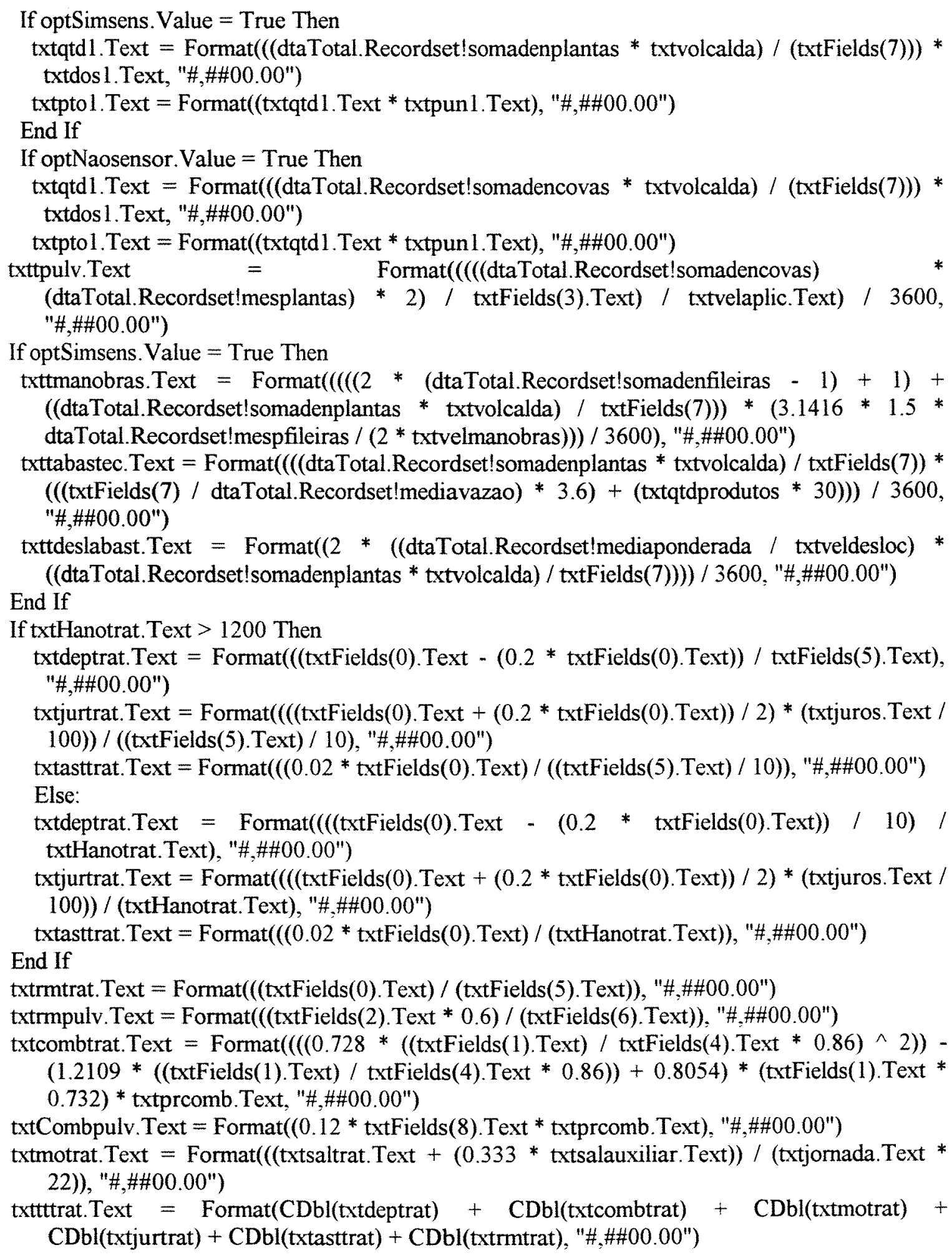


txttpulv.Text $=$ Format $(\mathrm{CDbl}($ txtdeppulv $\cdot$ Text $)+\mathrm{CDbl}($ txtjurpulv. Text $)+\mathrm{CDbl}($ txtastpulv. Text $)$ + CDbl(txtrmpulv.Text), "\#,\#\#00.00")

txtchorario. Text $=$ Format $(\mathrm{CDbl}($ txttttrat.Text) $+\mathrm{CDbl}($ txtttpulv. Text), "\#,\#\#00.00")

txttDisp.Text $=$ Format (txtresdia.Text * txtjornada. Text * txtqtdturnos. Text, "\#,\#\#00.00")

txtRO.Text = Format(dtaTotal.Recordset!SomaDeAreaplantada / txttDisp. Text, "\#,\#\#00.00")

If optSimsens. Value $=$ True Then

txtcco.Text $=$ Format $(((1 /) \quad((((($ dtaTotal.Recordset!somadencovas $/$ dtaTotal.Recordset!SomaDeAreaplantada) * (dtaTotal.Recordset!mesplantas) * 2) / txtFields(3). Text) / txtvelaplic. Text) / 3600)

$+\left(\left(\left(2^{*}\right)((\mathrm{dta}\right.\right.$ Total.Recordset!somadenfileiras / dtaTotal.Recordset!SomaDeAreaplantada) -1$)$ $+1)+(((\mathrm{dtaT}$ Total.Recordset!somadenplantas / dtaTotal.Recordset!SomaDeAreaplantada) * txtvolcalda) $/$ txtFields $(7))) *(3.1416 * 1.5 *$ dtaTotal.Recordset!mespfileiras / $(2 *$ txtvelmanobras))) / 3600)

$+\quad(((($ dtaTotal.Recordset!somadenplantas / dtaTotal.Recordset!SomaDeAreaplantada) * txtvolcalda $) /$ txtFields(7)) * $((($ txtFields(7) / dtaTotal.Recordset!mediavazao $) * 3.6)+$ (txtqtdprodutos * 15))) / 3600)

$+\quad((2 *) \quad((\mathrm{dta} T o t a l$.Recordset!mediaponderada / txtveldesloc $)$ * (((dtaTotal.Recordset!somadenplantas / dtaTotal.Recordset!SomaDeAreaplantada) * txtvolcalda) / txtFields(7)))) / 3600))) * (txtEfgerman / 100)), "\#,\#00.00")

End If

If optNaosensor. Value $=$ True Then

txtcco.Text $=$ Format $(((1) / \quad((()($ dtaTotal.Recordset!somadencovas $/$ dtaTotal.Recordset!SomaDeAreaplantada) * (dtaTotal.Recordset!mesplantas) * 2) / txtFields(3). Text) / txtvelaplic. Text) / 3600)

$+\left(\left(\left(2^{*}\right)((\mathrm{dta}\right.\right.$ Total.Recordset!somadenfileiras $/ \mathrm{dta}$ Total.Recordset!SomaDeAreaplantada $)-1)$ $+1)+(($ dtaTotal.Recordset!somadencovas / dtaTotal.Recordset!SomaDeAreaplantada) * txtvolcalda) $/ \mathrm{txtFields(7)))} *(3.1416 * 1.5 *$ dtaTotal.Recordset!mespfileiras / $(2 *$ txtvelmanobras))) / 3600)

$+\quad((((\mathrm{dtaT}$ Total Recordset!somadencovas / dtaTotal.Recordset!SomaDeAreaplantada) * txtvolcalda) $/$ txtFields $(7)) *((($ txtFields $(7) /$ dtaTotal.Recordset!mediavazao $) * 3.6)+$ (txtqtdprodutos * 15))) / 3600)

$+\quad((2 \quad * \quad$ ((dtaTotal.Recordset!mediaponderada / txtveldesloc) * (((dtaTotal.Recordset!somadencovas / dtaTotal.Recordset!SomaDeAreaplantada) * txtvolcalda) / txtFields(7)))) / 3600))) * (txtEfgerman / 100)), "\#,\#\#00.00")

End If

End Sub

Printer.Print Space(10) \& "Relatório de Defensivos"

Printer.Print "Quantidade de Plantas: " \& dtaTotal.Recordset!somadenplantas

Printer.Print "Área Plantada (ha): " \& Format(dtaTotal.Recordset!SomaDeAreaplantada, Printer.Print "Volume de Calda (L/planta): " \& txtvolcalda

Printer.Print "PRODUTO" \& Space(12) \& "DOSAGEM" \& Space(8) \& "PREÇO UNIT." \& Space (8) \& "QUANTIDADE" \& Space(8) \& "VALOR TOTAL"

Printer.Print Left(Controls("txtprod" \& i). Text \& Space(15), 15) \& Space(3) \&

Right(Space(10) \& Format(Controls("txtdos" \& i).Text, "0.000"), 10) \& Space(5) \& Right(Space(13) \& Format(Controls("txtpun" \& i).Text, "0.00"), 13) \& Space(7) \&

Right(Space(10) \& Format(Controls("txtqtd" \& i).Text, "0.00"), 10) \& Space(8) \& _

Right(Space(11) \& Format(Controls("txtpto" \& i).Text, "0.00"), 11)

Printer.Print Space(67) \& "Total: " \& txtptotal

Printer.Print Space(10) \& "Relatório de Máquinas Agrícolas" 
Printer.Print "Dados Gerais"

Printer.Print "Trator: " \& Left(Controls("cbotrator").Text \& Space(20), 20) \& Space(5) \&

"Volume de calda (L/pl): " \& Left(Controls("txtvolcalda"). Text \& Space(5), 5)

Printer.Print "Pulverizador: " \& Left(Controls("cbopulverizador").Text \& Space(14), 14) \& Space (5) \&

"Qtde de produtos: " \& Left(Controls("txtqtdprodutos"). Text \& Space(5), 5)

Printer.Print "Data Inicial: " \& Left(Controls("txtinicio").Text \& Space(14), 14) \& Space(5) \&

"Velocidade de aplicação (m/s): " \& Left(Controls("txtvelaplic").Text \& Space(5), 5)

Printer.Print "Data Final: " \& Left(Controls("txtfim").Text \& Space(16), 16) \& Space(5) \&

"Velocidade de manobras (m/s): "\& Left(Controls("txtvelmanobras"). Text \& Space(5), 5)

Printer.Print "Jornada de Trabalho (h): " \& Left(Controls("txtjornada").Text \& Space(5), 5) \& Space(3) \&

"Velocidade de deslocamento $(\mathrm{m} / \mathrm{s})$ : " \& Left(Controls("txtveldesloc").Text \& Space(5), 5)

Printer.Print "Qtde de turnos: " \& Left(Controls("txtqtdturnos").Text \& Space(12), 12) \& Space (5) \&

"Tempo de manutenção diária (min): " \& Left(Controls("txtmandia").Text \& Space(5), 5)

Printer.Print "Salário tratorista (US\$): " \& Left(Controls("txtsaltrat").Text \& Space(6), 6) \& Space(1) \&

"Tempo gerencial diário (min): " \& Left(Controls("txtgerdia").Text \& Space(5), 5)

Printer.Print "Salário auxiliar(US\$): " \& Left(Controls("txtsalauxiliar").Text \& Space(7), 7) \& Space(3) \&

"Qtde horas/trator/ano: " \& Left(Controls("txthanotrat"). Text \& Space(5), 5)

Printer.Print "Preço combustivel (US\$): " \& Left(Controls("txtprcomb").Text \& Space(5), 5) \& Space(3) \&

"Qtde horas/pulverizador/ano: " \& Left(Controls("txthanopulv"). Text \& Space(5), 5)

Printer.Print "Taxa de juros (\%): " \& Left(Controls("txtjuros").Text \& Space(14), 14) \&

Printer.Print "Resultados Obtidos"

Printer.Print "Tempo de pulverização (h): " \& Left(Controls("txttpulv").Text \& Space(20), 20)

"Tempo disponível (h): " \& Left(Controls("txttdisp"). Text \& Space(12), 12)

Printer.Print "Tempo de manobras (h): " \& Left(Controls("txttmanobras").Text \& Space(24),

"Ritmo Operacional (ha/h): " \& Left(Controls("txtro").Text \& Space(12), 12)

Printer.Print "Tempo de abastecimento (h): " \& Left(Controls("txttabastec"). Text \& Space(15),

"Capacidade de campo operacional (ha/h): " \& Left(Controls("txtcco").Text \& Printer.Print "Tempo de deslocamento p/ abast.(h): " \& Left(Controls("txttdeslabast"). Text \& Space(7), 7)

"Necessidade de sistemas mecanizados: " \& Left(Controls("txtnsm").Text \& Space(8), Printer.Print "Tempo de manutenção (h): " \& Left(Controls("txttmanut"). Text \& Space(22),

"Custo horário trator (US\$/h): " \& Left(Controls("txttttrat").Text \& Space(12), 12)

Printer.Print "Tempos gerenciais (h): " \& Left(Controls("txttgerenc").Text \& Space(24), 24) \& "Custo horário pulverizador (US\$/h): " \& Left(Controls("txtttpulv").Text \& Space(12), 12)

Printer.Print "Tempo total (h): " \& Left(Controls("txtttotal"). Text \& Space(30), 30) \& Space(1) "Custo horário total (US\$/h): " \& Left(Controls("txtchorario"). Text \& Space(12), 12)

Printer.Print "Eficiência produtiva (\%): " \& Left(Controls("txtefprod"). Text \& Space(21), 21) "Custo operacional (US\$/ha): " \& Left(Controls("txtcoperacional").Text \& Space(12), 12)

Printer.Print "Eficiência produtiva/auxiliar (\%): " \& Left(Controls("txtefpraux").Text \& "Custo total da operação (US\$/ha): " \& Left(Controls("txtcustototal").Text \& Space(12), 12) End Sub 
Anexo 2 - Dados do conjunto 1 .

Trator

Modelo: MF-275

Potência no motor: $75 \mathrm{cv}$

Valor de aquisição (US\$): 16279,00

Vida útil estimada: $12.000 \mathrm{~h}$

Pulverizador

Modelo: Arbus export 2000

Potência requerida: $65 \mathrm{cv}$

Valor de aquisição (US\$): 7.076,00

Quantidade de defletor(es): 1

Vida útil: $5.000 \mathrm{~h}$

Capacidade do tanque: $2.000 \mathrm{~L}$

Potência do motor próprio: 0 
Anexo 3 - Dados do conjunto 2.

Trator

Modelo: MF-250x

Potência no motor: $51 \mathrm{cv}$

Valor de aquisição (US\$): 11.627,00

Vida útil estimada: $12.000 \mathrm{~h}$

Pulverizador

Modelo: Martignani

Potência requerida: $50 \mathrm{cv}$

Valor de aquisição (US\$): $34.883,00$

Quantidade de defletor(es): 1

Vida útil: $10.000 \mathrm{~h}$

Capacidade do tanque: $2.100 \mathrm{~L}$

Potência do motor próprio: $70 \mathrm{cv}$ 
Anexo 4 - Dados do conjunto 3.

Trator

Modelo: MF-275

Potência no motor: $75 \mathrm{cV}$

Valor de aquisição (US\$): 16.279,00

Vida útil estimada: $12.000 \mathrm{~h}$

Pulverizador

Modelo: Protótipo "cortina de ar"

Potência requerida: $65 \mathrm{cv}$

Valor de aquisição (US\$): 14.705,00

Quantidade de defletor(es): 1

Vida útil: $5.000 \mathrm{~h}$

Capacidade do tanque: $2.000 \mathrm{~L}$

Potência do motor próprio: 0 
Anexo 5 - Dados da propriedade padrão A.

Clima: Não considerado

Sistema mecanizado: Conjunto 1

Área: $3.045,62$ ha

Quantidade de plantas: 663.904

Data inicial da pulverização: 01/03/00

Data final da pulverização: $31 / 03 / 00$

Jornada de trabalho: $8,8 \mathrm{~h}$

Quantidade de turnos: 2

Custo mensal do tratorista: US $\$ 430,00$

Custo mensal do auxiliar: US\$ 361,00

Valor do combustivel: US $\$ 0,229$ por $\mathrm{L}$

Taxa de juros anual: $12 \%$

Volume de calda médio: 22 L.planta $^{-1}$

Quantidade de produtos utilizados: 2

Velocidade de aplicação: $0,81 \mathrm{~m} \cdot \mathrm{s}^{-1}$

Velocidade de manobras: $0,6 \mathrm{~m} \cdot \mathrm{s}^{-1}$

Velocidade de deslocamento: $2 \mathrm{~m} \cdot \mathrm{s}^{-1}$

Eficiência de gerenciamento: $85 \%$

Utilização anual do trator: $1.200 \mathrm{~h}$

Utilização anual do pulverizador: $500 \mathrm{~h}$ 
Anexo 6 - Dados da propriedade B.

Clima: Não considerado

Sistema mecanizado: Conjunto 1

Área: 505,50 ha

Quantidade de plantas: 145.381

Data inicial da pulverização: 01/03/00

Data final da pulverização: $31 / 03 / 00$

Jornada de trabalho: $8,8 \mathrm{~h}$

Quantidade de turnos: 2

Custo mensal do tratorista: US $\$ 430,00$

Custo mensal do auxiliar: US $\$ 361,00$

Valor do combustivel: US $\$ 0,322$ por $\mathrm{L}$

Taxa de juros anual: $12 \%$

Volume de calda médio: 22 L.planta ${ }^{-1}$

Quantidade de produtos utilizados: 2

Velocidade de aplicação: $0,81 \mathrm{~m} \cdot \mathrm{s}^{-1}$

Velocidade de manobras: $0,6 \mathrm{~m} \cdot \mathrm{s}^{-1}$

Velocidade de deslocamento: $2 \mathrm{~m} . \mathrm{s}^{-1}$

Eficiência de gerenciamento: $85 \%$

Utilização anual do trator: $1.200 \mathrm{~h}$

Utilização anual do pulverizador: $500 \mathrm{~h}$ 


\section{REFERÊNCIAS BIBLIOGRÁFICAS}

ABECITRUS (Associação Brasileira dos Exportadores de Citrus). A produção brasileira de suco de laranja foi de 1,2 milhão de toneladas. http://www.agrosite.com.br (23 maio 2000).

AL-SOBOH, G.; SRIVASTAVA, A.K.; BURKHARDT, T.H.; KELLY, J.D. A mixedinteger linear programming (MILP) machinery selection model for navybean production systems. Transactions of the ASAE, v.29, n.1, p.81-89, 1986.

AMARO, A.A.; ARAUJO, C.M.; PORTO, O.M.; DORNELLES, C.M.; SOBRINHO, A.P.C.; PASSOS, O.S. Panorama da citricultura brasileira. In: RODRIGUEZ, O.; VIÉGAS, F.; POMPEU JUNIOR., J.; AMARO, A.A. (Ed.) Citricultura brasileira. 2.ed. Campinas: Fundação Cargill, 1991. v. 1, p. 22 - 54.

AMERICAN SOCIETY OF AGRICULTURAL ENGINEERING. ASAE standards. St. Joseph, 1997. p.357-370: Agricultural machinery management.

BAYAT, A.; ZEREN, Y.; ULUSOY, M.R. Spray deposition with conventional and electrostatically-charged spraying in citrus trees. Agricultural Mechanization in Asia, Africa and Latin America, v.25, n.4, p.35-39, 1994.

BEATTIE, G.A.C.; BROADBENT, P.; BAKER, H.; GOLLNOW, B.; KALDOR, C.J. Comparison of conventional medium to high-volume and high-volume sprayers with a low volume sprayer for the control of black spot, Guignardia citricarpa Keily, on Valencia orange. Plant Protection Quarterly, v.4, n.4, p.146-148, 1989. 
BOGGIO, A.M. Aspectos gerais sobre a aplicação e compatibilidade defensivos em citros. Revista Laranja, v. 16, n.2, p. 314-321, 1995.

BRITISH CROP PROTECTION COUNCIL. Boom sprayers handbook. Farnham, 1991. 60p.

BURROWS, W.C.; SIEMENS, J.C. Determination of optimum machinery for cornsoybean farms. Transactions of the ASAE, v.17, n.6, p.1130-1135, 1974.

CHEN, L.H. Microcomputer model for budgeting and schedulind crop production operations. Transactions of the ASAE, v.29, n.4, p. 908-911, July/Aug. 1986.

CHEN, L.H.; AHMAD, T.; WILLCUTT, M.H. Simulation model for cotton harvesting machinery. Transactions of the ASAE, v.35, n.3, p. 1071-1077, May/June 1992.

COLVIN, S.T.; McCONNELL, K.L.; CATUS, B.J. "TERMS": a computer model for field simulation. Transactions of the ASAE, v.32, n.2, p. 391-396, Mar./Apr. 1989.

CUNNINGHAM, G.P.; HARDEN, J. Sprayers to reduce spray volumes in mature citrus trees. Crop Protection, v. 18, n.4, p. 275-281, 1999.

DAHAB, M.H.; O'CALLAGHAM, J.R. Simulation modelling for crop-disease spraying management. Agricultural Mechanization in Asia, Africa and Latin America, v.29, n.3, p. 27-32, 1998.

FAO PRODUCTION YEARBOOK - 1999, v.51, p.163 - 164, 1999.

FERGUSON, J.J.; ISRAEL, G.D. Computer use by Florida citrus growers. In: INTERNATIONAL CONFERENCE ON COMPUTERS IN AGRICULURE, 7., Orlando, 1998. Proceedings. Orlando: ASAE, 1998. p.588-596. 
FERREIRA, M.C. Validação de modelo matemático na avaliação da capacidade operacional de turboatomizadores em citros. Jaboticabal, 2000. 57p. Dissertação (Mestrado) - Faculdade de Ciências Agrárias e Veterinárias, Universidade Estadual Paulista.

FNP CONSULTORIA E COMÉRCIO. AGRIANUAL 1999: anuário estatístico da agricultura brasileira. São Paulo, 1999. 395p.

FNP CONSUltORIA E COMÉRCIO. AGRIANUAL 2000: anuário estatístico da agricultura brasileira. São Paulo, 2000. 395p.

HAFFAR, I.; EE, G.V. "CHUCHARV": a simulation model for optimizing mechanical harvesting returns of pickling cucumbers. Transactions of the ASAE, v.35, n.1, p. 45-50, Jan./Feb. 1992.

HERNANDEZ, C.; ESCOBIO, J. Efecto de diferentes formas de aplicación con asperjadora de ventilador axial en la lucha contra las plagas de los cítricos. Revista de Protección Vegetal, v.1, n.1, p.65-70, 1986.

HOFFMANN, W.C.; SALYANI, M. Spray deposition on citrus canopies under different meteorological conditions. Transactions of the ASAE, v.39, n.1, p.17-33, 1996.

JUSTE, F.; SANCHEZ, S.; IBAÑES, R.; VAL, L.; GARCIA, C. Measurement of spray deposition and efficiency of pesticide application in citrus orchards. Journal of Agricultural Engineering Research, v.46, n.3, p.187-196, 1990.

MAIA, M.L. Citricultura paulista: evolução, estrutura e acordo de preços. São Paulo: IEA, 1996. 157p. 
MARTIN, N.B.; SERRA, R.; OLIVEIRA, M.D.M.; ÂNGELO, J.A.; OKAWA, H. Sistemas integrados de custos agropecuários - "CUSTAGRI". Informações Econômicas, v.28, n.1, p. 7-28, jan. 1998.

MATUO, T. Técnicas de aplicação de defensivos agrícolas. Jaboticabal: FUNEP, 1990. $138 \mathrm{p}$.

McClENDON, R.W.; WETZSTEN, M.E.; EDWARDS, D.M.; CHEN, L.H. Risk efficiency of machinery selection for double cropping via simulation. Transactions of the ASAE, v.30, n.5, p.1259-1265, 1987.

MLALHE, L.G. Manual de mecanização agrícola. Piracicaba: Agronômica Ceres, 1974. $301 \mathrm{p}$.

MILAN, M. Improving operational management of harvest, transport and mechanization for sugar-cane in Brazil. Silsoe, 1992. 226p. Ph.D. (Thesis) - Silsoe College, Cranfield Institute of Technology.

MONTEIRO, M.V.M. Estudo de um atomizador para trator. Piracicaba, 1970. 78p. Tese (Doutorado) - Escola Superior de Agricultura "Luiz de Queiroz", Universidade de São Paulo.

MOREIRA, C.S.; MOREIRA, S. História da citricultura no Brasil. In: RODRIGUEZ, O.; VIÉGAS, F.; POMPEU Jr., J.; AMARO, A.A.. (Ed) Citricultura brasileira. 2.ed. Campinas: Fundação Cargill, 1991. v. 1, p. 1 -21.

NEVES, E.M. Suco de laranja: estatísticas e tendências. Preços Agrícolas, v.16, n.7, p. $10-13,1996$. 
NEVES, E.M.; ZEN, S.; NEVES, M.F. Perspectivas econômicas da citricultura brasileira. In: MENTEN, J.O.M.; DOURADO NETO, D.; VIDAL TORRADO, P. (Ed.) Curso intensivo de citricultura. Piracicaba: ESALQ, 1991. p.1 - 20.

NEVES, E.M.; POMPEU, R.B.; NEVES, M.F.; POMPEU JR, J. A laranja no estado de São Paulo: produção regional, destino e mercados. Revista Laranja, v. 16, n.2, p. 37-61, 1995.

PALLADINI, L.A.; MATUO, T. Efeito de condições operacionais de um turboatomizador na cultura de folhas de citros. Summa Phytopathologica, v.17, n.3/4, p.257-271, 1991.

PARMAR, R.S.; McCLENDON, R.W.; POTTER, W.D. Farm machinery selection using simulation and genetic algorithms. Transactions of the ASAE, v.39, n.5, p.1905-1909, 1996.

PARMAR, R.S.; McCLENDON, R.W.; WILLIAMS, E.J. A computer simulation model for peanut machinery management. Applied Engineering in Agriculture, v. 10, n.4, p.455-461, 1994.

RAETANO, C. G. Condições operacionais de turboatomizadores na distribuição e deposição da pulverização em citros. Piracicaba, 1996. 93p. Tese (Doutorado) Escola Superior de Agricultura "Luiz de Queiroz", Universidade de São Paulo.

REIS, J.N.P. O impacto do crédito rural no desenvolvimento da citricultura no estado de São Paulo. Piracicaba, 1995. 91p. Tese (Doutorado) - Escola Superior de Agricultura "Luiz de Queiroz", Universidade de São Paulo.

RIGOLIN, A.T.; TERSI, F.E.A. Redução nos custos de aplicação dos defensivos em citros. Revista Laranja, v.20, n.1, p. 93-106, 1999. 
ROTZ, C.A.; MUHTAR, H.A.; BLACK, J.R. A multiple crop machinery selection algorithm. Transactions of the ASAE, v.26, n.6, p.1644-1649, 1983.

SALYANI, M. Droplet size effect on spray deposition efficiency on citrus leaves. Transactions of the ASAE, v.31, n.6, p.1680-1684, 1988.

SALYANI, M. Spray technology research for orchard applications. Acta Horticulturae, v.372, p.67-74, 1994.

SALYANI, M.; CROMWELL, R.P. Drift losses from citrus spray applications. Proceedings of the Florida State Horticultural Society, v.105, p.13-18, 1992.

SALYANI, M.; McCOY, C.W. Spray deposition on citrus trees for different spray volumes. Citrus and Vegetable Magazine, v.53, n.5, p.16-17, 1990.

SALYANI, M.; WHITNEY, J.D. Spraying speed effect on deposition inside citrus trees. St. Joseph: ASAE, 1989. 11p. (ASAE Paper, 89-1048).

SALYANI, M.; HEDDEN, S.L.; EDWARDS, G.J. Deposition efficiency of different droplet sizes for citrus spraying. Transactions of the ASAE, v.30, n.6, p.15951599, 1987.

SILVA, O.M. Situação econômica da cultura citrícola. Revista Laranja, v.15, n.2, p. 13-34, 1994.

SINGH, D.; HOLTMAN, J.B. An heuristic agricultural field machinery selection algorithm for multicrop farms. Transactions of the ASAE, v.22, n.4, p.763-770, 1979. 
SOFFNER, R.K.; MILAN, M.; RIPOLI, T.C.C. Gerenciamento global de sistema agrícola em unidades sucroalcoleiras através de programação linear. STAB, v.11, n. 5, p.16-20, 1993.

SOGAARD, H.T.; SORENSEN, C.G. A model for optimal selection of machinery sizes within the farm machinery system. In: INTERNATIONAL CONFERENCE ON COMPUTERS IN AGRICUluRE, 6., Cancun, 1996. Proceedings. St. Joseph: ASAE, 1996. p.588-596.

STULP, V.J.; MATTUELLA, J.L. Dimensionamento econômico do estoque de tratores para a lavoura do arroz. Revista de Economia e Sociologia Rural, v.35, n.3, p. 4561, jul./set. 1997.

TACHIBANA, A.; MILAN, M.; MOURÃO FILHO, F.A.A. Modelo para avaliar um sistema mecanizado para a cultura do limão Siciliano (Citrus limon, BURM.). Revista Engenharia Agrícola, v. 18, n.3, p. 34-43, 1999.

VIEIRA, L. F. A citricultura no Estado de São Paulo e a contribuição da pesquisa a bibliografia citrícola nacional. São Paulo: ITAL, 1976. 91p.

WHITNEY, J.D.; SALYANI, M. Spray penetration characteristics of the air curtain and airblast sprayers. Proceedings of the Florida State Horticultural Society, v.103, p. $25-28,1990$.

WHITNEY, J.D.; SALYANI, M. Deposition characteristics of two air-carrier sprayers in citrus trees. Transactions of the ASAE, v.34, n.1, p.47-50, 1991.

WHITNEY, J.D.; HEDDEN, S.L.; CHURCHILL, D.B.; CROMWELL, R.P. Performance characteristics of PTO airblast sprayers for citrus. Proceedings of the Florida State Horticultural Society, v.99, p.59-65, 1986. 
WHITNEY, J.D.; SALYANI, M.; CHURCHILL, D.B.; WHITESIDE, J.O.; KNAPP, J.L.; LITTELL, R.C. Ground speed and spray volume of airblast sprayers affect copper deposition and greasy spot control. Proceedings of the Florida State Horticultural Society, v.101, p.13-17, 1988.

WHITSON, R.E.; KAY, R.D.; LEPORI, W.A.; RISTER, E.M. Machinery and crop selection with weather risk. Transactions of the ASAE, v.24, n.2, p.288-295, 1981. 